Universidade de São Paulo - USP

Escola de Engenharia de São Carlos - EESC

Departamento de Engenharia Elétrica

\title{
FILTROS DE KALMAN NO TEMPO E FREQÜÊNCIA DISCRETOS COMBINADOS COM SUBTRAÇÃO ESPECTRAL
}

\author{
Autor: LEANDRO AURELIANO DA SILVA
}

Dissertação de mestrado apresentada à Escola de Engenharia de São Carlos da Universidade de São Paulo, como parte dos requisitos para obtenção do título de Mestre em Engenharia Elétrica.

Orientador: Prof. Dr. Marcelo Basílio Joaquim 


\section{Agradecimentos}

Aos meus pais, Ivone Maria da Silva, Joana Darc e Ronaldo Rodrigues da Silva, pela compreensão, paciência e incentivo nos momentos mais difíceis.

À minha namorada, Lucianna Camilo Vilela e ao meu filho Edson Roberto Alves Barbosa e familiares pelo apoio durante esse período conturbado.

Ao Professor Doutor Marcelo Basílio Joaquim, pela excelente orientação, confiança e paciência demonstrada durante toda a realização desse trabalho.

Aos professores José Carlos Pereira e Carlos Dias Maciel, o meu obrigado, pelos conhecimentos transmitidos durante inúmeras discussões.

Aos professores e funcionários do Departamento de Engenharia Elétrica da EESCUSP, pela amizade e colaboração.

Aos amigos, Danilo Spadoti, Betiol, Pizolato e amigos do LIM (Laboratório de Instrumentação e Microeletrônica) pela a amizade.

Aos grandes companheiros de Uberaba Helvécio, Marcelo Eustáquio pela amizade sólida demonstrada ao longo dos anos.

A todos que contribuíram direta e indiretamente para o sucesso deste trabalho 
Dedico este trabalho,

A Deus

Aos meus familiares: 


\section{SUMÁRIO}

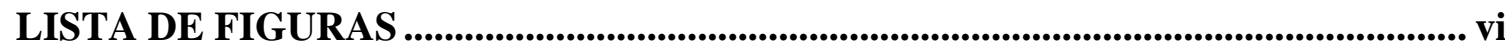

LISTA DE TABELAS ................................................................................................................... ix

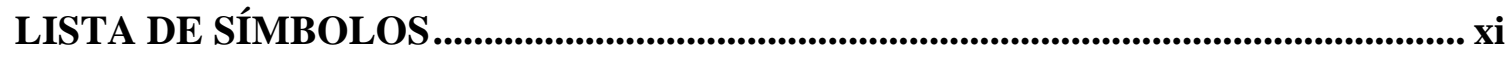

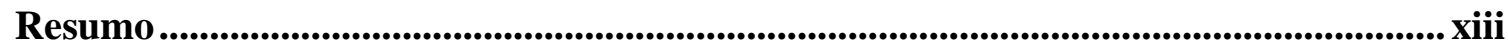

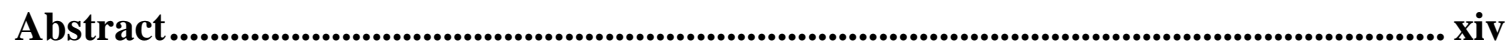

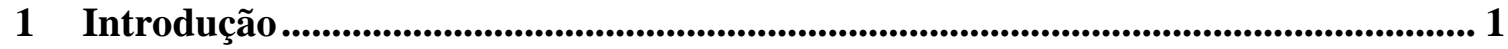

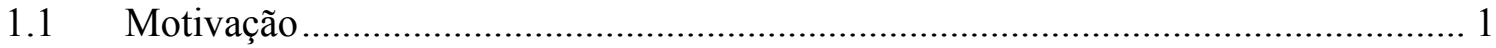

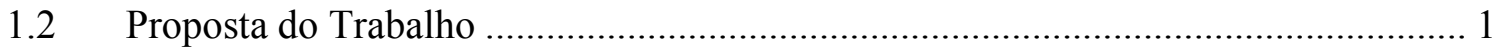

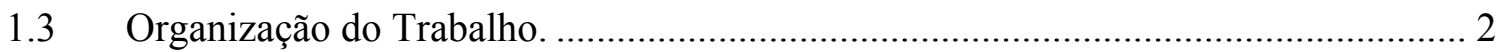

2 Mecanismo de Produção da Fala e Predição Linear ..................................................... 4

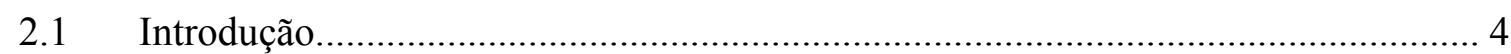

2.2 Mecanismo de Produção da Fala........................................................................... 4

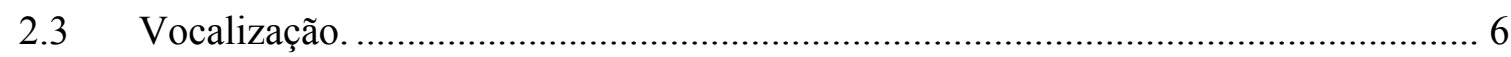

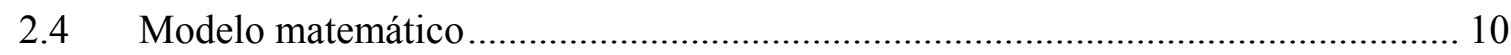

2.5 Modelo de Predição Linear do Sinal de Voz............................................................ 13

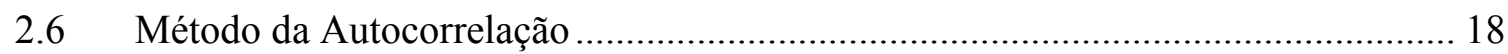

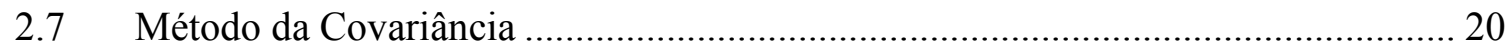

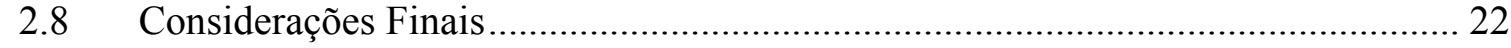

3 Subtração Espectral .................................................................................................................... 24

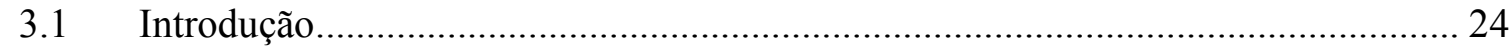

3.2 Subtração Espectral de Magnitude ………............................................................... 25

3.3 Subtração Espectral de Potência ................................................................................ 30

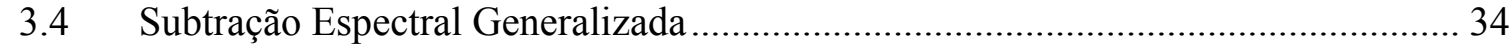

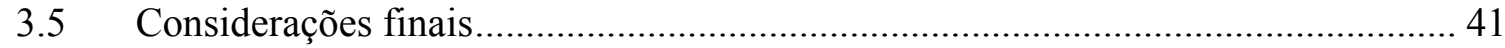

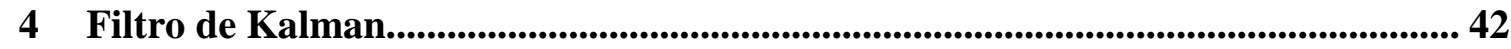

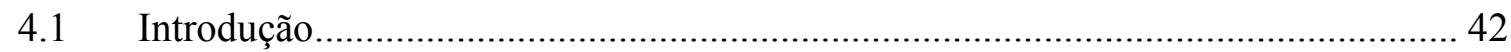

4.2 Filtro de Kalman de Tempo Discreto (FKT) .......................................................... 42

4.3 As origens computacionais do Filtro de Kalman ................................................... 46

4.4 Algoritmo para o Filtro de Kalman de Tempo Discreto ........................................... 54 
4.5 Forma Alternativa para o Filtro de Kalman de Tempo Discreto............................. 57

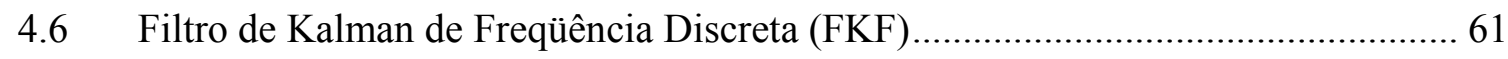

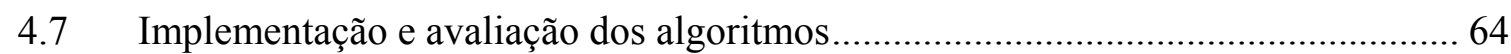

4.8 Divergência do Filtro de Kalman .............................................................................. 72

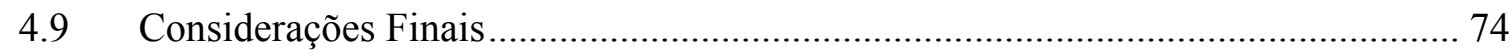

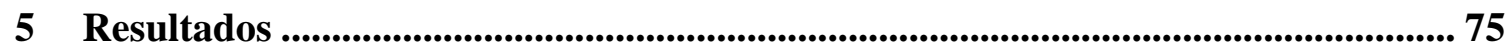

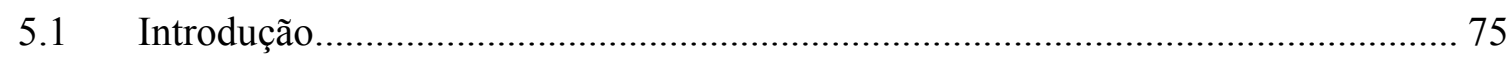

5.2 Relação sinal/ruído segmentada (SNRseg) …...................................................... 75

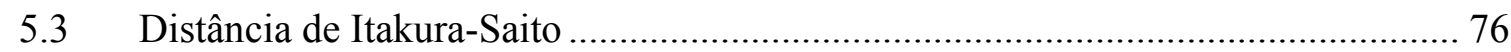

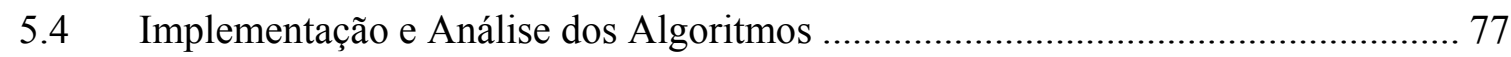

5.4.1 Processamento utilizando Ruído Branco Gaussiano.................................. 78

5.4.2 Processamento utilizando Ruído Colorido............................................... 96

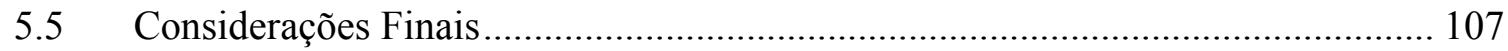

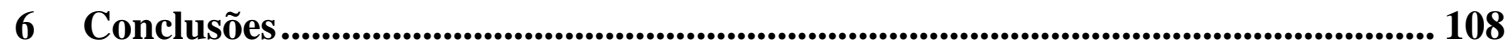

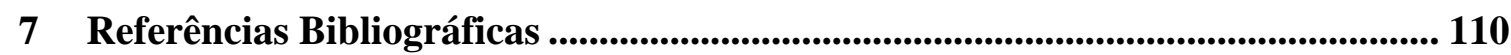




\section{LISTA DE FIGURAS}

FIGURA 2. 1 - Aparato vocal. Fonte:

http://www.corpohumano.hpg.ig.com.br/ab_news_health/noticias.html...................... 5

FIGURA 2. 2 - Forma de onda de um sinal-sonoro correspondente a vogal "a" ................. 7

FIGURA 2. 3 - Forma de onda de um sinal-não sonoro ….................................................. 7

FIGURA 2. 4 - Etapas do processo de produção de voz........................................................ 9

FIGURA 2. 5 - Modelo da produção de fala...................................................................... 10

FIGURA 2. 6 - Modelo matemático de produção de fala .................................................... 13

FIGURA 2. 7 - Modelo simplificado da produção de fala ................................................... 14

FIGURA 3. 1 - Diagrama em blocos da Subtração Espectral de Magnitude....................... 29

FIGURA 3. 2 - Fator de subtração em função da relação sinal/ruído (SNR) em dB.......... 31

FIGURA 3. 3 - Diagrama em blocos da Subtração Espectral de Potência........................... 33

FIGURA 3. 4 - Sinal original correspondente à palavra "janela"..................................... 36

FIGURA 3. 5 - Sinal contaminado por ruído branco. ......................................................... 36

FIGURA 3. 6 - Sinal estimado após a Subtração Espectral de Magnitude........................... 37

FIGURA 3. 7 - Sinal original correspondente à palavra "janela"’ ..................................... 38

FIGURA 3. 8 - Sinal contaminado por ruído branco. ........................................................... 38

FIGURA 3. 9 - Sinal estimado após a Subtração Espectral de Potência............................. 39

FIGURA 4. 1 - Diagrama em blocos das equações que regem a teoria do filtro de Kalman

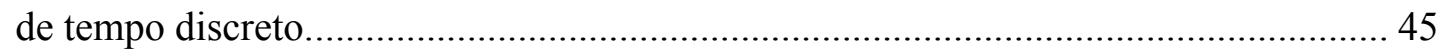

FIGURA 4. 2 - O ciclo contínuo do filtro de Kalman de tempo discreto. ........................... 54

FIGURA 4. 3 - O diagrama completo da operação do filtro de Kalman de tempo discreto.

FIGURA 4. 4 - Ciclo de operação do filtro de Kalman de tempo discreto para as formas alternativas

FIGURA 4. 5 - Diagrama em blocos do algoritmo original proposto por Fujimoto e Ariki.

FIGURA 4. 6 - Diagrama em blocos do algoritmo do filtro de Kalman de freqüência discreta, em conjunto com a subtração espectral de potência. ......................................... 68

FIGURA 4. 7 - Sinal original correspondente à palavra "Elétrica". 69 
FIGURA 4. 8 - Sinal contaminado por ruído branco.

FIGURA 4. 9 - Sinal estimado após a filtragem de Kalman na freqüência, em conjunto com subtração espectral de potência.

FIGURA 4. 10 - Diagrama em blocos do algoritmo do filtro de Kalman de tempo discreto, em conjunto com a subtração espectral de potência...................................................... 70

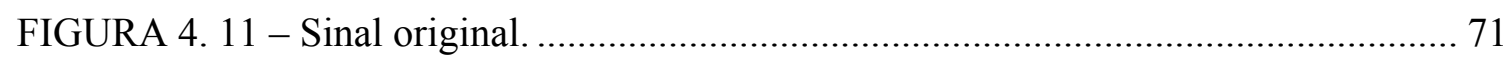

FIGURA 4. 12 - Sinal contaminado por ruído branco ...................................................... 71

FIGURA 4. 13 - Sinal estimado após a filtragem usando o filtro de Kalman de tempo discreto, em conjunto com a subtração espectral de potência...................................... 72

FIGURA 5. 1 - Sinal original correspondente à palavra "Elétrica".................................... 78

FIGURA 5. 2 - Sinal contaminado por ruído branco ....................................................... 78

FIGURA 5. 3 - Sinal estimado após o processamento da filtragem de Kalman no tempo em

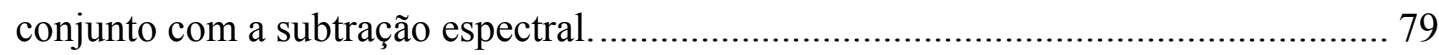

FIGURA 5. 4 - Distância de Itakura-Saito em função da SNRseg de entrada, para o algoritmo FKT com ruído branco......................................................................... 80

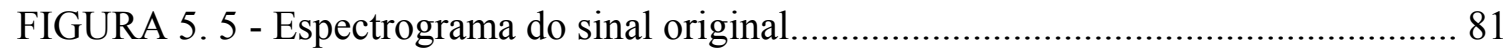

FIGURA 5. 6 - Espectrograma do sinal contaminado. ....................................................... 81

FIGURA 5. 7 - Espectrograma do sinal estimado, após o processamento da filtragem de Kalman no tempo em conjunto com a subtração espectral. ........................................... 81

FIGURA 5. 8 - Sinal original correspondente à palavra "Elétrica".................................... 82

FIGURA 5. 9 - Sinal contaminado por ruído branco. ...................................................... 83

FIGURA 5. 10 - Sinal estimado após o processamento da filtragem de Kalman na freqüência em conjunto com a subtração espectral. ....................................................... 83

FIGURA 5. 11 - Distância de Itakura-Saito em função da SNR de entrada segmentada, para

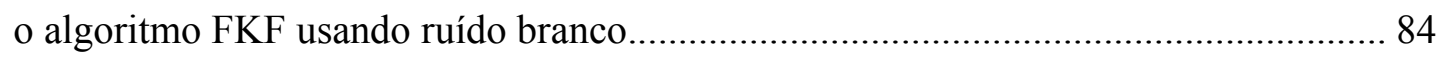

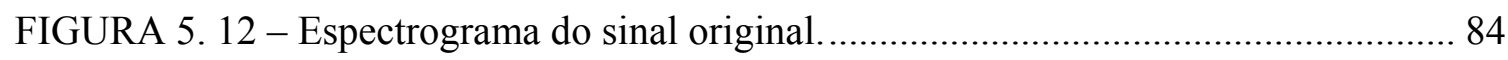

FIGURA 5. 13 - Espectrograma do sinal contaminado por ruído branco........................... 85

FIGURA 5. 14 - Espectrograma do sinal estimado após o processamento da filtragem de Kalman na freqüência em conjunto com a subtração espectral................................... 85

FIGURA 5. 15 - Distância de Itakura-Saito em função da SNR de entrada segmentada, como comparação para as três técnicas utilizadas neste trabalho. 
FIGURA 5. 16 - Sinal original correspondente à palavra "Elétrica". 97

FIGURA 5. 17 - Sinal contaminado por ruído colorido. 97

FIGURA 5. 18 - Sinal estimado após o processamento da filtragem de Kalman no tempo em conjunto com a subtração espectral, para o caso de ruído colorido. ..... 97

FIGURA 5. 19 - Espectrograma do sinal original............................................................. 98

FIGURA 5. 20 - Espectrograma do sinal de voz contaminado por ruído colorido. 98

FIGURA 5. 21 - Espectrograma após a filtragem de Kalman no tempo em conjunto com a subtração espectral, para o caso do ruído colorido 99

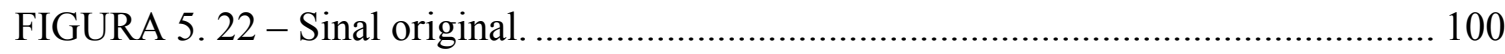

FIGURA 5. 23 - Sinal contaminado por ruído colorido................................................. 100

FIGURA 5. 24 - Sinal estimado após o processamento da filtragem de Kalman na freqüência em conjunto com a subtração espectral, para o caso de ruído colorido..... 100

FIGURA 5. 25 - Espectrograma do sinal original......................................................... 101

FIGURA 5. 26 - Espectrograma do sinal contaminado por ruído colorido........................ 101

FIGURA 5. 27 - Espectrograma após a filtragem de Kalman na freqüência em conjunto com a subtração espectral, para o caso de ruído colorido. 102

FIGURA 5. 28 - Distância de Itakura-Saito em função da SNR de entrada segmentada para o caso do ruído ser colorido. 103 


\section{LISTA DE TABELAS}

TABELA 2. 1 - Modelo tudo-pólo usando o método da autocorrelação. ............................. 20

TABELA 2. 2 - Modelo tudo-pólo usando o método da covariância. ................................. 22

TABELA 3. 1 - Resultados da Subtração Espectral de Magnitude, para 10 sinais de voz contaminados por ruído branco.

TABELA 3. 2 - Resultados da Subtração Espectral de Potência, para 10 sinais de voz contaminados por ruído branco.

TABELA 4. 1 - As equações de atualização de tempo do filtro de Kalman de Tempo discreto.

TABELA 4. 2 - Equações de atualização de medida do filtro de Kalman de Tempo discreto.

TABELA 5. 1 - Resultados dos testes para as 25 palavras com SNR de entrada de $0 \mathrm{~dB}$, usando a subtração espectral de potência, para o caso do ruído ser branco.

TABELA 5. 2 - Resultados dos testes para as 25 palavras com SNR de entrada de $0 \mathrm{~dB}$, usando FKF, para o caso do ruído ser branco.

TABELA 5. 3 - Resultados dos testes para as 25 palavras com SNR de entrada de $0 \mathrm{~dB}$, usando FKT, para o caso do ruído ser branco.

TABELA 5. 4 - Resultados dos testes para as 25 palavras com SNR de entrada de $3 \mathrm{~dB}$, usando a subtração espectral de potência, para o caso do ruído ser branco.

TABELA 5. 5 - Resultados dos testes para as 25 palavras com SNR de entrada de $3 \mathrm{~dB}$, usando FKF, para o caso do ruído ser branco.

TABELA 5. 6 - Resultados dos testes para as 25 palavras com SNR de entrada de $3 \mathrm{~dB}$, usando FKT, para o caso do ruído ser branco.

TABELA 5. 7 - Resultados dos testes para as 25 palavras com SNR de entrada de $6 \mathrm{~dB}$, usando a subtração espectral de potência, para o caso do ruído ser branco.

TABELA 5. 8 - Resultados dos testes para as 25 palavras com SNR de entrada de $6 \mathrm{~dB}$, usando FKF, para o caso do ruído ser branco.

TABELA 5. 9 - Resultados dos testes para as 25 palavras com SNR de entrada de $6 \mathrm{~dB}$, usando FKT, para o caso do ruído ser branco. 
TABELA 5. 10 - Resultados dos testes para as 25 palavras com SNR de entrada de $3 \mathrm{~dB}$, usando a subtração espectral de potência, para o caso do ruído ser colorido. 104

TABELA 5. 11 - Resultados dos testes para as 25 palavras com SNR de entrada de $3 \mathrm{~dB}$, usando FKF, para o caso do ruído ser colorido.

TABELA 5. 12 - Resultados dos testes para as 25 palavras com SNR de entrada de $3 \mathrm{~dB}$, usando FKT, para o caso do ruído ser colorido. 


\section{LISTA DE SÍMBOLOS}

$V(z) \quad$ Modelo do trato vocal

$G(z) \quad$ Modelo do pulso glotal

$R(z) \quad$ Modelo de radiação labial

$H(z) \quad$ Função de transferência do sistema cascateado do trato vocal

$X(z) \quad$ Transformada $\mathrm{z}$ do sinal de voz original

$E(z) \quad$ Transformada $\mathrm{z}$ da função de excitação

$z^{-k} \quad$ Unidade de atraso

$A(z) \quad$ Filtro inverso

$e(n) \quad$ Erro de predição

$\varepsilon \quad$ Erro médio quadrático

$r_{x x} \quad$ Função de autocorrelação do sinal

$\boldsymbol{R}_{x x} \quad$ Matriz de autocorrelação

$a_{p} \quad$ Coeficientes de predição (linear)

$x(n) \quad$ Sinal de voz sem ruído

$\widetilde{x}(n) \quad$ Sinal de voz sem ruído gerado pela aplicação de uma janela

$w_{l} \quad$ Janela aplicada ao sinal

$\hat{x}(n) \quad$ Sinal de voz estimado após a filtragem

$y(n) \quad$ Sinal de voz contaminado por ruído

$v(n) \quad$ Ruído aditivo

$X\left(e^{j \omega_{k}}\right) \quad$ Espectro do sinal de voz sem ruído

$Y\left(e^{j \omega_{k}}\right) \quad$ Espectro do sinal de voz contaminado por ruído

$V\left(e^{j \omega_{k}}\right) \quad$ Espectro do ruído aditivo

$\left|X\left(e^{j \omega_{k}}\right)\right| \quad$ Espectro de magnitude sinal de voz sem ruído

$\left|Y\left(e^{j \omega_{k}}\right)\right| \quad$ Espectro de magnitude sinal de voz contaminado por ruído

$\mu\left(e^{j \omega_{k}}\right) \quad$ Estimativa média do espectro de magnitude do ruído 
$\left|X\left(e^{j \omega_{k}}\right)\right|^{2} \quad$ Espectro de potência do sinal de voz sem ruído

$\left|Y\left(e^{j \omega_{k}}\right)\right|^{2} \quad$ Espectro de potência do sinal de voz contaminado por ruído

$\theta_{Y}\left(e^{j \omega_{k}}\right) \quad$ Fase do sinal de voz contaminado

$V_{R}\left(e^{j \omega_{k}}\right) \quad$ Ruído residual encontrado em instantes de silêncio

$\alpha \quad$ Fator de subtração

$\beta \quad$ Limite espectral mínimo

A $(n-1) \quad$ Matriz transição de estados

$w(n) \quad$ Ruído de estado

$Q(n) \quad$ Matriz de covariância para o ruído de estado

$\boldsymbol{R}(n) \quad$ Matriz de covariância para o ruído aditivo

$\boldsymbol{P}^{-}(n) \quad$ Matriz de covariância do erro de estimação antes da anexação de uma nova medida

$\boldsymbol{P}(n) \quad$ Matriz de covariância do erro de estimação após da anexação de uma nova medida

$\hat{\boldsymbol{x}}^{-}(n) \quad$ Estimativa do sinal de voz antes da anexação de uma nova medida

$\boldsymbol{K}(n) \quad$ Ganho de Kalman

$\boldsymbol{F}_{n} \quad$ Vetor que contém a base da Transformada Inversa Discreta de Fourier (IDFT)

SNR Relação Sinal/Ruído

$S N R_{\text {seg }} \quad$ Relação Sinal/Ruído segmentada

$d(a, b) \quad$ Distância de Itakura-Saito 


\section{Resumo}

Silva, L. A. (2007). Filtros de Kalman no Tempo e Freqüência Discretos Combinados com Subtração Espectral. Dissertação (mestrado) - Escola de Engenharia de São Carlos, Universidade de São Paulo, São Carlos, 2007.

Este trabalho tem a finalidade de apresentar e comparar técnicas de redução de ruído utilizando como critérios de avaliação a mínima distorção espectral e a redução de ruído, na reconstrução dos sinais de voz degradados por ruído. Para tanto, utilizou-se os filtros de Kalman de tempo discreto e de freqüência discreta em conjunto com a técnica de subtração espectral de potência. Os sinais utilizados foram contaminados por ruídos branco e colorido, e a avaliação do desempenho dos algoritmos foi realizada tendo-se como parâmetros a relação sinal/ruído segmentada (SNRseg) e a distância de Itakura-Saito $(d(a, b))$. Após o processamento, verificou-se que a técnica, proposta neste trabalho, de filtragem de Kalman no tempo em conjunto com a subtração espectral de potência, apresentou resultados um pouco melhores em relação à filtragem de Kalman na freqüência em conjunto com a subtração espectral de potência.

Palavras-Chave: Filtro de Kalman, Subtração Espectral, Supressão de ruído. 


\section{Abstract}

Silva, L. A. (2007). Kalman Filters of Time and Frequency Discrete Combined with Spectral Subtraction. M. Sc. Dissertation - Escola de Engenharia de São Carlos, Universidade de São Paulo, São Carlos, 2007.

This work has as main objective to present and to compare techniques of noise reduction using as evaluation criterion the low spectral distortion and the noise reduction in the reconstruction of corrupted speech signals. For so much, it was used the Kalman's filters in the time and frequency domain together with the technique of power spectral subtraction. The used signals were corrupted by white and colored noises and the evaluation of effectiveness of the algorithms was accomplished using the segmental signal-to-noise ratio $\left(\mathrm{SNR}_{\text {seg }}\right)$ and the Itakura-Saito distance $(\mathrm{d}(\mathrm{a}, \mathrm{b}))$. After the processing, it was noticed that the Kalman filtering in the time together with power spectral subtraction presented better results than the Kalman filtering in the frequency together with power spectral subtraction.

Keywords: Kalman Filters, Spectral Subtraction, Noise Suppression. 


\section{Introdução}

\subsection{Motivação}

A fala é um dos principais meios de comunicação. Sua qualidade e inteligibilidade são de extrema importância para a facilidade e precisão na troca de informação. Praticamente, em quase todas as aplicações de transmissão de voz sua qualidade pode ser afetada por fatores como ruído ambiente, perdas devidas à codificação em enlaces digitais, através de outras conversações ou outras fontes de sinais. Diante deste fato, vários estudos estão sendo realizados pela comunidade científica no sentido de melhoria da qualidade dos sinais da fala. Alguns estudos se destacam, tais como: Subtração Espectral, Filtro de Kalman, Redes Neurais combinadas com filtro de Kalman, Wavelets entre outros.

\subsection{Proposta do Trabalho}

Baseado no contexto de redução de ruído e na mínima distorção espectral para um sinal reconstruído a partir de sua contaminação, é apresentado neste trabalho um estudo visando a implementação de técnicas que fazem uso dos filtros de Kalman de tempo discreto e de freqüência discreta em conjunto com a técnica de subtração espectral. Estas técnicas, quando aplicadas em conjunto, têm como finalidade a reconstrução do sinal de voz, cujos objetivos são a redução de ruído e a mínima distorção espectral, uma vez que a subtração espectral, quando aplicada isoladamente para reconstrução do sinal contaminado, provoca uma distorção espectral um pouco mais alta.

O algoritmo desenvolvido por Fujimoto e Ariki [1] serviu de base para o desenvolvimento deste trabalho. Porém, diferentemente dos dois estudiosos, pretendeu-se, aqui, comprovar ser possível a reconstrução do sinal contaminado por ruído substituindo-se 
o filtro de Kalman de freqüência discreta combinado com a subtração espectral, pelo filtro de Kalman de tempo discreto, em conjunto com a subtração espectral de potência. Os vários testes realizados para diferentes sinais de voz, mostraram de forma satisfatória, que as substituições realizadas neste trabalho apresentaram resultados um pouco melhores em relação à distorção espectral. Com respeito à medida da relação sinal/ruído segmentada os resultados dos dois algoritmos foram muito próximos.

\subsection{Organização do Trabalho.}

Este trabalho está estruturado em 6 capítulos:

1. Introdução

2. Mecanismos de produção da fala e predição linear

3. Subtração Espectral

4. Filtro de Kalman e Implementação dos algoritmos

5. Resultados

6. Conclusões

O capítulo 2 apresenta o modelo fisiológico e matemático de produção da fala, bem como as formas de onda dos tipos de sons: sonoros e não-sonoros. O modelo de predição linear, também abordado neste capítulo, será utilizado para representar o sinal de voz, quando o mesmo for utilizado no filtro de Kalman.

No capítulo 3 é abordada a subtração espectral, técnica esta que será utilizada para pré-filtrar o sinal contaminado. O sinal pré-filtrado a partir desta técnica será usado como condição inicial para os filtros de Kalman no tempo e na freqüência. Neste capítulo então serão abordadas as subtrações espectrais de potência e magnitude, mostrando vantagens e desvantagens de ambos os métodos. 
No capítulo 4 são apresentados os estudos dos filtros de Kalman de tempo discreto e freqüência discreta, demostrando as equações que definem ambos os filtros, suas propriedades, características e eventuais problemas que possam ser encontrados quando eles são utilizados. Este capítulo também apresenta duas técnicas para reconstrução do sinal contaminado, cujo objetivo é a redução de ruído e mínima distorção espectral.

O capítulo 5 é o responsável pela apresentação dos resultados. Neste capítulo, são mostrados todos testes realizados para diferentes sinais de voz, mostrando a eficiência dos algoritmos de filtragem, tanto para ruído branco, como para colorido. Os resultados obtidos comprovaram a eficiência da técnica proposta neste trabalho, mostrando que os sinais após o processamento, apresentaram uma considerável redução de ruído e uma distorção espectral baixa.

Finalmente, o capítulo 6 reúne conclusões do trabalho desenvolvido e algumas sugestões de trabalhos futuros que foram surgindo ao longo do desenvolvimento do trabalho. 


\section{Mecanismo de Produção da Fala e Predição Linear}

\subsection{Introdução.}

Este capítulo tem como finalidade apresentar o mecanismo de produção da fala, bem como a modelagem matemática que representa a forma de onda desses sinais.

Para realizar aplicações em sinais da fala tais como sintetizar, reconhecer e até mesmo melhorar a qualidade destes sinais, é necessário entender o mecanismo da sua produção e o seu modelo matemático em conjunto com as técnicas de processamento digital de sinais. Dessa forma, o capítulo começa com uma rápida abordagem sobre a teoria acústica da fala, tendo como principal objetivo dar ao leitor uma noção da produção dos sinais emitidos e seu modelo matemático.

O capítulo termina com a teoria de predição linear aplicada à representação de sinais da fala quando da utilização na equação de espaço de estados, tema a ser abordado no filtro de Kalman. Neste tópico são abordados dois métodos para extração dos coeficientes de predição linear. Os métodos são: o método da autocorrelação e o método da covariância.

\subsection{Mecanismo de Produção da Fala}

Os sinais da fala são compostos por uma seqüência de sons ou segmentos fonéticos regulados pelas regras da linguagem e pelas características do orador [2].

Os órgãos responsáveis pela produção da fala são apresentados na figura 2.1. Estes órgãos se dividem em três grupos: subglotal, glotal e supraglotal [3]. Dependendo do tipo de som emitido cada grupo contribui para a formação dos sons específicos. Além disto, permitem uma modelagem das diversas características que contribuem para a emissão 
sonora. O primeiro grupo formado pelos pulmões, brônquios e traquéia, servem como fonte de energia para produção da fala, sendo esta apresentada na forma de um fluxo de ar. Situados na laringe, os órgãos do segundo grupo formados pelas cartilagens e pregas vocais, são os responsáveis pela produção de uma onda quase-periódica mediante vibração das pregas vocais. O terceiro grupo é composto pela cavidade nasal e oral, língua, dentes e lábios, cuja função é a de produzir os fonemas de uma língua, pois esta cavidade funciona como uma cadeia de filtros ressonadores que respondem, seletivamente, às diversas freqüências contidas nos sons produzidos.

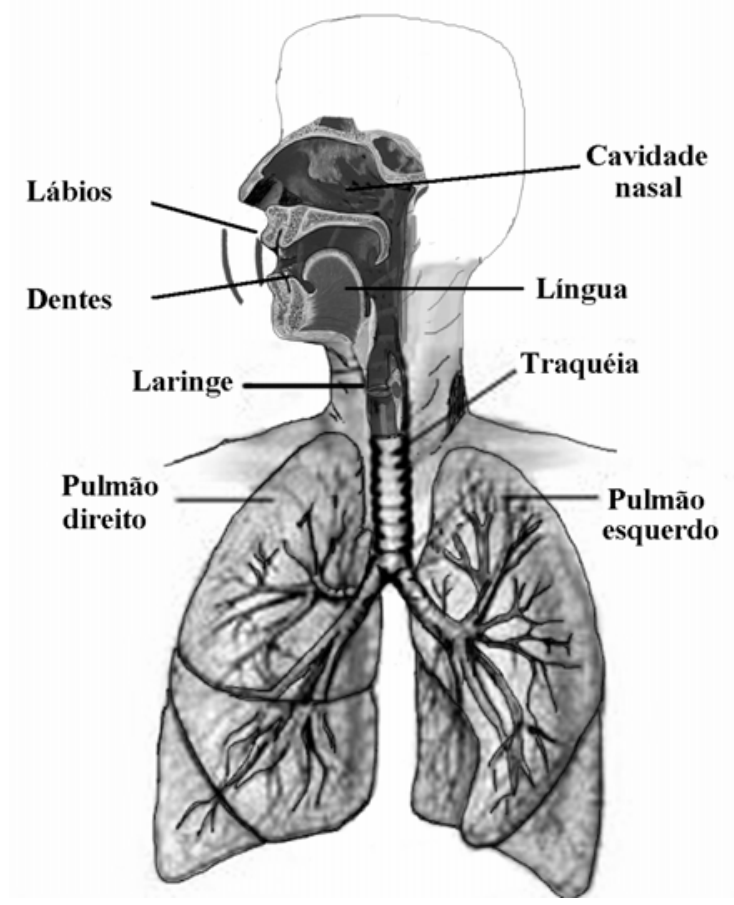

FIGURA 2. 1 - Aparato vocal. Fonte: http://www.corpohumano.hpg.ig.com.br/ab news health/noticias.html 


\subsection{Vocalização.}

Os sinais da fala são gerados com ou sem vibração das pregas vocais. Os sons produzidos sem a vibração das pregas vocais são designados de sons não sonoros, enquanto que os sons produzidos com vibração das pregas vocais, ou seja, através da abertura e fechamento da glote (espaço entre as pregas vocais), são designados de sonoros. À medida que as pregas vocais vibram, estas fazem variar o grau de abertura da glote e, conseqüentemente, o volume de ar proveniente dos pulmões que passa através dela. É esta variação quase periódica na velocidade de volumétrica de ar na glote que vai excitar o trato vocal, produzindo sons quase periódicos, espaçados por um período médio denominado de período fundamental $\left(T_{0}\right)$ ou período de pitch [4]. Nos trechos onde se tem som não sonoro a glote mantém-se aberta e o ar proveniente dos pulmões, ao passar com suficiente velocidade por uma constrição do trato vocal, produz sons com turbulência que se assemelham a um ruído.

As vogais, os sons nasais e os ditongos são exemplos de fonemas sonoros, enquanto que algumas consoantes $(s, p, t)$ são exemplos de fonemas não sonoros. Sendo assim, as Figuras 2.2 e 2.3 mostram as formas de onda de um sinal sonoro e um sinal não sonoro para um sinal de voz.

Por assemelhar-se a um conjunto de tubos acústicos, o trato vocal apresenta ressonâncias em freqüências determinadas pelas relações entre as dimensões das diversas seções transversais tomadas ao longo de sua extensão [2]. Essas freqüências são chamadas de formantes, as quais permitem diferenciar os diferentes sons produzidos de acordo com o posicionamento da língua e dos lábios. 


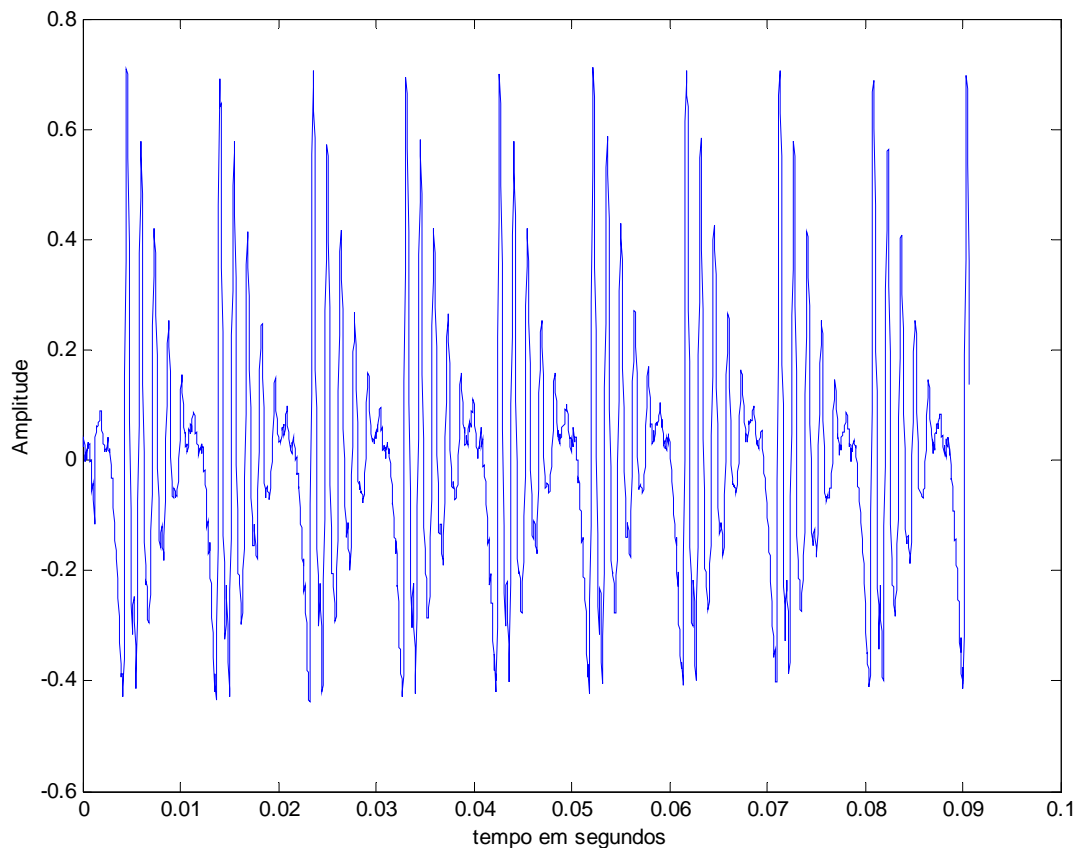

FIGURA 2. 2 - Forma de onda de um sinal-sonoro correspondente a vogal "a"

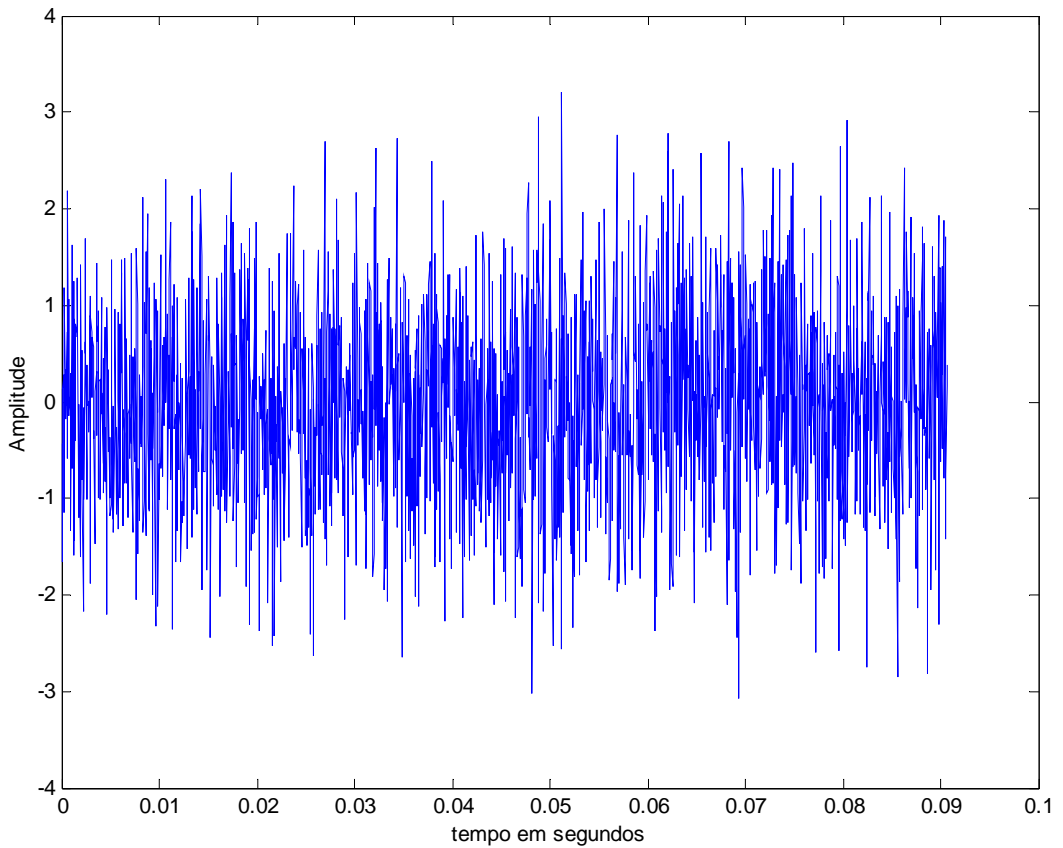

FIGURA 2. 3 - Forma de onda de um sinal-não sonoro 
A fonte de excitação, no caso dos fonemas sonoros, tem a forma de uma seqüência quase periódica de pulsos, espaçados de um intervalo denominado período de pitch. No caso dos trechos não sonoros, a fonte de excitação toma a forma de um fluxo de ar turbulento, que apresenta características de um ruído branco, de envoltória espectral praticamente plana. Ao atravessar o trato vocal, o espectro da excitação é moldado de acordo com as suas freqüências, resultando no sinal de fala [5].

Estes sons, gerados pelo aparato vocal em resposta à excitação, podem ser classificados em três classes de acordo com o modo de excitação: sons sonoros, fricativos e plosivos [2].

- Sons Sonoros:

São produzidos por pulsos de ar quase periódicos gerados na laringe pelo movimento cíclico das pregas vocais que excitam o trato vocal. A taxa de vibração das pregas vocais depende de um conjunto de características do locutor, tais como: sexo, idade, pressão do ar nos pulmões e também do comprimento, da espessura e da tensão das pregas vocais [6]. Quanto maior a tensão, maior será a taxa de vibração que, por sua vez define a freqüência fundamental da voz. Esta classe de som é identificada principalmente pela emissão de vogais (/a/, /e/, /i/, /o/, /u/).

- $\quad$ Sons fricativos:

Estes sons são produzidos da passagem turbulenta do ar através de alguma constrição formada no trato vocal. Esta constrição por sua vez é o que determina os sons fricativos. As constrições, segundo Deller et all [5], podem ser:

- Labiodentais (dentes superiores abaixo dos lábios) que caracterizam as consoantes $(/ \mathrm{f} /, / \mathrm{v} /)$ 
- Interdentário (língua atrás dos dentes) que caracterizam as consoantes (/d/);

- Alveolares (língua em contato com alvéolo dentário) que caracterizam as consoantes $(/ \mathrm{s} /, / \mathrm{z} /)$;

- Glótico (pregas vocais fixas e tencionadas). Este tipo de constrição se assemelha a de um ruído branco como exemplo temos a consoante $(/ \mathrm{r} /, / \mathrm{h} /)$.

- Sons Plosivos:

São sons produzidos pelo fechamento completo do trato vocal, com um aumento da pressão anterior à obstrução e liberação abrupta desta. Alguns exemplos são (/t/, /p/, /b/). Estes sons são caracterizados por um instante de silêncio seguido de uma explosão. Estes sons também caracterizam os sons nasais $(/ \mathrm{m} /, / \mathrm{n} /)$.

De acordo com o exposto, a geração do sinal da fala pode ser composta por três processos: fonte de excitação, o trato vocal e a radiação, conforme indica a figura 2.4.

A fonte de excitação é responsável por excitar o trato vocal. O trato vocal se comporta como um filtro acústico variante no tempo, que modela o sinal de voz através de seus articuladores. Por fim, este sinal é irradiado pela boca e/ou nariz.

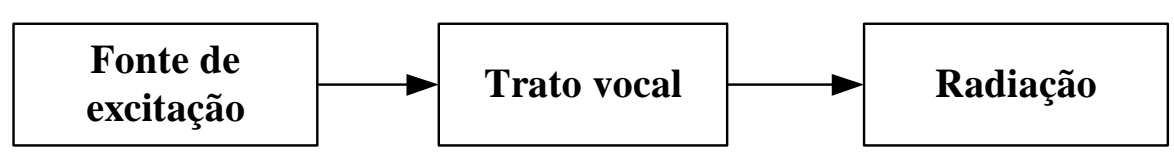

FIGURA 2. 4 - Etapas do processo de produção de voz 


\subsection{Modelo matemático}

Para se obter um modelo matemático representativo deste sistema, é extremamente útil conhecer as importantes características físicas do sistema fonador. O modelo inclui todas as estruturas responsáveis pela produção da fala citadas em detalhe anteriormente, podendo ser dividida funcionalmente em três estruturas distintas: um elemento produtor de excitação, caracterizado biologicamente pelo pulmão e suas estruturas de transporte de ar, um sistema produtor de oscilações periódicas, definido organicamente pelas pregas vocais e órgãos anexos, e um sistema produtor de ressonância compreendendo os órgãos da cavidade supraglotal (Articulação). Este modelo é apresentado na Figura 2.5.

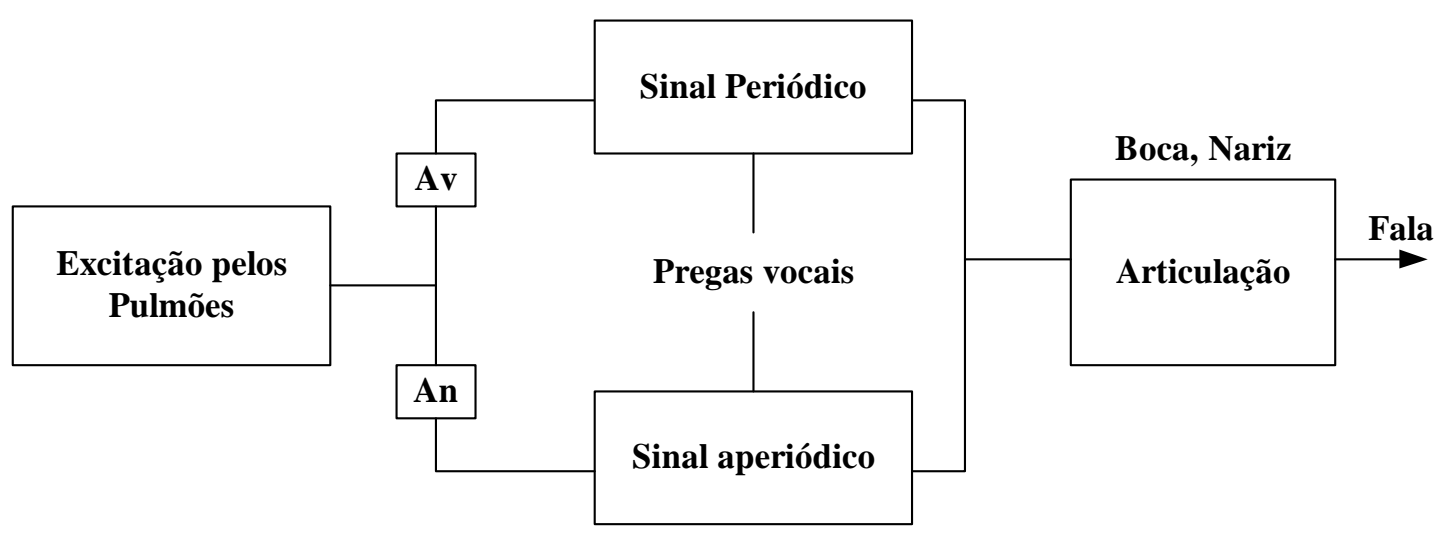

FIGURA 2. 5 - Modelo da produção de fala

Os valores de ganho, $A_{v}$ e $A_{n}$, na figura 2.5 , levam em consideração os efeitos de maior ou menor pressão exercida pelo pulmão durante a fonação.

Sendo $V(z)$ a função de transferência do trato vocal, a qual consiste de uma série de tubos acústicos, esta pode ser modelada de acordo com Rabinner e Schafer [2] por: 


$$
V(z)=\frac{H}{1-\sum_{k=1}^{N} a_{k} z^{-k}}
$$

em que $H$ e $\left\{a_{k}\right\}$ são valores dependentes da função de área e do comprimento do trato supraglotal. Cabe salientar que o sistema de produção da fala é variante no tempo; assim, os parâmetros $H$ e $\left\{a_{k}\right\}$ devem ser modificados de modo adequarem-se aos novos sinais de voz durante o tempo [2].

Diante das reflexões feitas, o subsistema ressonador pode ser representado adequadamente por um modelo tudo-pólo para a maioria dos fonemas (sons fricativos e nasalados necessitam de zeros adicionais para serem produzidos pelo modelo matemático, ou pela inclusão sistemática de mais pólos) [2]. Utilizando a equação 2.1, tem-se que os pólos aparecem na forma de complexos conjugados desde que os coeficientes $\left(a_{k}\right)$ da equação 2.1 forem reais. Assim:

$$
z_{k}, z_{k}^{*}=e^{-\sigma_{k} T} e^{ \pm j 2 \pi F_{k} T}
$$

em que a largura de banda de ressonância do trato vocal é aproximadamente $2 \sigma_{\mathrm{k}}$ e a freqüência central é $2 \pi F_{k}$.

O sinal de fala, entretanto ainda não é totalmente descrito somente por $V(z)$. Existe ainda a consideração sobre o efeito de radiação dos lábios que, aumenta a energia das altas freqüências. Desta forma é necessário prover tal característica no modelo de produção de fala. Uma aproximação deste efeito pode ser modelada por um filtro passa-alta dado por [2]: 


$$
R(z)=1-z^{-1}
$$

em que $R(z)$ é o modelo da radiação dos lábios

Com todos os elementos agora definidos, os sistemas podem ser cascateados, dando origem a uma única função de transferência que rege este modelo simplificado do trato vocal:

$$
H(z)=G(z) V(z) R(z)
$$

em que $G(z)$ representa o modelo do pulso glotal, responsável pela produção da onda quase-periódica para sinais vocálicos e ruído branco para sinais não-vocálicos, $V(z)$ representando a influência moduladora do trato supraglotal, caracterizando assim as formantes e deste modo os fonemas, e $R(z)$ produzindo a influência das perdas acústicas ao longo do trato vocal e principalmente devido à difração da onda sonora nos lábios. A Figura 2.6 representa o modelo matemático completo do sistema.

A partir da Figura 2.6 tem-se que o gerador de ruído aleatório representa a emissão de sinal não-vocálico. Já o modelo do pulso glotal é necessário para que se produza um sinal similar ao produzido pela vibração das pregas vocais de modo a excitar adequadamente o trato supraglotal artificial e produzir o sinal de voz desejado. 


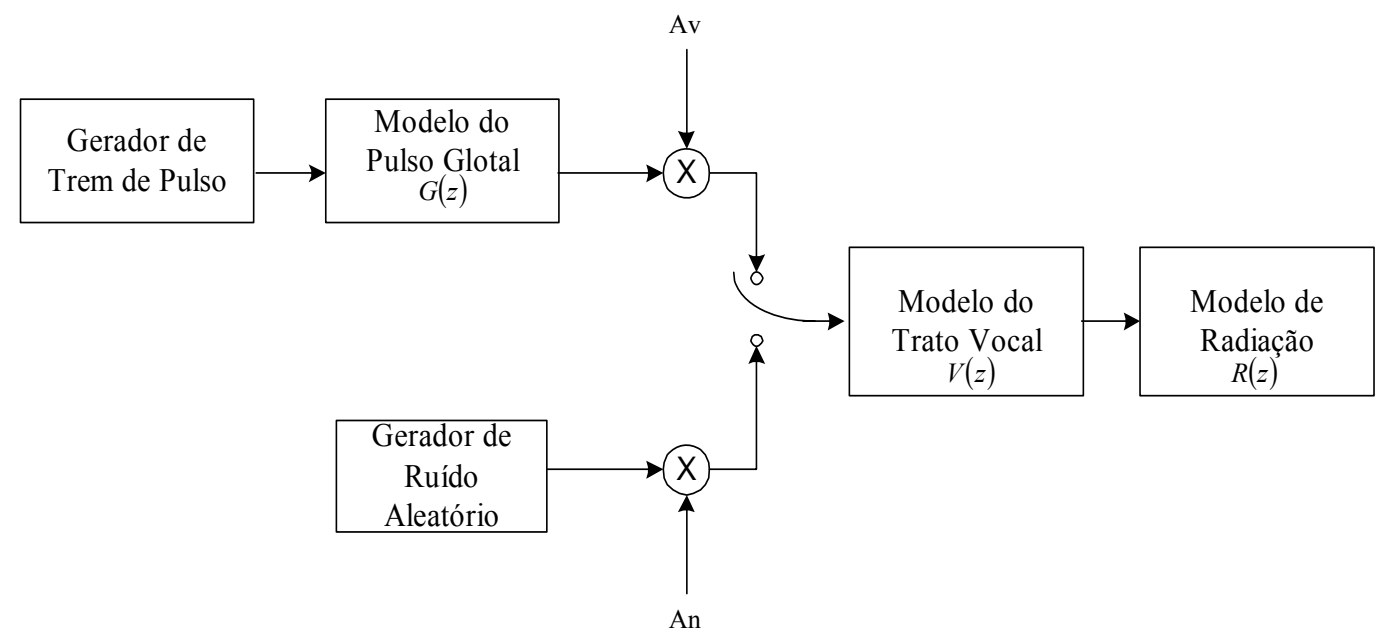

FIGURA 2. 6 - Modelo matemático de produção de fala

\subsection{Modelo de Predição Linear do Sinal de Voz}

O modelo de predição linear representa uma poderosa ferramenta matemática para a análise de sinais de voz. Esta é usada em diversas áreas de aplicações tais como: codificação de vídeo e voz, reconstrução de sinais de voz e modelos baseados em análise espectral dentre outras. A sua ampla aplicabilidade deve-se principalmente a sua capacidade de apresentar estimativas precisas utilizando representação do sinal com baixa taxa de bits, velocidade e precisão nos cálculos [6].

De acordo com a definição de predição linear, a amostra de um sinal pode ser expressa em termos de suas amostras passadas, ou seja, como uma combinação linear de seus valores passados. Desta forma, o sinal é aproximado pela modelagem de um filtro tudo-pólo cujos coeficientes são obtidos de modo a minimizar o erro quadrático médio entre as amostras originais e as amostras preditas.

A Figura 2.7 representa o modelo de predição linear para a produção de sinais de voz descrito nas seções anteriores. Neste modelo o sinal de excitação $e(n)$, pode ser um trem 
de pulsos (sons sonoros) ou um ruído branco (sons não sonoros). A combinação espectral do modelo glotal, do trato vocal e da radiação pelos lábios, podem ser representados por um filtro digital variante no tempo. A função de transferência do filtro, possui pólos e zeros, mas para simplificarmos a análise, considera-se que o filtro seja tudo-pólo. Assim, a função de transferência do filtro é dada por:

$$
H(z)=\frac{X(z)}{E(z)}=\frac{1}{1-\sum_{k=1}^{P} a_{P}(k) z^{-k}}
$$

na qual $\left\{a_{P}(1), \ldots, a_{P}(P)\right\}$, são os coeficientes do preditor, $P$ é a ordem do filtro, $z^{-k}$ representa $\mathrm{k}$ unidades de atrasos do sinal, $X(z)$ representa a transformada $\mathrm{z}$ do sinal de voz e $E(z)$ a transformada $z$ da função de excitação.

A escolha da ordem do filtro depende de um conjunto de características, sendo as principais: a natureza do som e ressonância do trato vocal. Um valor estipulado para $P$ normalmente deve estar na faixa de 8 e 12 [6].

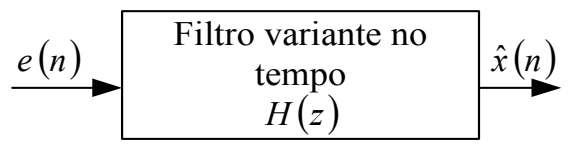

FIGURA 2. 7 - Modelo simplificado da produção de fala

Definindo $A(z)$ como o filtro inverso de $H(z)$, desta forma tem-se que:

$$
A(z)=1-\sum_{k=1}^{P} a_{P}(k) z^{-k}
$$


Pode-se dessa forma, mostrar as equações que definem o modelo digital tudo-pólo. Estas equações são dadas por:

$$
\begin{aligned}
& X(z)=\frac{1}{A(z)} E(z) \\
& E(z)=A(z) X(z)
\end{aligned}
$$

A função de excitação, como descrita anteriormente na equação (2.8), pode assumir a forma de sons sonoros ou não sonoros.

Substituindo a equação (2.6) em (2.8) tem-se que:

$$
E(z)=\left(1-\sum_{K=1}^{P} a_{P}(k) z^{-k}\right) X(z)
$$

Tomando-se a transformada $z$ inversa da equação 2.9 tem-se que:

$$
e(n)=x(n)-\sum_{k=1}^{P} a_{P}(k) x(n-k)
$$

Pela análise da equação (2.10), observa-se que o sinal de erro é a diferença entre o sinal atual, $x(n)$, e o preditor linear, que é formado por uma combinação linear (ponderada) de amostras passadas, $x(n-k)$, do sinal da voz. 
A amostra predita do sinal de voz $\hat{x}(n)$, de acordo com o preditor linear de ordem $P$ é dada por:

$$
\hat{x}(n)=\sum_{k=1}^{P} a_{P}(k) x(n-k)
$$

Dessa forma, o erro de predição $e(n)$ pode ser interpretado como a diferença entre a amostra $x(n)$ e o preditor $\hat{x}(n)$ então:

$$
e(n)=x(n)-\hat{x}(n)
$$

A expressão que define o erro quadrático médio entre o sinal de voz $x(n)$ e o sinal de voz predito $\hat{x}(n)$ é dada por:

$$
\varepsilon=\sum_{n=n_{0}}^{n_{1}} e^{2}(n)
$$

em que $n_{0}$ e $n_{1}$ são os limites do somatório.

Substituindo a equação (2.10) em (2.13) e desenvolvendo as equações chega-se a:

$$
\varepsilon=\sum_{n=n_{0}}^{n_{1}} x^{2}(n)-2 \sum_{k=1}^{P} a_{P}(k) \sum_{n=n_{0}}^{n_{1}} x(n) x(n-k)+\sum_{n=n_{0}}^{n_{1}}\left\{\sum_{k=1}^{P} a_{P}(k) x(n-k)\right\}^{2}
$$


Para minimizar o erro médio quadrático da equação (2.14), calcula-se as derivadas parciais do erro em relação aos coeficientes de predição e iguala-se o resultado a zero, assim:

$$
\frac{\partial \varepsilon}{\partial a_{i}}=0=-2 \sum_{n=n_{0}}^{n_{1}} x(n) x(n-i)+2 \sum_{n=n_{0}}^{n_{1}}\left\{\sum_{k=1}^{P} a_{P}(k) x(n-k)\right\} x(n-i), \quad 1 \leq i \leq P
$$

Rearranjando os termos da equação (2.15) como:

$$
\sum_{n=n_{0}}^{n_{1}} x(n) x(n-i)=\sum_{k=1}^{P} a_{P}(k) \sum_{n_{0}}^{n_{1}} x(n-k) x(n-i)
$$

Admitindo $n_{0} \rightarrow-\infty$ e $n_{1} \rightarrow \infty$, o primeiro somatório da equação acima define a função de auocorrelação de $x(n)$, isto é,

$$
r_{x x}(i)=\sum_{n=-\infty}^{\infty} x(n) x(n-i)
$$

Assim, a equação (2.16) pode ser reescrita da seguinte forma:

$$
r_{x x}(i)=\sum_{k=1}^{P} a_{P}(k) r_{x x}(k-i), \quad 1 \leq i \leq P
$$


Esta equação acima recebe o nome de equação de predição linear ou equação de Yule-Walker. Reescrevendo a mesma na forma matricial tem-se:

$$
\underbrace{\left[\begin{array}{c}
r_{x x}(0) \\
r_{x x}(1) \\
\vdots \\
r_{x x}(P)
\end{array}\right]}_{\boldsymbol{r}_{x x}}=\underbrace{\left[\begin{array}{cccc}
r_{x x}(0) & r_{x x}(1) & \cdots & r_{x x}(P-1) \\
r_{x x}(1) & r_{x x}(0) & \cdots & r_{x x}(P-2) \\
\vdots & \vdots & \ddots & \vdots \\
r_{x x}(P-1) & r_{x x}(P-2) & \cdots & r_{x x}(0)
\end{array}\right]}_{\boldsymbol{R}_{x x}} \underbrace{\left[\begin{array}{c}
a_{P}(1) \\
a_{P}(2) \\
\vdots \\
a_{P}(P)
\end{array}\right]}_{\boldsymbol{a}_{P}}
$$

A solução da equação (2.19) envolve, portanto, uma inversão de matrizes de modo a obtermos:

$$
\boldsymbol{a}_{p}=\boldsymbol{R}_{x x}{ }^{-1} \boldsymbol{r}_{x x}
$$

em que $\boldsymbol{a}_{p}$ é um vetor que contém os coeficientes de predição com dimensão $P \times 1, \boldsymbol{R}_{x x}$ é a matriz de autocorrelação com estrutura Toeplitz e dimensão $P \times P$, e $\boldsymbol{r}_{x x}$ um vetor de autocorrelação com dimensão $P \times 1$.

Para realizar a inversão de matrizes, de forma a extrair os coeficientes $a_{p}$ de predição, faz-se o uso dos métodos de autocorrelação e covariância que serão descritos nas seções seguintes.

\subsection{Método da Autocorrelação}

Neste método supõem-se que o sinal $x(n)$ é conhecido apenas dentro de um intervalo finito de tamanho $N[0, N-1]$ e que é aproximado por um modelo tudo-pólo, 
como descrito nas seções anteriores. Os coeficientes $a_{i}$ são determinados para minimizar o erro médio quadrático [10].

Neste método assume-se que o sinal $x(n)$ é zero fora do intervalo $[0, N-1]$. Desta forma, um novo sinal $\widetilde{x}(n)$ é gerado pela aplicação de uma janela de análise ao sinal $x(n)$. Estas janelas de análise podem ser do tipo Hamming, Hanning, Barlett, Blackmam e Kaiser Cada um dos tipos de janela apresentam características diferentes para manipular os dados a serem analisados [6].

$$
\widetilde{x}(n)=x(n) w_{l}(n)
$$

em que $w_{l}(n)$, é uma janela de análise como descrito acima.

A aplicação de uma janela de análise assegura que o modelo será estável, ou seja, os pólos da função de transferência estarão dentro do circulo de raio unitário e a estrutura de Toeplitz é assegurada segundo Hayes [10].

Dessa forma, o cálculo da equação (2.17), dentro do intervalo de comprimento $N$ $[0, N-1]$, é realizado utilizando-se o sinal $\widetilde{x}(n)$ ao invés de $x(n)$ :

$$
\hat{r}_{x x}(i)=\sum_{n=n_{0}}^{n_{1}} \widetilde{x}(n) \widetilde{x}(n-i)=\sum_{n=i}^{N} \widetilde{x}(n) \widetilde{x}(n-i) ; \quad i=0,1, \ldots \ldots, P
$$

As equações para o modelo tudo-pólo usando o método da autocorrelação estão resumidas na tabela 2.1. Para a resolução do conjunto de $P$ equações lineares é utilizado a recursão de Levinson-Durbin que pode ser encontrada em [2], [5], [9] e [10]. 
TABELA 2. 1 - Modelo tudo-pólo usando o método da autocorrelação.

\begin{tabular}{|l|c|}
\hline \multirow{2}{*}{ Equações Normais } & $\sum_{l=1}^{P} \hat{a}_{P}(l) \hat{r}_{x x}(i-l)=\hat{r}_{x x}(i) ; \quad i=1,2, \ldots, P$ \\
& $\hat{r}_{x x}(i)=\sum_{n=i}^{N} \widetilde{x}(n) \widetilde{x}^{*}(n-i) ; \quad i \geq 0$ \\
\hline Erro mínimo & $\varepsilon=\hat{r}_{x x}(0)-\sum_{i=1}^{P} \hat{a}_{p}(i) \hat{r}^{*}{ }_{x x}(i)$ \\
\hline
\end{tabular}

\subsection{Método da Covariância}

Como mostrado na seção anterior, o método da autocorrelação considera um intervalo finito entre $[0, N-1]$ aplicado a um sinal e fora deste intervalo o mesmo passa a ser zero aplicando-se uma janela de análise.

Diferentemente do método de autocorrelação, o método da covariância não impõe nenhuma restrição para o sinal fora do intervalo especificado e nenhuma janela de análise é aplicada ao mesmo. Desta forma, a estrutura de Toeplitz da equação normal é perdida segundo Hayes [10]. De forma análoga, este método também é usado para determinar os coeficientes de predição $a_{i}$ que minimizam a soma dos quadrados do erro $e(n)$.

Considerando o intervalo de $[0, N-1]$, o erro quadrático médio pode ser minimizado para os valores de $n$ no intervalo de $[p, N-1]$. Sendo assim, a expressão do erro é dada por:

$$
\varepsilon_{p}{ }^{c}=\sum_{n=p}^{N-1}|e(n)|^{2}
$$


Dessa forma, não é necessário aplicar janela nos dados ou fazer qualquer restrição para os dados fora do intervalo especificado.

As equações usadas neste método são as mesmas usadas para o método da autocorrelação mostradas na tabela 2.1. A diferença está na matriz de autocorrelação, que é substituída pela matriz de covariância que neste caso segundo Hayes [10] é dada por:

$$
c_{x x}(k, l)=\sum_{n=0}^{N-1} x(n-l) x^{*}(n-k)
$$

O cálculo dos coeficientes do filtro tudo-pólo pode ser encontrado na forma matricial como:

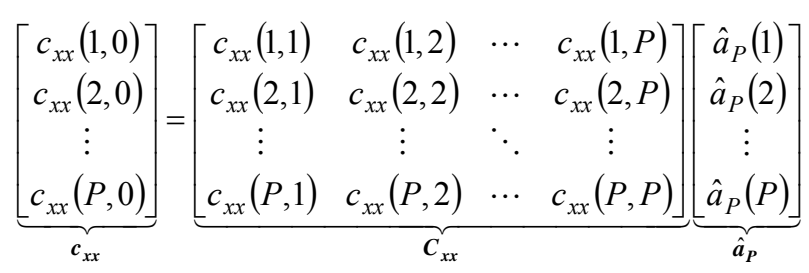

em que $\hat{\boldsymbol{a}}_{p}$ é um vetor que contém os coeficientes de predição estimados com dimensão $P \times 1, C_{x x}$ é a matriz de covariância com dimensão $P \times P$ e $\boldsymbol{c}_{x x}$ um vetor de covariância com dimensão $P \times 1$.

Dessa forma o erro mínimo para este método é dado por:

$$
\left\{\varepsilon_{p}{ }^{c}\right\}_{\min }=c_{x x}(0,0)-\sum_{k=1}^{p} \hat{a}_{p}(k) c_{x x}(0, k)
$$


A tabela 2.2 mostra as equações usadas na modelagem de um sinal somente com pólos para o método da covariância.

Entretanto para este método a recursão de Levinson-Durbin não pode ser usada para solucionar a equação (2.28) uma vez que a mesma não possui uma estrutura Toeplitz.

Dessa forma, a determinação dos coeficientes utilizando o método da covariância pode ser realizada pela decomposição de Cholesky [10].

TABELA 2. 2 - Modelo tudo-pólo usando o método da covariância.

\begin{tabular}{|l|l|}
\hline \multirow{2}{*}{ Equações Normais } & $\sum_{l=1}^{P} \hat{a}_{P}(l) c_{x x}(k, l)=c_{x x}(k) ; \quad k=1,2, \ldots, P$ \\
& $c_{x x}(k, l)=\sum_{n=0}^{N-1} x(n-l) x^{*}(n-k) ; \quad k, l \geq 0$ \\
\hline Erro mínimo & $\left\{\varepsilon_{p}{ }^{c}\right\}_{\min }=c_{x x}(0,0)-\sum_{k=1}^{P} \hat{a}_{p}(k) c^{*}{ }_{x x}(0, k)$ \\
\hline
\end{tabular}

\subsection{Considerações Finais}

Neste capitulo foi apresentado de forma resumida o processo da produção da fala bem como a sua modelagem matemática.

O modelo de predição linear também descrito nas seções anteriores, será utilizado para representar o sinal de voz no filtro de Kalman, quando da utilização da matriz transição de estados no capítulo 4. Dessa forma temos que o sinal de voz $x(n)$, pode ser modelado pela seguinte equação de estado:

$$
\boldsymbol{x}(n)=\boldsymbol{A} \boldsymbol{x}(n-1)+\boldsymbol{w}(n)
$$


em que $\boldsymbol{A}$ é a matriz transição de estados com dimensão $P \times P$ que é dado pela equação (2.28), $x(n)$ é um vetor de dimensão $P \times 1$ e $w(n)$ é o ruído do processo de entrada que possui dimensão $P \times 1$.

$$
\boldsymbol{A}=\left[\begin{array}{ccccc}
a_{P}(1) & a_{P}(2) & \cdots & a_{P}(P-1) & a_{P}(P) \\
1 & 0 & \cdots & 0 & 0 \\
0 & 1 & \cdots & 0 & 0 \\
\vdots & \vdots & \cdots & \vdots & \vdots \\
0 & 0 & \cdots & 1 & 0
\end{array}\right]
$$

em que $a_{P}$ são os coeficintes de predição linear determinados de modo a minimizar o sinal de erro conforme a equação (2.10), segundo um critério estabelecido. O método mais comum usado para minimizar este erro, é a minimização da soma dos quadrados das amostra $\varepsilon(n)$, o qual resulta em equações lineares facilmente tratáveis.

O capítulo se encerra com os dois métodos clássicos utilizados na determinação dos coeficientes do preditor linear. Os métodos são: método da autocorrelação que usa como solução para as $P$ equações lineares, a recursão de Levinson-Durbin e o método da covariância que usa como solução a decomposição de Cholesky. 


\section{Subtração Espectral}

\subsection{Introdução}

Em muitas aplicações de processamento de sinais de voz, a presença de ruído aditivo pode degradar a qualidade e a inteligibilidade dos sinais de voz. Basicamente na transmissão destes sinais, vários fatores tais como: ruído ambiente, perdas devidas à codificação de enlaces digitais ou até mesmo através de outras conversações ou outras fontes de sinais podem comprometer a qualidade do sinal transmitido.

Com base nestas informações, muitas pesquisas têm sido realizadas nesta área e conseqüentemente muitos algoritmos para melhoria na qualidade de sinais de voz têm surgido com o objetivo de eliminar ou mesmo reduzir a intensidade do ruído aditivo. Dentre estes algoritmos, tem-se as subtrações espectrais de magnitude e potência, que são métodos utilizados para a reconstrução de sinais degradados por ruído. Nessas técnicas, a melhoria na qualidade do sinal de voz é realizada por meio da subtração espectral (domínio da freqüência) entre o sinal de voz contaminado por ruído aditivo e a estimativa média do ruído, avaliada em instantes de silêncio.

Neste capítulo são descritos os detalhes das duas abordagens usadas para o préprocessamento do sinal contaminado por ruído: subtração espectral de magnitude e subtração espectral de potência. Os valores estimados a partir destas técnicas são usados como condição inicial no filtro de Kalman no tempo e na freqüência. 


\subsection{Subtração Espectral de Magnitude}

O método de subtração espectral de magnitude foi proposto por Boll [11] em 1979. Neste método uma estimativa que corresponde ao espectro de magnitude do sinal livre de ruído é obtida a partir da subtração entre o espectro de magnitude do sinal contaminado e o espectro médio de magnitude do ruído estimado em trechos onde não se tem atividade sonora.

Para que se possa desenvolver o método, assume-se que o sinal contaminado por ruído seja dado por:

$$
y(n)=x(n)+v(n)
$$

em que $y(n), x(n)$ e $v(n)$ são, sinal contaminado por ruído, sinal livre de ruído e ruído aditivo, respectivamente.

Tomando-se a transformada discreta de Fourier (DFT) da equação (3.1) temos:

$$
Y\left(e^{j \omega_{k}}\right)=X\left(e^{j \omega_{k}}\right)+V\left(e^{j \omega_{k}}\right)
$$

em que $Y\left(e^{j \omega_{k}}\right)$ é o espectro de magnitude do sinal contaminado $y(n)$. Similarmente $X\left(e^{j \omega_{k}}\right)$ e $V\left(e^{j \omega_{k}}\right)$ representam os espectros de magnitudes dos sinais livre de ruído, $x(n)$, e ruído aditivo, $v(n)$.

Pela análise da equação (3.2) nota-se que tendo o espectro de magnitude do sinal contaminado $Y\left(e^{j \omega_{k}}\right)$ e tendo uma estimativa media do espectro de magnitude do ruído 
$\mu\left(e^{j \omega_{k}}\right)$, encontrada em trechos de silêncio, determina-se a estimativa do espectro de magnitude do sinal estimado $\hat{X}\left(e^{j \omega_{k}}\right)$, de acordo com a seguinte equação:

$$
\left|\hat{X}\left(e^{j \omega_{k}}\right)\right|=\left|Y\left(e^{j \omega_{k}}\right)\right|-\left|\mu\left(e^{j \omega_{k}}\right)\right|
$$

Para que se tenha o sinal estimado $\hat{x}(n)$ no domínio do tempo, a fase do sinal contaminado $\theta_{Y}\left(e^{j \omega_{k}}\right)$ é combinada com o espectro de magnitude do sinal estimado $\hat{X}\left(e^{j \omega_{k}}\right)$, e em seguida, aplica-se a transformada discreta de Fourier inversa (IDFT) como:

$$
\hat{x}(n)=\sum_{k=0}^{N-1}\left|\hat{X}\left(e^{j \omega_{k}}\right)\right| e^{j \theta_{Y}\left(e^{j \omega_{k}}\right)} e^{-j \omega_{k} n}
$$

em que $w_{k}=\frac{2 \pi}{N} k$ é a freqüência discreta da transformada.

Definindo o erro espectral resultante do sinal estimado pela equação (3.5), Boll desenvolveu algumas modificações de modo a reduzir o efeito audível do erro espectral resultante [5].

$$
\varepsilon\left(e^{j \omega_{k}}\right)=\hat{X}\left(e^{j \omega_{k}}\right)-X\left(e^{j \omega_{k}}\right)
$$

As modificações propostas por Boll [11], a fim de melhorar a subtração espectral de magnitude foram as seguintes:

1) Magnitude média: Nesta modificação, o valor da magnitude do sinal ruidoso $\left|Y\left(e^{j \omega_{k}}\right)\right|$ na equação (3.3) é substituído pelo seu valor médio $\overline{\left|Y\left(e^{j \omega_{k}}\right)\right|}$, levando dessa forma a uma redução do erro de estimação. A magnitude média pode ser calculada desta forma: 


$$
\overline{\left|Y\left(e^{j \omega_{k}}\right)\right|}=\frac{1}{M} \sum_{i=0}^{M-1}\left|Y_{i}\left(e^{j \omega_{k}}\right)\right|
$$

em que $Y_{i}\left(e^{j \omega_{k}}\right)$ é a transformada da i-ésima janela de $y(n)$. Dessa forma, o estimador espectral utilizando a média do espectro do ruído é dado por:

$$
X_{\mu}\left(e^{j \omega_{k}}\right)=\left[\left|\overline{Y\left(e^{j \omega_{k}}\right)}\right|-\left|\mu\left(e^{j \omega_{k}}\right)\right|\right] e^{j \theta_{y}\left(e^{j \omega_{k}}\right)}
$$

em que $X_{\mu}\left(e^{j \omega_{k}}\right)$ é o valor estimado do sinal de voz determinado a partir da subtração espectral entre o valor médio do espectro do sinal contaminado por ruído $\left|\overline{Y\left(e^{j \omega_{k}}\right)}\right|$ e o valor médio do ruído $\mu\left(e^{j \omega_{k}}\right)$ determinado durante os instantes de silêncio.

2) Retificação de meia onda: Devido à natureza aleatória do ruído podem ocorrer situações em que a magnitude do espectro do sinal contaminado por ruído $Y\left(e^{j \omega_{k}}\right)$ seja menor do que a magnitude média do ruído $\mu\left(e^{j \omega_{k}}\right)$, o que resulta em valores negativos para subtração espectral e gera um problema conhecido como ruído musical. Neste caso, é comum a aplicação do conceito de retificação de meia onda, que consiste em igualar a zero os valores negativos resultantes da subtração espectral de magnitude. A retificação de meia onda é dada por:

$$
\left|\hat{X}\left(e^{j \omega_{k}}\right)\right|=\left\{\begin{array}{l}
\left|\hat{X}\left(e^{j \omega_{k}}\right)\right|, \text { se }\left|\hat{X}\left(e^{j \omega_{k}}\right)\right|>0 \\
0, \text { caso con trário }
\end{array}\right.
$$


3) Redução do ruído residual: O ruído residual é o ruído restante após a subtração espectral. Sua redução é feita após a retificação de meia onda. A eliminação ou diminuição deste ruído pode ser feita substituindo seu valor corrente por um valor mínimo, determinado a partir da análise de janelas adjacentes aplicadas ao sinal da seguinte forma: um valor mínimo de $\hat{X}\left(e^{j \omega_{k}}\right)$ é determinado e usado se a magnitude espectral da estimativa $\hat{X}\left(e^{j \omega_{k}}\right)$ for menor que o máximo valor do ruído residual determinado durante os instantes de silêncio, caso contrário o valor permanece constante. Desta forma tem-se:

$$
\left|\hat{X}\left(e^{j \omega_{k}}\right)\right|=\left\{\begin{array}{l}
\left|\hat{X}\left(e^{j \omega_{k}}\right)\right|, \text { se }\left|\hat{X}\left(e^{j \omega_{k}}\right)\right| \geq \operatorname{Max}\left|V_{R}\left(e^{j \omega_{k}}\right)\right| \\
\operatorname{Min}\left|\hat{X}\left(e^{j \omega_{k}}\right)\right|, \text { se }\left|\hat{X}\left(e^{j \omega_{k}}\right)\right|<\operatorname{Max}\left|V_{R}\left(e^{j \omega_{k}}\right)\right|
\end{array}\right.
$$

em que $\left|V_{R}\left(e^{j \omega_{k}}\right)\right|$ é o ruído residual e pode ser determinado em instantes de silêncio pela equação (3.10).

$$
V_{R}\left(e^{j \omega_{k}}\right)=V\left(e^{j \omega_{k}}\right)-\mu\left(e^{j \omega_{k}}\right)
$$

Desta forma, a Figura 3.1 mostra em forma de diagrama em blocos, as operações envolvidas no algoritmo proposto por Boll [11]. 


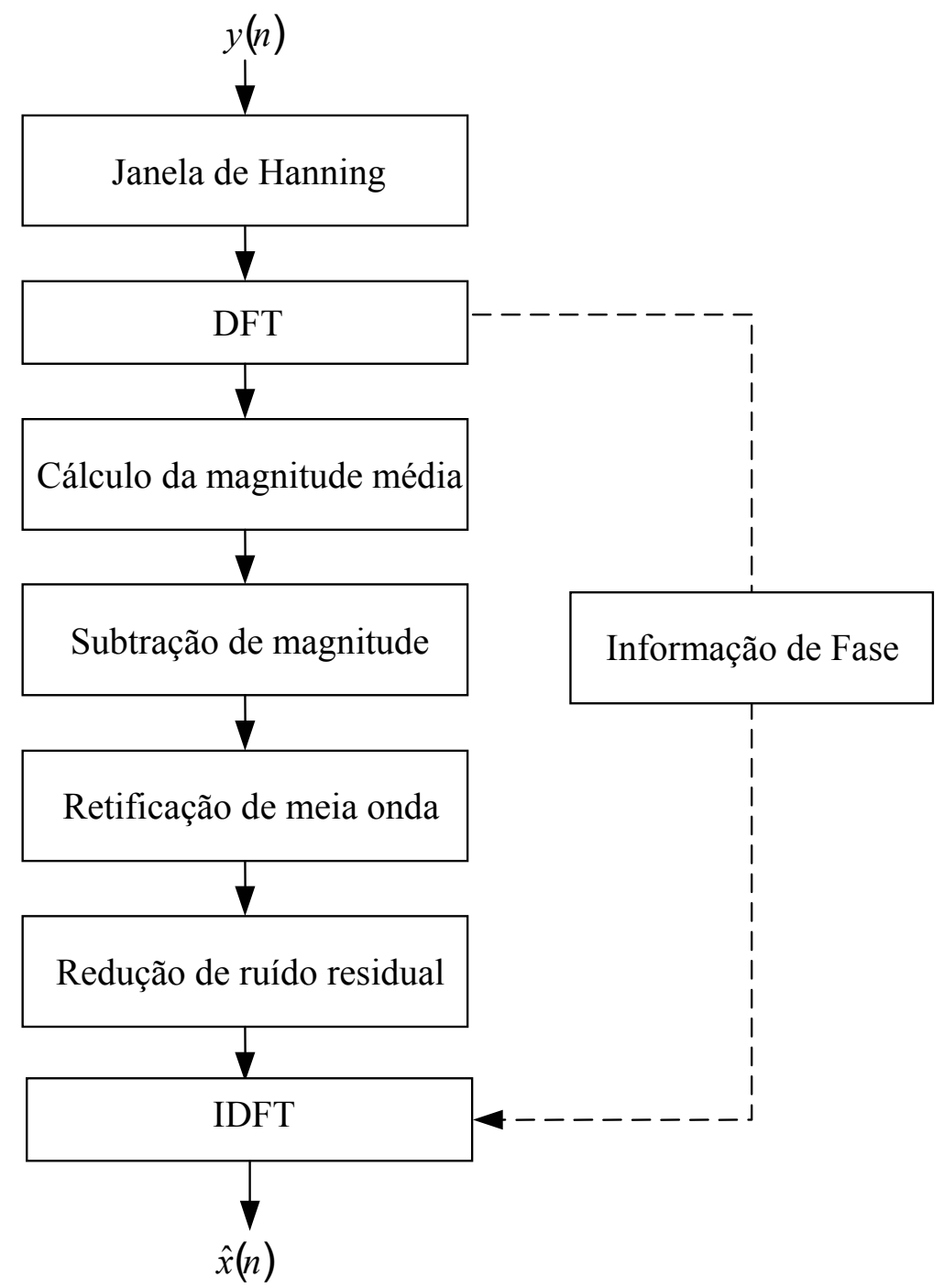

FIGURA 3. 1 - Diagrama em blocos da Subtração Espectral de Magnitude.

As modificações desenvolvidas por Boll [11], com o propósito da redução do erro espectral, podem comprometer a qualidade do sinal e conseqüentemente a inteligibilidade do mesmo. Por exemplo, a magnitude média pode provocar perdas de informação em sinais de voz que apresentam variações rápidas, como início de fonemas e consoantes plosivas ( $p$, b, t). Outro problema é a retificação de meia onda que contribui para a perda de informação de baixa amplitude [12]. 
Baseando-se nessas informações, variações no método proposto por Boll foram desenvolvidas. Uma das variações importantes é a subtração espectral de potência, que tem como objetivo a redução do ruído musical com maior intensidade e o aumento da inteligibilidade. O método é descrito na seção seguinte.

\subsection{Subtração Espectral de Potência}

A subtração espectral de potência é um método proposto por Berouti et all [13] em 1979. O método consiste na subtração do espectro de potência do sinal contaminado por ruído pelo espectro de potência do ruído estimado em trechos de silêncio. Dessa forma a subtração espectral de potência pode ser realizada como:

$$
\left|\hat{X}\left(e^{j \omega_{k}}\right)\right|^{2}=\left|Y\left(e^{j \omega_{k}}\right)\right|^{2}-\left|\mu\left(e^{j \omega_{k}}\right)\right|^{2}
$$

em que $\left|\hat{X}\left(e^{j \omega_{k}}\right)\right|^{2}$ é o espectro de potência estimado do sinal livre de ruído, $\left|Y\left(e^{j \omega_{k}}\right)\right|^{2}$ é o espectro de potência do sinal degradado por ruído e $\left|\mu\left(e^{j \omega_{k}}\right)\right|^{2}$ é o valor médio do espectro de potência do ruído avaliado em trechos de silêncio.

Para a redução do ruído musical, Berouti et all [13], modificou a equação (3.11) incluindo um termo denominado fator de subtração. Esta modificação é dada por:

$$
\left|\hat{X}\left(e^{j \omega_{k}}\right)\right|^{2}=\left|Y\left(e^{j \omega_{k}}\right)\right|^{2}-\alpha\left|\mu\left(e^{j \omega_{k}}\right)\right|^{2}
$$


em que $\alpha$ é o fator de subtração. Este por sua vez, tem como finalidade o controle de redução de ruído, e é determinado empiricamente por Berouti et all [13]:

$$
\alpha=\alpha_{0}-\frac{3}{20} S N R \quad-5 d B \leq S N R \leq 20 d B
$$

em que $\alpha_{0}$ é o valor de $\alpha$ encontrado quando a relação sinal/ruído (SNR) for $0 \mathrm{~dB}$. A Figura 3.2 mostra os valores de $\alpha$ em função da (SNR). Desta forma pode se verificar que $\alpha$ é uma função da SNR.

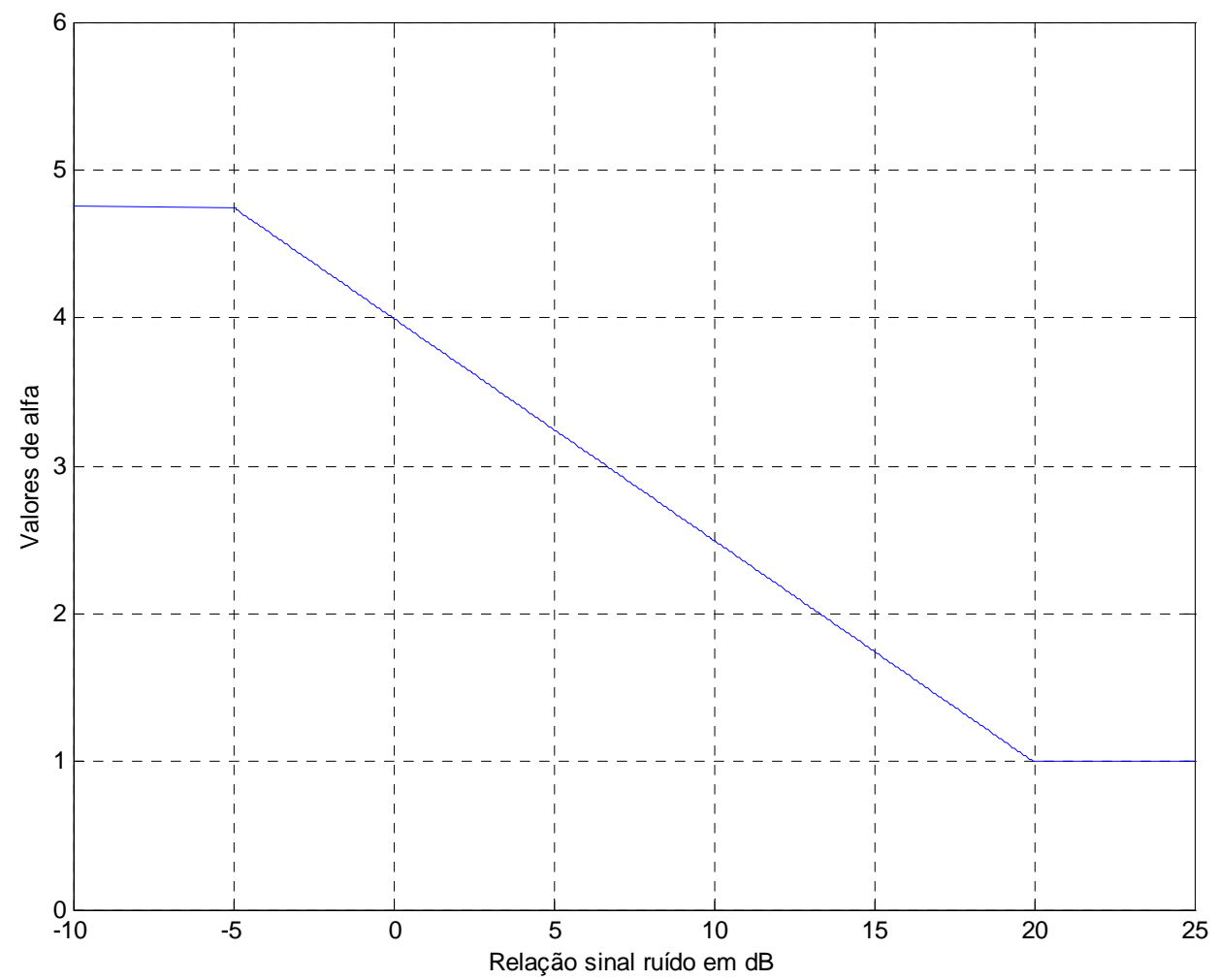

FIGURA 3. 2 - Fator de subtração em função da relação sinal/ruído (SNR) em dB. 
Outra mudança significativa realizada por Berouti et all [13], foi no processo de retificação. Neste caso é adicionado um limite espectral cuja função é não perder informações do sinal de baixa amplitude. Esta mudança é dada por:

$$
\left|\hat{X}\left(e^{j \omega_{k}}\right)\right|^{2}=\left\{\begin{array}{l}
\left|\hat{X}\left(e^{j \omega_{k}}\right)\right|^{2}, \text { se }\left|\hat{X}\left(e^{j \omega_{k}}\right)\right|^{2}>\beta\left|\mu\left(e^{j \omega_{k}}\right)\right|^{2} \\
\beta\left|\mu\left(e^{j \omega_{k}}\right)\right|^{2}, \text { caso con trário }
\end{array}\right.
$$

em que $\beta$ é o limite espectral, cuja função é mascarar o efeito das componentes do ruído musical. Segundo Berouti et all [13], $\beta$ é encontrado a partir da relação sinal/ruído (SNR) podendo ter valores típicos que variam de 0,02 até 0,06 para uma $\mathrm{SNR} \leq 0 \mathrm{~dB}$ e valores que estão entre 0,0005 até 0,02 para $\mathrm{SNR}>0 \mathrm{~dB}$. Neste trabalho o valor de $\beta$, foi fixado com o valor de 0,02 .

Assim, o diagrama em blocos apresentado pela Figura 3.3, mostra as operações envolvidas no método de subtração espectral de potência. 


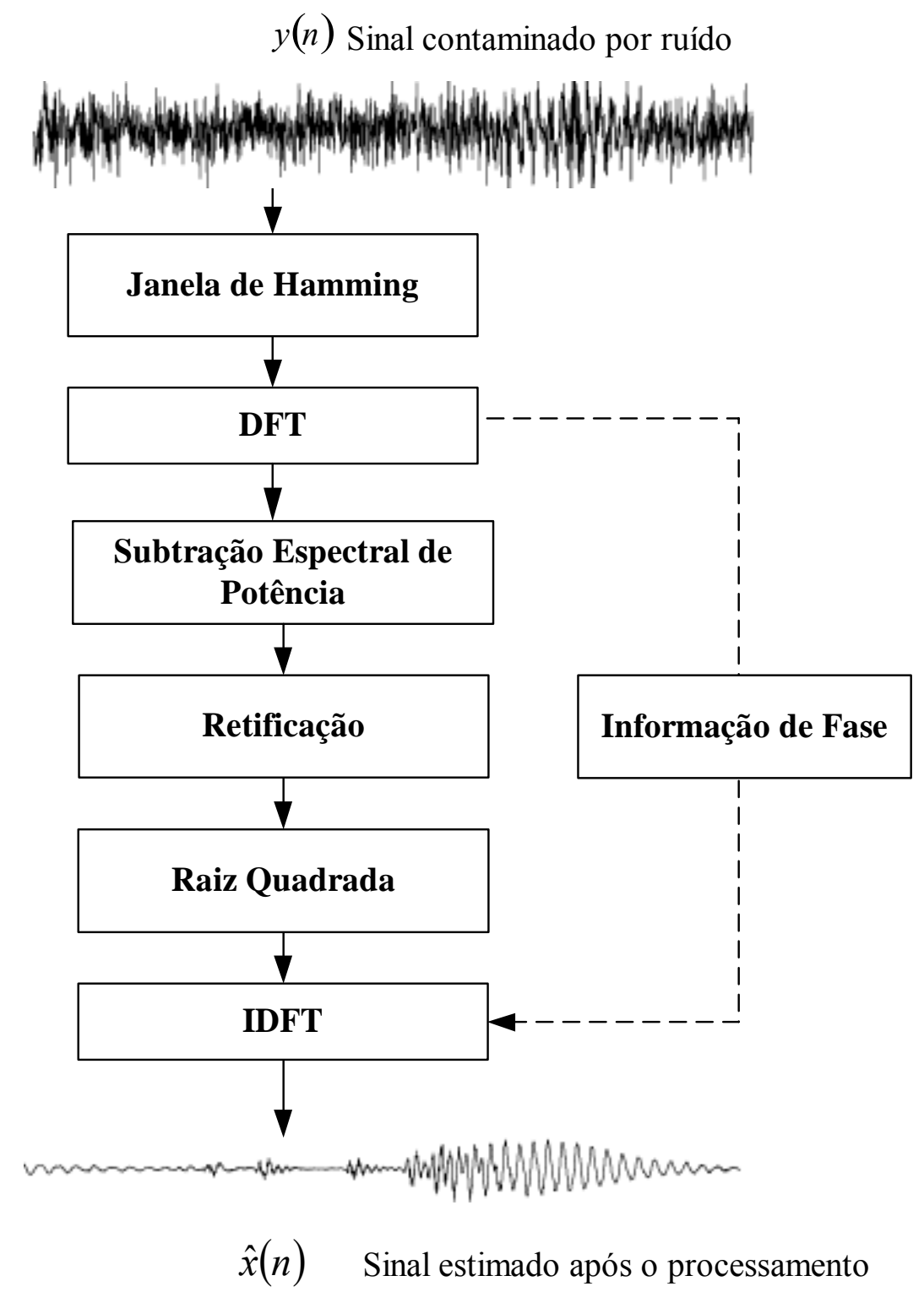

FIGURA 3. 3 - Diagrama em blocos da Subtração Espectral de Potência. 


\subsection{Subtração Espectral Generalizada}

De um modo geral, a subtração espectral pode ser entendida como um método para restauração do espectro de potência ou do espectro de magnitude de um sinal observado na presença de ruído aditivo [8]. Sendo assim, a subtração espectral generalizada desenvolvida por Berouti et all [13], pode ser dada por:

$$
\left|\hat{X}\left(e^{j \omega_{k}}\right)\right|^{a}=\left|Y\left(e^{j \omega_{k}}\right)\right|^{a}-\alpha\left|\mu\left(e^{j \omega_{k}}\right)\right|^{a}
$$

em que $\mid \hat{X}\left(\left.e^{j w_{k}}\right|^{a}\right.$ é uma estimativa do espectro do sinal livre de ruído e $\mid \mu\left(e^{j w_{k}}\right)^{a}$ é a média do espectro do ruído avaliada em trechos de silêncio. Para que se tenha a subtração espectral de magnitude o expoente a é igual a 1, e para o espectro de potência o expoente a é igual a 2.

Para o caso da subtração espectral de magnitude o valor de $\alpha$ usado neste trabalho é igual a 1. No caso da subtração espectral de potência o valor de $\alpha$ é dado pela equação (3.13), e o processo de retificação por:

$$
\left|\hat{X}\left(e^{j \omega_{k}}\right)\right|^{a}=\left\{\begin{array}{l}
\left|\hat{X}\left(e^{j \omega_{k}}\right)\right|^{a}, \text { se }\left|\hat{X}\left(e^{j \omega_{k}}\right)\right|^{a}>\beta\left|\mu\left(e^{j \omega_{k}}\right)\right|^{a} \\
\beta\left|\mu\left(e^{j \omega_{k}}\right)\right|^{a}, \text { caso con trário }
\end{array}\right.
$$

em que $\beta$ é o limite espectral e para ambos os casos neste trabalho teve seu valor igual a 0,02 
O uso desta retificação tanto na subtração espectral de magnitude quanto na subtração espectral de potência, mascara o efeito do ruído musical com um ruído residual de baixa intensidade.

Para restauração do sinal no domínio do tempo, o espectro de magnitude do sinal estimado $\left|\hat{X}\left(e^{j w_{k}}\right)\right|$ é combinado com a fase do sinal contaminado por ruído, e então passado para o domínio do tempo via transformada discreta de Fourier inversa (IDFT) como:

$$
\hat{x}(n)=\sum_{k=0}^{N-1}\left|\hat{X}\left(e^{j \omega_{k}}\right)\right| e^{j \theta_{Y}\left(e^{j \omega_{k}}\right)} e^{-j \omega_{k} n}
$$

em que $w_{k}=\frac{2 \pi}{N} k$ é a freqüência discreta da transformada e $\theta_{Y}\left(e^{j \omega_{k}}\right)$ é a fase do sinal contaminado por ruído no domínio da freqüência.

Desta forma para exemplificar a subtração espectral generalizada, são apresentados exemplos, em que um sinal de voz correspondente à palavra "janela", é contaminado por ruído do tipo branco.

No primeiro exemplo usou-se a subtração espectral de magnitude, na qual o expoente da equação (3.15) é igual a $1(\mathrm{a}=1)$. Já o parâmetro $\alpha$ teve seu valor igual a 1 e o parâmetro $\beta$ fixado em 0,02 como descrito anteriormente. Para este exemplo, a janela aplicada foi uma janela de Hamming com tamanho de 512 amostras usando sobreposição espectral de 50\%. A relação sinal/ruído segmentada de entrada (SNRI), que será descrita no capítulo 5, foi de $3 \mathrm{~dB}$. Sendo assim, as figuras 3.4, 3.5 e 3.6, mostram os resultados obtidos para este exemplo. 


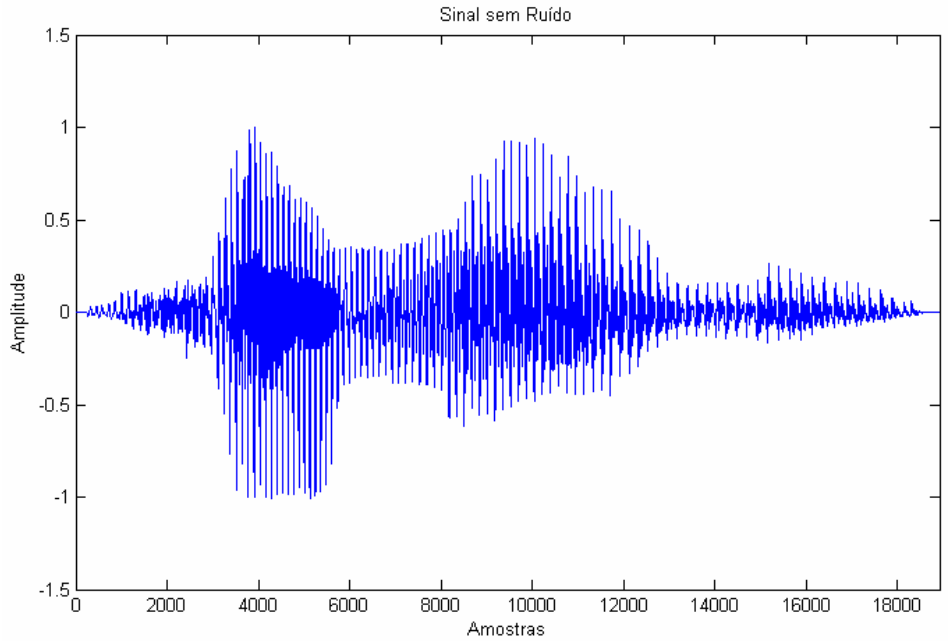

FIGURA 3. 4 - Sinal original correspondente à palavra "janela".

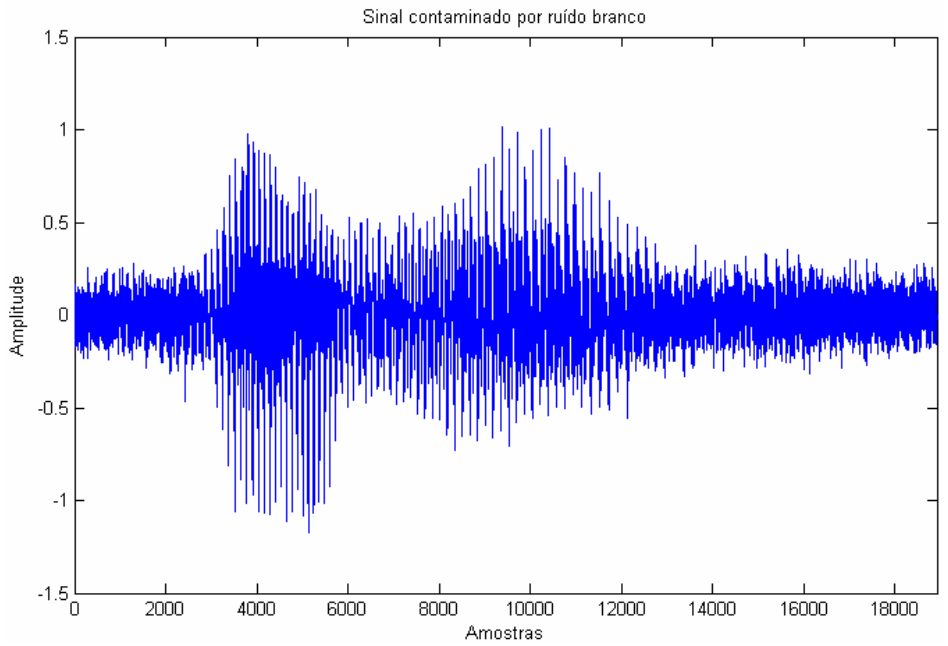

FIGURA 3. 5 - Sinal contaminado por ruído branco. 


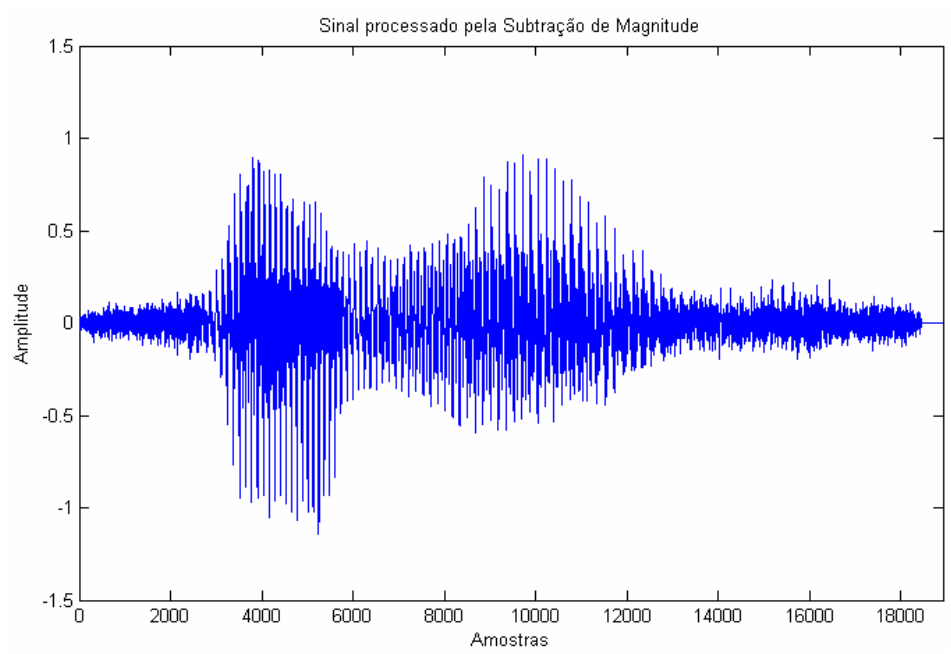

FIGURA 3. 6 - Sinal estimado após a Subtração Espectral de Magnitude.

Observando as figuras 3.5 e 3.6 que correspondem respectivamente, ao sinal contaminado por ruído branco e sinal após a subtração espectral de magnitude, nota-se uma redução do nível de ruído nos trechos de silêncio, o que proporcionou um aumento na relação sinal/ruído segmentada de $4 \mathrm{~dB}$ para este exemplo, e uma distância de ItakuraSaito, medida está que será discutida no capítulo 5 de 0,7071 .

No segundo exemplo, foi utilizada a subtração espectral de potência. Neste exemplo o expoente da equação (3.15) é igual a $(\mathbf{a}=2)$. Já o parâmetro $\alpha$ é dado pela equação (3.13) e o valor de $\beta$, o mesmo usado no exemplo anterior. Para este caso foi adicionado também ao sinal de voz original um ruído branco, o qual também resultou em uma relação sinal/ruído segmentada de entrada de $3 \mathrm{~dB}$. Sendo assim, os resultados são mostrados nas figuras $3.7,3.8$ e 3.9 , as quais se referenciam ao sinal original, sinal contaminado por ruído e sinal estimado após a subtração espectral de potência respectivamente. 


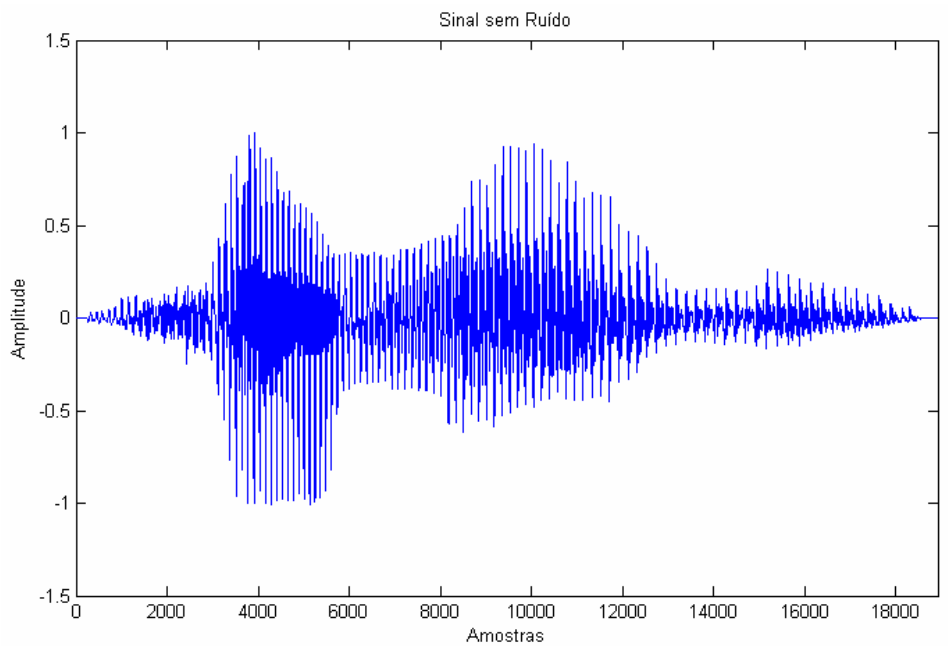

FIGURA 3. 7 - Sinal original correspondente à palavra "janela".

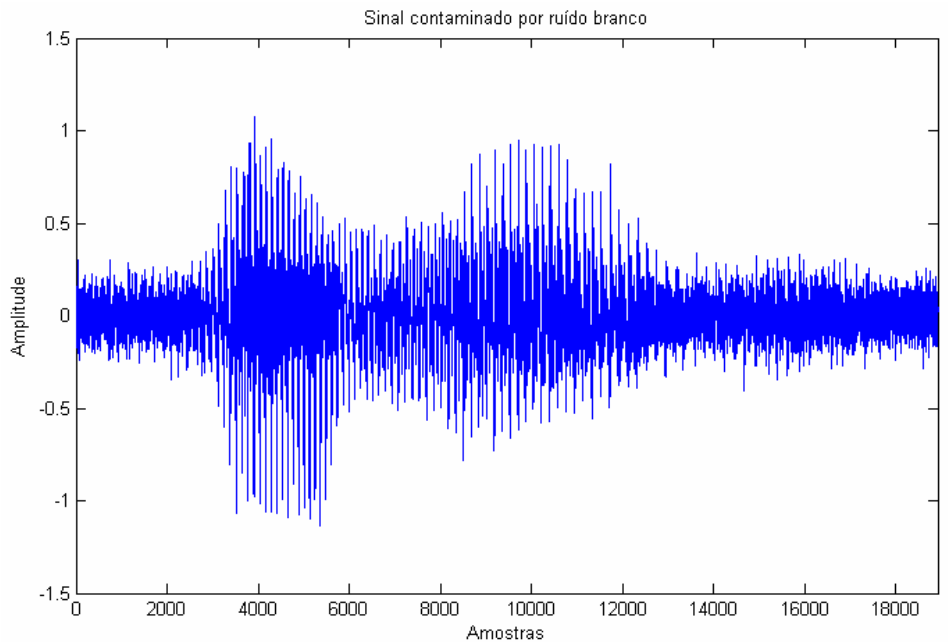

FIGURA 3. 8 - Sinal contaminado por ruído branco. 


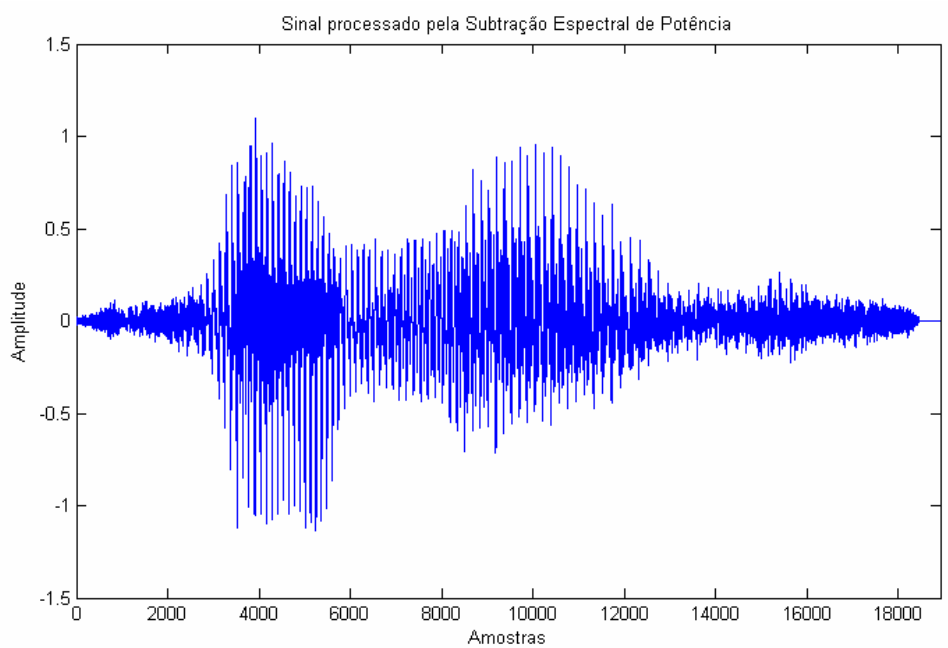

FIGURA 3. 9 - Sinal estimado após a Subtração Espectral de Potência.

Observando as figuras 3.8 e 3.9 pode-se notar a redução de ruído envolvida neste processamento. $\mathrm{O}$ aumento da relação sinal/ruído segmentada neste caso foi de $5 \mathrm{~dB}$ e a distância de Itakura-Saito de 0,6015. Isto significa que para este teste, a subtração espectral de potência apresenta resultados um pouco melhor do que a subtração espectral de magnitude. Sendo assim, depois de realizados outros testes para outros sinais de voz (Tabela 3.1 e Tabela 3.2), pode-se concluir que o método de subtração espectral de potência apresenta resultados melhores em relação à subtração espectral de magnitude tanto com relação à SNR, quanto a distância de Itakura-Saito. Dessa forma, esta técnica será usada neste trabalho para realizar o pré-processamento do sinal contaminado utilizado como condição inicial para os filtros de Kalman de tempo discreto e freqüência discreta, descritos no capítulo 4. 
TABELA 3. 1 - Resultados da Subtração Espectral de Magnitude, para 10 sinais de voz contaminados por ruído branco.

\begin{tabular}{|l|c|c|c|}
\hline \multicolumn{4}{|c|}{ Subtração Espectral de Magnitude } \\
\hline Palavras & SNRI & SNRO & Distância de Itakura-Saito \\
\hline Bar & $3 \mathrm{~dB}$ & $8 \mathrm{~dB}$ & 1,2457 \\
\hline Barco & $3 \mathrm{~dB}$ & $8 \mathrm{~dB}$ & 0,9350 \\
\hline Boi & $3 \mathrm{~dB}$ & $6 \mathrm{~dB}$ & 0,9588 \\
\hline Dado & $3 \mathrm{~dB}$ & $6 \mathrm{~dB}$ & 0,6304 \\
\hline Elétrica & $3 \mathrm{~dB}$ & $8 \mathrm{~dB}$ & 0,4570 \\
\hline Fala & $3 \mathrm{~dB}$ & $4 \mathrm{~dB}$ & 0,9592 \\
\hline Janela & $3 \mathrm{~dB}$ & $7 \mathrm{~dB}$ & 0,7071 \\
\hline Manga & $3 \mathrm{~dB}$ & $8 \mathrm{~dB}$ & 0,7548 \\
\hline Lata & $3 \mathrm{~dB}$ & $11 \mathrm{~dB}$ & 0,3931 \\
\hline Tabela & $3 \mathrm{~dB}$ & $7 \mathrm{~dB}$ & 0,4571 \\
\hline & & & \\
\hline Média & $3 \mathrm{~dB}$ & $7 \mathrm{~dB}$ & 0,7600 \\
\hline
\end{tabular}

TABELA 3. 2 - Resultados da Subtração Espectral de Potência, para 10 sinais de voz contaminados por ruído branco.

\begin{tabular}{|l|c|c|c|}
\hline \multicolumn{4}{|c|}{ Subtração Espectral de Potência } \\
\hline Palavras & SNRI & SNRO & Distância de Itakura-Saito \\
\hline Bar & $3 \mathrm{~dB}$ & $8 \mathrm{~dB}$ & 1,1719 \\
\hline Barco & $3 \mathrm{~dB}$ & $8 \mathrm{~dB}$ & 0,8738 \\
\hline Boi & $3 \mathrm{~dB}$ & $7 \mathrm{~dB}$ & 0,8925 \\
\hline Dado & $3 \mathrm{~dB}$ & $7 \mathrm{~dB}$ & 0,6304 \\
\hline Elétrica & $3 \mathrm{~dB}$ & $8 \mathrm{~dB}$ & 0,3947 \\
\hline Fala & $3 \mathrm{~dB}$ & $6 \mathrm{~dB}$ & 0,8639 \\
\hline Janela & $3 \mathrm{~dB}$ & $8 \mathrm{~dB}$ & 0,6015 \\
\hline Manga & $3 \mathrm{~dB}$ & $8 \mathrm{~dB}$ & 0,6848 \\
\hline Lata & $3 \mathrm{~dB}$ & $11 \mathrm{~dB}$ & 0,3991 \\
\hline Tabela & $3 \mathrm{~dB}$ & $8 \mathrm{~dB}$ & 0,4003 \\
\hline & & & \\
\hline Média & $3 \mathrm{~dB}$ & $8 \mathrm{~dB}$ & 0,6913 \\
\hline
\end{tabular}




\subsection{Considerações finais}

Neste capítulo foram apresentadas duas técnicas de redução de ruído, mostrando vantagens e desvantagens de ambas. A partir então dos exemplos descritos na seção 3.4, pode-se notar que a subtração espectral de potência apresentou resultados um pouco melhor em relação à subtração espectral de magnitude, no que se diz respeito ao aumento da relação sinal/ruído segmentada e distância de Itakura-Saito. Assim, a subtração espectral de potência será utilizada como condição inicial para os filtros de Kalman descritos no capítulo 4. 


\section{$4 \quad$ Filtro de Kalman}

\subsection{Introdução}

O filtro de Kalman foi desenvolvido em 1960 por Rudolf Emil Kalman [14], que publicou o seu famoso artigo descrevendo uma solução recursiva para o problema da filtragem linear de dados discretos. Desde então, devido aos grandes avanços da computação digital, o filtro de Kalman tem sido uma ferramenta muito importante nas áreas da navegação, da monitoração de processos, da instrumentação de usinas nucleares, da astronomia, da economia e da reconstrução de sinais degradados por ruído.

Na realidade o filtro de Kalman é um algoritmo para o cálculo de estimativa de estados instantâneos de um sistema dinâmico linear perturbado por ruído branco usando-se medidas linearmente relacionadas aos estados que também podem estar corrompidas por ruído branco.

Na prática, o Filtro de Kalman é um conjunto de equações de estados, as quais contêm informações necessárias sobre o comportamento do sistema e permitem uma solução computacional e eficiente para o método dos mínimos quadrados. Por isso o filtro é considerado uma ferramenta tão poderosa.

\subsection{Filtro de Kalman de Tempo Discreto (FKT)}

Sendo o principal objetivo deste trabalho a aplicação do filtro de Kalman discreto na filtragem de sinais de voz contaminados por ruído, inicia-se o desenvolvimento do filtro, mostrando a modelagem do sinal de voz $x(n)$, o qual é representado por um processo auto- 
regressivo (AR) de ordem $P$ de acordo com a seguinte equação de diferenças segundo Rabinner e Schafer [2]:

$$
x(n)=\sum_{k=1}^{P} a_{P}(k) x(n-k)+w(n)
$$

em que $x(n)$ é o sinal de voz, $a_{P}(k)$ são os coeficientes de predição e $w(n)$ o ruído de excitação de entrada ou ruído de estado.

Observando a equação (4.1), percebe-se que esta pode ser representada por um modelo de espaço de estados de acordo com Hayes [10]:

$$
\left[\begin{array}{c}
x(n) \\
x(n-1) \\
x(n-2) \\
\vdots \\
x(n-P+1)
\end{array}\right]=\left[\begin{array}{ccccc}
a_{P}(1) & a_{P}(2) & \cdots & a_{P}(P-1) & a_{P}(P) \\
1 & 0 & \cdots & 0 & 0 \\
0 & 1 & \cdots & 0 & 0 \\
\vdots & \vdots & \cdots & \vdots & \vdots \\
0 & 0 & \cdots & 1 & 0
\end{array}\right]\left[\begin{array}{c}
x(n-1) \\
x(n-2) \\
x(n-3) \\
\vdots \\
x(n-P)
\end{array}\right]+w(n)
$$

Considerando que os sinais de voz $x(n)$ são medidos na presença de ruído aditivo tem-se que:

$$
y(n)=x(n)+v(n)
$$

Sabendo que $x(n)$ é um vetor de estado, a equação (4.3), pode ser reescrita de acordo com Hayes [10] da seguinte forma: 


$$
y(n)=\left[\begin{array}{lllll}
1 & 0 & 0 & \cdots & 0
\end{array}\right] \boldsymbol{x}(n)+v(n)
$$

Usando a notação matricial para representar as equações (4.2) e (4.4) tem-se:

$$
\begin{gathered}
\boldsymbol{x}(n)=\boldsymbol{A} \boldsymbol{x}(n-1)+\boldsymbol{w}(n) \\
y(n)=\boldsymbol{H}^{T} \boldsymbol{x}(n)+v(n)
\end{gathered}
$$

nas quais:

$\boldsymbol{A}$ é a matriz transição de estados com dimensão $P x P$;

$w(n)$ é o vetor de excitação de entrada com dimensão $P x 1$;

$\boldsymbol{H}$ é um vetor unitário de dimensão $P x 1$.

As equações (4.5) e (4.6) representam respectivamente a equação de estado e equação de observação do modelo do sinal de voz contaminado por ruído para a aplicação com filtros de Kalman.

Sendo o objetivo do trabalho a filtragem de sinais de voz contaminados por ruído e sabendo que a voz é um processo não estacionário, as equações (4.5) e (4.6) podem ser reescritas da seguinte forma:

$$
\begin{gathered}
\boldsymbol{x}(n)=\boldsymbol{A}(n-1) \boldsymbol{x}(n-1)+\boldsymbol{w}(n) \\
\boldsymbol{y}(n)=\boldsymbol{H}(n) \boldsymbol{x}(n)+\boldsymbol{v}(n)
\end{gathered}
$$

nas quais: 
$\boldsymbol{x}(n)$ é um vetor de estado com dimensão $P x 1$ no instante $n$;

$\boldsymbol{A}(n-1)$ é a matriz transição de estados com dimensão $P x P$, que relaciona os instantes atuais $n$ com os instantes passados $n-1$, variante no tempo;

$\boldsymbol{w}(n)$ é um vetor de excitação de entrada da equação de estado de ordem $P x 1$ modelado por um ruído branco;

$\boldsymbol{y}(n)$ é o vetor de observação de dimensão $M x 1$;

$\boldsymbol{H}(n)$ é uma matriz variante no tempo de ordem $M x P$;

$v(n)$ é um vetor de ruído branco aditivo de dimensão $M x 1$;

Desta forma, a figura 4.1 apresenta as equações que regem a teoria do filtro de Kalman de tempo discreto na forma de diagrama em blocos [8]:

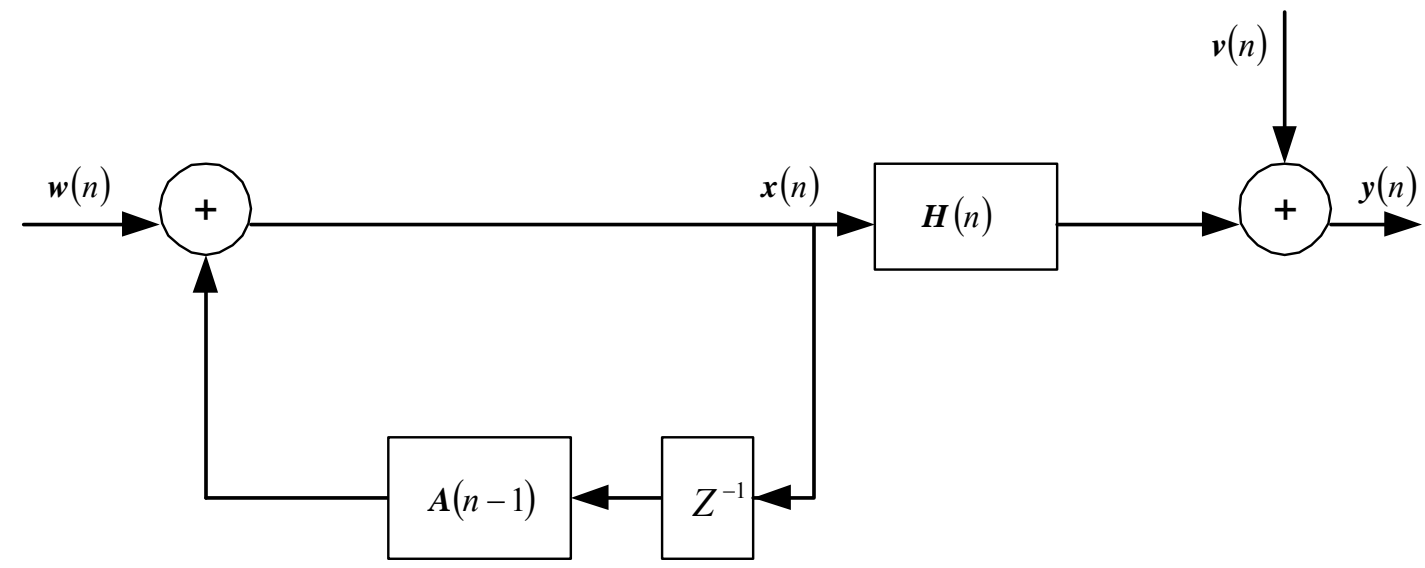

FIGURA 4. 1 - Diagrama em blocos das equações que regem a teoria do filtro de Kalman de tempo discreto.

Admitindo os processos $w(n)$ e $v(n)$ como sendo ruídos brancos e independentes, as equações de correlação podem ser escritas da seguinte forma: 


$$
\begin{gathered}
E\left[\boldsymbol{v}(n) \boldsymbol{v}^{\mathbf{T}}(k)\right]= \begin{cases}\boldsymbol{R}(n) ; & k=n \\
0 ; & k \neq n\end{cases} \\
E\left[\boldsymbol{w}(n) \boldsymbol{w}^{\mathbf{T}}(k)\right]= \begin{cases}\boldsymbol{Q}(n) ; & k=n \\
0 ; & k \neq n\end{cases}
\end{gathered}
$$

nas quais $\boldsymbol{R}(n)$ e $\boldsymbol{Q}(n)$ são matrizes de covariância relacionadas ao ruído aditivo $\boldsymbol{v}(n)$ e ao vetor de excitação de entrada $w(n)$.

\subsection{As origens computacionais do Filtro de Kalman}

Para o início do desenvolvimento das equações, considera-se a existência de uma estimativa inicial do estado $\boldsymbol{x}$ que é dada por:

$$
\hat{\boldsymbol{x}}^{-}(0)=E[\boldsymbol{x}(0)]
$$

em que o sinal de menos ("-“") indica uma estimativa inicial antes da assimilação de uma nova medida. $\mathrm{O}$ erro de estimação associado à estimativa inicial é dado pela seguinte expressão:

$$
\boldsymbol{e}^{-}(0)=\boldsymbol{x}(0)-\hat{\boldsymbol{x}}^{-}(0)
$$

e a matriz de covariância do erro é: 


$$
\boldsymbol{P}^{-}(0)=E\left[\boldsymbol{e}^{-}(0) \boldsymbol{e}^{-T}(0)\right]=E\left[\left(\boldsymbol{x}(0)-\hat{\boldsymbol{x}}^{-}(0)\right)\left(\boldsymbol{x}(0)-\hat{\boldsymbol{x}}^{-}(0)\right)^{T}\right]
$$

Depois de definida as estimativas iniciais, o processo é repetido para cada nova observação $y(n)$ disponível, com o objetivo de determinar a estimativa $\hat{\boldsymbol{x}}(n)$. A determinação de $\hat{\boldsymbol{x}}(n)$ envolve dois passos: primeiro determina-se a estimativa $\hat{\boldsymbol{x}}^{-}(n)$ sem a utilização de uma nova medida $y(n)$ e no segundo passo, quando $y(n)$ torna-se disponível então calcula-se $\hat{\boldsymbol{x}}(n)[6]$.

Inicialmente, nenhuma medida está disponível para o cálculo de $\hat{\boldsymbol{x}}^{-}(n)$, que é dada pela seguinte equação:

$$
\hat{\boldsymbol{x}}^{-}(n)=\boldsymbol{A}(n-1) \hat{\boldsymbol{x}}(n-1)
$$

Assim, a melhor fonte de informação é $\hat{\boldsymbol{x}}(n-1)$ para a estimação de $\hat{\boldsymbol{x}}^{-}(n)$ sem a observação $\boldsymbol{y}(n)$.

Para a determinação da matriz de covariância do erro associado com a estimativa $\hat{\boldsymbol{x}}^{-}(n)$, é necessário calcular primeiro a expressão para o erro associado com o valor da estimativa predita. Sendo o erro da estimativa predita definido por [16]:

$$
\boldsymbol{e}^{-}(n)=\boldsymbol{x}(n)-\hat{\boldsymbol{x}}^{-}(n)
$$

Substituindo as equações (4.7) e (4.14) em (4.15) tem-se: 


$$
\boldsymbol{e}^{-}(n)=\boldsymbol{A}(n-1) \boldsymbol{x}(n-1)+\boldsymbol{w}(n)-\boldsymbol{A}(n-1) \hat{\boldsymbol{x}}(n-1)
$$

ou

$$
\boldsymbol{e}^{-}(n)=\boldsymbol{A}(n-1) \boldsymbol{e}^{-}(n-1)+\boldsymbol{w}(n)
$$

Sendo a estimativa do erro $\boldsymbol{e}^{-}(n-1)$ descorrelacionada com o ruído de excitação de entrada $\boldsymbol{w}(n)$, a expressão para a matriz de covariância associada com a estimativa $\hat{\boldsymbol{x}}^{-}(n)$ é dada por [10]:

$$
\begin{gathered}
\boldsymbol{P}^{-}(n)=E\left[\boldsymbol{e}^{-}(n-1) \boldsymbol{e}^{-}(n-1)^{T}\right] \\
\boldsymbol{P}^{-}(n)=E\left[\{\boldsymbol{A}(n-1) \boldsymbol{e}(n-1)+\boldsymbol{w}(n)\}\{\boldsymbol{A}(n-1) \boldsymbol{e}(n-1)+\boldsymbol{w}(n)\}^{T}\right] \\
\boldsymbol{P}^{-}(n)=\boldsymbol{A}(n-1) \boldsymbol{P}(n-1) \boldsymbol{A}^{T}(n-1)+\boldsymbol{Q}(n)
\end{gathered}
$$

em que $\boldsymbol{Q}(n)$ é a matriz de covariância associada ao ruído de estado $\boldsymbol{w}(n)$.

Depois de determinada as estimativas iniciais, o passo seguinte consiste em usar a medida $\boldsymbol{y}(n)$ para a determinação de $\hat{\boldsymbol{x}}(n)$ da seguinte forma:

$$
\hat{\boldsymbol{x}}(n)=\hat{\boldsymbol{x}}^{-}(n)+\boldsymbol{K}(n)\left\lfloor\boldsymbol{y}(n)-\boldsymbol{H}(n) \hat{\boldsymbol{x}}^{-}(n)\right\rfloor
$$


em que $\hat{\boldsymbol{x}}(n)$ é a estimativa do vetor de estado a posteriori, $\hat{\boldsymbol{x}}^{-}(n)$ é a estimativa do vetor de estado a priori, $\boldsymbol{K}(n)$ é o ganho de Kalman, $\boldsymbol{y}(n)$ é o vetor de observação e $\boldsymbol{H}(n)$ uma matriz variante no tempo conhecida como matriz de distorção do canal.

O termo entre colchetes na equação (4.19) é chamado de medida de inovação ou resíduo. O resíduo reflete a discrepância entre a predição da medida $\boldsymbol{H}(n) \hat{\boldsymbol{x}}^{-}(n)$ e a medida atual $y(n)$. Desta forma, a medida de inovação é um vetor que contém as observações passadas incluindo o ruído e mais parte do sinal. Para uma estimativa ótima linear do erro quadrático médio, o sinal de inovação deverá ser descorrelacionado e ortogonal aos vetores de observações passadas [9].

Para que a equação (4.19) produza uma estimativa ótima de $x(n)$ baseado no método dos mínimos quadrados é necessário encontrar o ganho de Kalman ótimo $\boldsymbol{K}(n)$. Para o cálculo do ganho ótimo de Kalman é necessário calcular a matriz de covariância do erro associada com a estimativa atualizada:

$$
\boldsymbol{P}(n)=E\left[\boldsymbol{e}(n) \boldsymbol{e}(n)^{T}\right]=E\left[(\boldsymbol{x}(n)-\hat{\boldsymbol{x}}(n))(\boldsymbol{x}(n)-\hat{\boldsymbol{x}}(n))^{T}\right]
$$

Substituindo a equação (4.8) em (4.19) segundo a referência [16] tem-se:

$$
\boldsymbol{P}(n)=E\left[\begin{array}{l}
\left\{\left(\boldsymbol{x}(n)-\hat{\boldsymbol{x}}^{-}(n)\right)-\boldsymbol{K}(n)\left[\boldsymbol{H}(n) \boldsymbol{x}(n)+\boldsymbol{v}(n)-\boldsymbol{H}(n) \hat{\boldsymbol{x}}^{-}(n)\right]\right\} \\
\left\{\left(\boldsymbol{x}(n)-\hat{\boldsymbol{x}}^{-}(n)\right)-\boldsymbol{K}(n)\left[\boldsymbol{H}(n) \boldsymbol{x}(n)+\boldsymbol{v}(n)-\boldsymbol{H}(n) \hat{\boldsymbol{x}}^{-}(n)\right]\right\}^{T}
\end{array}\right]
$$

na qual $E[\bullet]$ é o valor esperado. 
Considerando que o valor esperado de $\left(x(n)-\hat{\boldsymbol{x}}^{-}(n)\right)$, que está associado ao erro anterior esteja descorrelacionado de $\boldsymbol{v}(n)$, a matriz erro de covariância $\boldsymbol{P}(n)$ pode ser reescrita da seguinte forma [16]:

$$
\boldsymbol{P}(n)=[\boldsymbol{I}-\boldsymbol{K}(n) \boldsymbol{H}(n)] \boldsymbol{P}^{-}(n)[\boldsymbol{I}-\boldsymbol{K}(n) \boldsymbol{H}(n)]^{\mathbf{T}}+\boldsymbol{K}(n) \boldsymbol{R}(n) \boldsymbol{K}^{\mathbf{T}}(n)
$$

em que $\boldsymbol{P}(n)$ é a matriz do erro de covariância associada a estimativa posteriori, $\boldsymbol{I}$ é a matriz identidade, $\boldsymbol{K}(n)$ é o ganho de Kalman, $\boldsymbol{P}^{-}(n)$ é a matriz do erro de covariância associada a estimativa a priori, $\boldsymbol{H}(n)$ é a matriz de distorção do canal ou matriz variante no tempo e $\boldsymbol{R}(n)$ é a covariância associada ao ruído aditivo $\boldsymbol{v}(n)$.

Assim, a equação (4.22) é a expressão que realiza a atualização da matriz de covariância do erro para algum ganho de Kalman quase ótimo segundo Brown e Wang $[16]$.

Retornando então ao problema da otimização, é preciso encontrar um ganho de Kalman ótimo que será responsável pela minimização dos termos ao longo da diagonal principal de $\boldsymbol{P}(n)$, pois estes representam as variâncias dos erros que estão associados a estimação dos elementos do vetor de estado $\hat{\boldsymbol{x}}$.

O processo de otimização pode ser realizado de diversas maneiras. Neste trabalho a derivação da expressão para o ganho de Kalman será desenvolvida utilizando métodos de cálculo diferencial, mais especificamente fórmulas de diferenciação de matrizes.

Para as fórmulas de diferenciação de matrizes, considere três matrizes quadradas $\boldsymbol{A}$, $\boldsymbol{B}$ e $\boldsymbol{C}$, sendo que a matriz $\boldsymbol{C}$ é simétrica. O traço de uma matriz é definido 
matematicamente como a soma dos elementos da diagonal principal. As fórmulas de diferenciação são dadas de acordo com Brown e Wang [16] por:

$$
\begin{gathered}
\frac{d[\operatorname{traço}(\boldsymbol{A B})]}{d \boldsymbol{A}}=\boldsymbol{B}^{T} \\
\frac{d\left[\operatorname{traço}\left(\boldsymbol{A C A}^{T}\right)\right]}{d \boldsymbol{A}}=2 \boldsymbol{A C}
\end{gathered}
$$

e a derivada de um escalar em relação a matriz é definida como:

$$
\frac{d s}{d \boldsymbol{A}}=\left[\begin{array}{ccc}
\frac{d s}{d a_{11}} & \frac{d s}{d a_{12}} & \ldots \\
\frac{d s}{d a_{21}} & \frac{d s}{d a_{21}} & \ldots \\
\vdots & \vdots & \\
& &
\end{array}\right]
$$

Desenvolvendo a equação (4.22) de acordo com [16] chega-se a:

$$
\begin{aligned}
& \boldsymbol{P}(n)=\boldsymbol{P}^{-}(n)-\boldsymbol{K}(n) \boldsymbol{H}(n) \boldsymbol{P}^{-}(n)-\boldsymbol{P}^{-}(n) \boldsymbol{H}^{\mathbf{T}}(n) \boldsymbol{K}^{\mathbf{T}}(n) \\
& +\boldsymbol{K}(n)\left[\boldsymbol{H}(n) \boldsymbol{P}^{-}(n) \boldsymbol{H}^{\mathbf{T}}(n)+\boldsymbol{R}(n)\right] \boldsymbol{K}^{\mathbf{T}}(n)
\end{aligned}
$$

Para determinar o valor de $\boldsymbol{K}(n)$ que fornece um valor mínimo para o erro de estimação, é equivalente a minimizar a soma dos elementos da diagonal principal da matriz $\boldsymbol{P}$. Aplicando as fórmulas de diferenciação de matrizes para calcular a derivada parcial do traço de $\mathbf{P}(n)$ em relação a $\boldsymbol{K}(n)$, tem-se: 


$$
\frac{d(\operatorname{traçoP}(n))}{d \boldsymbol{K}(n)}=-2\left[\boldsymbol{H}(n) \boldsymbol{P}^{-}(n)\right]^{\mathbf{T}}+2 \boldsymbol{K}(n)\left[\boldsymbol{H}(n) \boldsymbol{P}^{-}(n) \boldsymbol{H}^{\mathbf{T}}(n)+\boldsymbol{R}(n)\right]
$$

Igualando-se a equação (4.27) a zero e resolvendo a equação, determina-se a expressão para o ganho de Kalman $\boldsymbol{K}(n)$, que é responsável pela minimização do erro de estimação médio quadrático. A expressão resultante é:

$$
\boldsymbol{K}(n)=\boldsymbol{P}^{-}(n) \boldsymbol{H}^{\mathbf{T}}(n)\left[\boldsymbol{H}(n) \boldsymbol{P}^{-}(n) \boldsymbol{H}^{\mathbf{T}}(n)+\boldsymbol{R}(n)\right]^{-1}
$$

Uma vez determinada a expressão para o ganho de Kalman, tem-se calculada a estimativa do estado $\hat{x}$ no instante de tempo $n$ que é dada pela equação (4.19). Mas ainda é necessário calcular a matriz de covariância do erro de estimação associada ao ganho ótimo. A partir da equação (4.22) tem-se:

$$
\begin{gathered}
\boldsymbol{P}(n)=[\boldsymbol{I}-\boldsymbol{K}(n) \boldsymbol{H}(n)] \boldsymbol{P}^{-}(n)[\boldsymbol{I}-\boldsymbol{K}(n) \boldsymbol{H}(n)]^{\mathbf{T}}+\boldsymbol{K}(n) \boldsymbol{R}(n) \boldsymbol{K}^{\mathbf{T}}(n) \\
\boldsymbol{P}(n)=\boldsymbol{P}^{-}(n)-\boldsymbol{K}(n) \boldsymbol{H}(n) \boldsymbol{P}^{-}(n)-\boldsymbol{P}^{-}(n) \boldsymbol{H}^{T}(n) \boldsymbol{K}^{T}(n)+\boldsymbol{K}(n)\left\lfloor\boldsymbol{H}(n) \boldsymbol{P}^{-}(n) \boldsymbol{H}^{T}(n)+\boldsymbol{R}(n)\right] \boldsymbol{K}^{T}(n)
\end{gathered}
$$

Substituindo a equação (4.28) em (4.30) e rearranjando os termos, obtém-se as seguintes expressões para $\boldsymbol{P}(n)$ de acordo com Brown e Wang [16]:

$$
\boldsymbol{P}(n)=\boldsymbol{P}^{-}(n)-\boldsymbol{P}^{-}(n) \boldsymbol{H}^{T}(n)\left[\boldsymbol{H}(n) \boldsymbol{P}^{-}(n) \boldsymbol{H}^{T}(n)+\boldsymbol{R}(n)\right]^{-1} \boldsymbol{H}(n) \boldsymbol{P}^{-}(n)
$$


ou

$$
\left.\boldsymbol{P}(n)=\boldsymbol{P}^{-}(n)-\boldsymbol{K}(n) \mid \boldsymbol{H}(n) \boldsymbol{P}^{-}(n) \boldsymbol{H}^{T}(n)+\boldsymbol{R}(n)\right] \mid \boldsymbol{K}^{T}(n)
$$

Ou ainda,

$$
\boldsymbol{P}(n)=[\boldsymbol{I}-\boldsymbol{K}(n) \boldsymbol{H}(n)] \boldsymbol{P}^{-}(n)
$$

Das três expressões apresentadas para $\boldsymbol{P}(n)$ a equação (4.33) é a mais simples e a mais utilizada. Apresentadas estas equações, pode-se estimar a medida no instante de tempo $n$ pelo uso da equação (4.19) com ganho $K(n)$ que é dado pela equação (4.28), sendo necessário o valor de $\hat{\boldsymbol{x}}^{-}(n)$ e $\boldsymbol{P}^{-}(n)$ para estimar uma nova medida.

Observa-se em (4.28), que quando a covariância do erro na medida $\boldsymbol{R}(n)$ se aproxima de zero, o ganho $\boldsymbol{K}(n)$ atua sobre a medida de inovação mais intensamente.

Por outro lado, quando a covariância do erro do estimador $\boldsymbol{P}^{-}(n)$ se aproxima de zero, o ganho $K(n)$ atua menos intensamente na medida de inovação.

Outra interpretação para a atuação de $\boldsymbol{K}(n)$ é que quando a covariância do erro de medida $\boldsymbol{R}(n)$ se aproxima de zero, a medida atual é cada vez mais confiável, enquanto a predição da medida $\boldsymbol{H}(n) \hat{\boldsymbol{x}}^{-}(n)$ é cada vez menos confiável. Por outro lado, quando a covariância do erro estimador $\boldsymbol{P}^{-}(n)$ se aproxima de zero, a medida atual $\boldsymbol{y}(n)$ é cada vez menos confiável, enquanto a predição da medida $\boldsymbol{H}(n) \hat{\boldsymbol{x}}^{-}(n)$ é cada vez mais confiável. 


\subsection{Algoritmo para o Filtro de Kalman de Tempo Discreto}

O filtro de Kalman de tempo discreto faz as estimativas de um processo usando uma forma de controle de realimentação: o filtro estima o estado do processo em algum momento e então obtém a realimentação na forma de uma nova medida a qual é acrescentada ao algoritmo. Como tal, as equações para o filtro de Kalman se dividem em dois grupos: equações de atualização de tempo ou projeção e equações de atualização da medida ou correção. As equações de atualização de tempo são responsáveis para projetar adiante o estado atual e o estimador de covariância do erro para obter um estimador a priori para o próximo instante. As equações de atualização de medida são responsáveis pela realimentação, isto é, por incorporar uma medida nova na estimativa a priori para obter um estimador a posteriori.

Resumindo, pode-se dizer que o filtro de Kalman é apenas um algoritmo computacional para o mapeamento de medidas discretas (entradas) em estimativas ótimas (saídas). A figura 4.2 mostra o ciclo de execução das equações.

A cada instante de tempo $n$, o par projeção (predição) e atualização (correção) é repetido utilizando as estimativas iniciais $\hat{x}^{-}(n-1)$ e $P^{-}(n-1)$ para determinar o valor da estimativa corrente $\hat{\boldsymbol{x}}(n)$

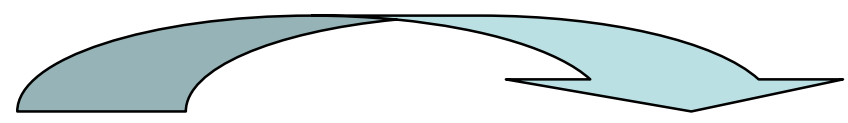

Atualização de tempo

("Predição")
Atualização de medida ("Correção")

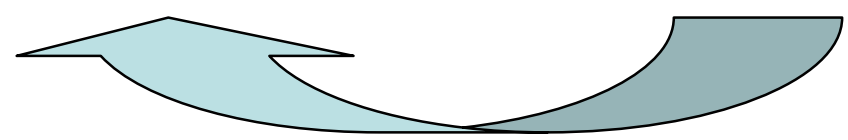

FIGURA 4. 2 - O ciclo contínuo do filtro de Kalman de tempo discreto. 
Desta forma as equações que realizam as atualizações de tempo e medida são apresentadas abaixo na Tabela 4.1 e Tabela 4.2.

TABELA 4. 1 - As equações de atualização de tempo do filtro de Kalman de Tempo discreto.

\begin{tabular}{c}
$\hat{\boldsymbol{x}}^{-}(n)=\boldsymbol{A}(n-1) \hat{\boldsymbol{x}}(n-1)$ \\
\hline $\boldsymbol{P}^{-}(\mathbf{n})=\boldsymbol{A}(n-1) \boldsymbol{P}(n-1) \boldsymbol{A}^{\mathrm{T}}(n-1)+\boldsymbol{Q}(n)$ \\
\hline
\end{tabular}

TABELA 4. 2 - Equações de atualização de medida do filtro de Kalman de Tempo discreto.

\begin{tabular}{|c|}
\hline $\boldsymbol{K}(n)=\boldsymbol{P}^{-}(n) \boldsymbol{H}^{\mathbf{T}}(n)\left[\boldsymbol{H}(n) \boldsymbol{P}^{-}(n) \boldsymbol{H}^{\mathbf{T}}(n)+\boldsymbol{R}(n)\right]^{-1}$ \\
\hline$\hat{\boldsymbol{x}}(n)=\hat{\boldsymbol{x}}^{-}(n)+\boldsymbol{K}(n)\left[\boldsymbol{y}(n)-\boldsymbol{H}(n) \hat{\boldsymbol{x}}^{-}(n)\right]$ \\
\hline $\boldsymbol{P}(n)=[\boldsymbol{I}-\boldsymbol{K}(n) \boldsymbol{H}(n)] \boldsymbol{P}^{-}(n)$ \\
\hline
\end{tabular}

Sendo assim, a primeira tarefa do algoritmo durante a atualização de medida é calcular o ganho de Kalman. O próximo passo é medir o processo para obter $\mathbf{y}(n)$, e então gerar um estimador de estado a posteriori incorporando a medida como na equação (4.19). O passo final é obter um estimador da covariância de erro a posteriori.

Depois de cada par de atualizações de tempo e medida, o processo é repetido com a estimativa a posteriori anterior usada para projetar ou predizer a nova estimativa a priori. Sendo assim, a operação completa do filtro de Kalman é mostrada na figura 4.3. 


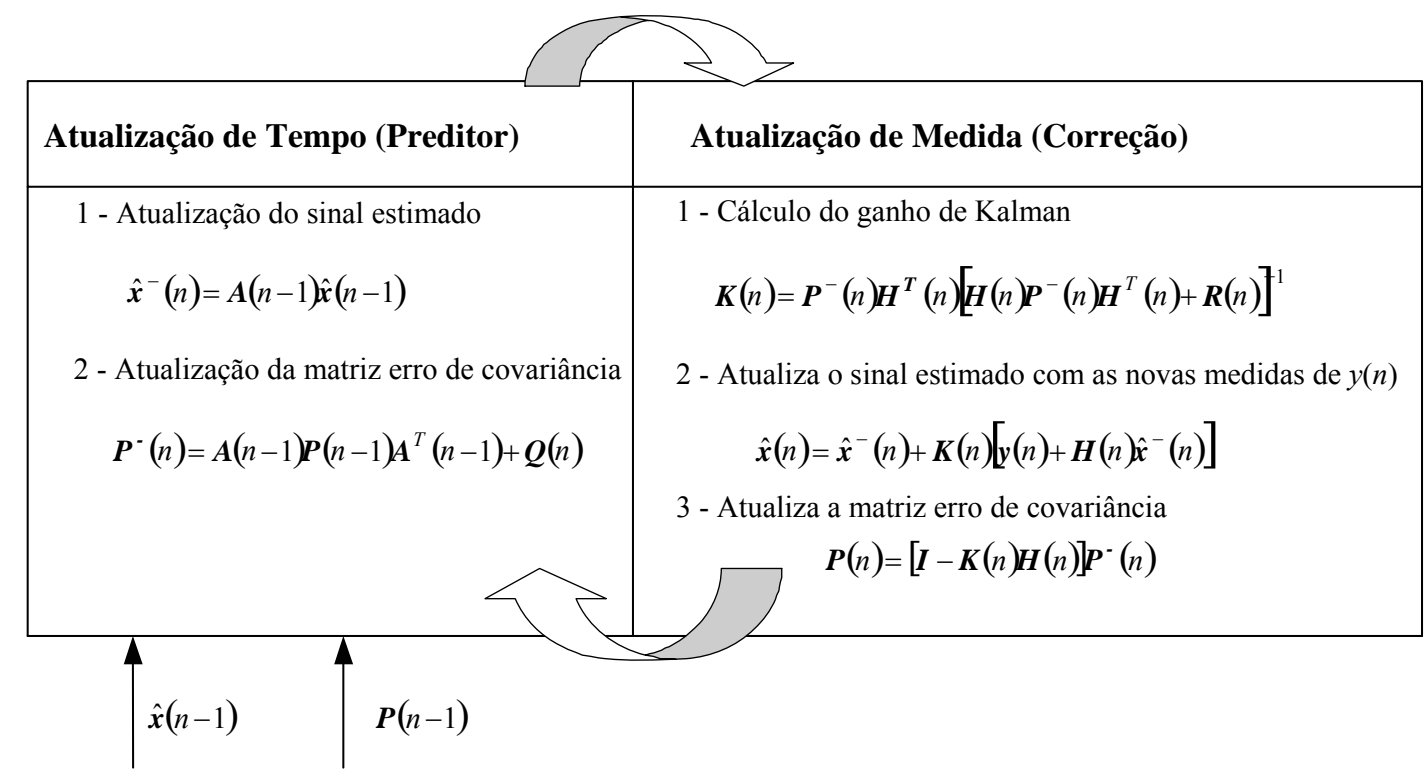

FIGURA 4. 3 - O diagrama completo da operação do filtro de Kalman de tempo discreto.

De forma esquemática, o algoritmo recursivo do filtro de Kalman, processa as medidas da seguinte forma:

1. Cálculo das estimativas iniciais $\hat{\boldsymbol{x}}^{-}(0)=\mathrm{E}\{\boldsymbol{x}(0)\}$ e $\boldsymbol{P}^{-}(0)=\mathrm{E}\left\{e(0) e^{-T}(0)\right\}$

2. Início

Para $n=1,2,3, \ldots . .$, faça

$$
\begin{aligned}
& \hat{\boldsymbol{x}}^{-}(n)=\boldsymbol{A}(n-1) \hat{\boldsymbol{x}}(n-1) \\
& \boldsymbol{P}^{-}(n)=\boldsymbol{A}(n-1) \boldsymbol{P}(n-1) \boldsymbol{A}^{\mathbf{T}}(n-1)+\boldsymbol{Q}(n) \\
& \boldsymbol{K}(n)=\boldsymbol{P}^{-}(n) \boldsymbol{H}^{\mathbf{T}}(n)\left[\boldsymbol{H}(n) \boldsymbol{P}^{-}(n) \boldsymbol{H}^{\mathbf{T}}(n)+\boldsymbol{R}(n)\right]^{-1} \\
& \hat{\boldsymbol{x}}(n)=\hat{\boldsymbol{x}}^{-}(n)+\boldsymbol{K}(n)\left[\boldsymbol{y}(n)-\boldsymbol{H}(n) \hat{\boldsymbol{x}}^{-}(n)\right] \\
& \boldsymbol{P}(n)=[\boldsymbol{I}-\boldsymbol{K}(n) \boldsymbol{H}(n)] \boldsymbol{P}^{-}(n)
\end{aligned}
$$

Fim 


\subsection{Forma Alternativa para o Filtro de Kalman de Tempo Discreto}

As equações recursivas que compõem o filtro de Kalman podem ser manipuladas de diversas maneiras. Nesta seção serão apresentadas algumas formas alternativas para algumas das expressões apresentadas na seção anterior [16].

Considerando a equação (4.31), é possível mostrar que $\boldsymbol{P}(n)$ pode ser reescrito em função da sua inversa $[\boldsymbol{P}(n)]^{-1}$, da seguinte forma $[16]$ :

$$
[\boldsymbol{P}(n)]^{-1}=\left[\boldsymbol{P}^{-}(n)\right]^{-1}+\boldsymbol{H}^{T}(n)[\boldsymbol{R}(n)]^{-1} \boldsymbol{H}(n)
$$

A justificativa para a equação acima pode ser dada da seguinte forma: multiplicando-se o lado direito das equações. (4.31) e (4.34), isto se reduz a matriz identidade.

Para o desenvolvimento da multiplicação comentada acima será omitido o índice de tempo $n$. Desenvolvendo então desta forma:

$$
\begin{gathered}
{\left[\boldsymbol{P}^{-}-\boldsymbol{P}^{-} \boldsymbol{H}^{T}\left(\boldsymbol{H} \boldsymbol{P}^{-} \boldsymbol{H}^{T}+\boldsymbol{R}\right)^{-1} \boldsymbol{H} \boldsymbol{P}^{-}\right]\left[\left(\boldsymbol{P}^{-}\right)^{-1}+\boldsymbol{H}^{T} \boldsymbol{R}^{-1}\right] \boldsymbol{H}} \\
=\boldsymbol{I}-\boldsymbol{P}^{-} \boldsymbol{H}^{T}\left[\left(\boldsymbol{H} \boldsymbol{P}^{-} \boldsymbol{H}^{T}+\boldsymbol{R}\right)^{-1}-\boldsymbol{R}^{-1}+\left(\boldsymbol{H} \boldsymbol{P}^{-} \mathbf{H}^{T}+\boldsymbol{R}\right)^{-1} \boldsymbol{H} \boldsymbol{P}^{-} \boldsymbol{H}^{T} \boldsymbol{R}^{-1}\right] \boldsymbol{H} \\
\boldsymbol{I}-\boldsymbol{P}^{-} \boldsymbol{H}^{T}\left[\boldsymbol{R}^{-1}-\boldsymbol{R}^{-1}\right] \boldsymbol{H}=\boldsymbol{I}
\end{gathered}
$$


A expressão apresentada na equação (4.34) representa uma forma alternativa para a matriz de covariância associada ao erro de estimação. Também pode ser derivada uma expressão alternativa para a expressão do ganho de Kalman. Tomando-se a equação. (4.28) e omitindo o índice de tempo $n$ como ponto de partida tem-se:

$$
\boldsymbol{K}=\boldsymbol{P}^{-} \boldsymbol{H}^{T}\left[\boldsymbol{H} \boldsymbol{P}^{-} \boldsymbol{H}^{T}+\boldsymbol{R}\right]^{-1}
$$

Inserindo os termos $\boldsymbol{P P}^{-1}$ e $\boldsymbol{R}^{-1}$ não haverá mudança no ganho e a equação anterior será escrita da seguinte forma:

$$
\boldsymbol{K}=\boldsymbol{P} \boldsymbol{P}^{-1} \boldsymbol{P}^{-} \boldsymbol{H}^{T} \boldsymbol{R}^{-1} \boldsymbol{R}\left[\boldsymbol{H} \boldsymbol{P}^{-} \boldsymbol{H}^{T}+\boldsymbol{R}\right]^{-1}
$$

Substituindo a equação (4.34) em (4.36), tem-se de acordo com Brown e Wang [16]:

$$
\begin{gathered}
\boldsymbol{K}=\boldsymbol{P}\left[\left(\boldsymbol{P}^{-}\right)^{-1}+\boldsymbol{H}^{T} \boldsymbol{R}^{-1} \boldsymbol{H}\right] \boldsymbol{P}^{-} \boldsymbol{H}^{T} \boldsymbol{R}^{-1}\left[\boldsymbol{H} \boldsymbol{P}^{-} \boldsymbol{H}^{T} \boldsymbol{R}^{-1}+\boldsymbol{I}\right]^{-1} \\
\boldsymbol{K}=\boldsymbol{P}\left[\boldsymbol{I}+\boldsymbol{H}^{T} \boldsymbol{R}^{-1} \boldsymbol{H} \boldsymbol{P}^{-}\right] \boldsymbol{H}^{T} \boldsymbol{R}^{-1}\left[\boldsymbol{H} \boldsymbol{P}^{-} \boldsymbol{H}^{T} \boldsymbol{R}^{-1}+\boldsymbol{I}\right]^{-1} \\
\boldsymbol{K}=\boldsymbol{P} \boldsymbol{H}^{T} \boldsymbol{R}^{-1}\left[\boldsymbol{I}+\boldsymbol{H} \boldsymbol{P}^{-} \boldsymbol{H}^{T} \boldsymbol{R}^{-1}\right]\left[\boldsymbol{H} \boldsymbol{P}^{-} \boldsymbol{H}^{T} \boldsymbol{R}^{-1}+\boldsymbol{I}\right]^{-1}
\end{gathered}
$$




$$
\boldsymbol{K}=\boldsymbol{P} \boldsymbol{H}^{T} \boldsymbol{R}^{-1}
$$

Dessa forma, obtêm-se duas expressões alternativas para o ganho de Kalman e para a matriz de covariância associada ao erro de estimação. Tomando-se novamente essas duas expressões e reescrevendo com o índice de tempo, obtém-se:

$$
\begin{gathered}
{[\boldsymbol{P}(n)]^{-1}=\left[\boldsymbol{P}^{-}(n)\right]^{-1}+\boldsymbol{H}^{T}(n)[\boldsymbol{R}(n)]^{-1} \boldsymbol{H}(n)} \\
\boldsymbol{K}(n)=\boldsymbol{P}(n) \boldsymbol{H}^{T}(\boldsymbol{n})[\boldsymbol{R}(n)]^{-1}
\end{gathered}
$$

O processamento do filtro de Kalman usando a forma alternativa é semelhante ao filtro de Kalman clássico. A diferença é que utilizando as expressões alternativas, a matriz de covariância associada ao erro de estimação pode ser calculada antes de se calcular o ganho, o que não ocorre no filtro de Kalman clássico. Outra alteração ocorre na expressão de ganho que agora utiliza $\boldsymbol{P}(n)$, dessa forma o cálculo de $\boldsymbol{P}(n)$ deve ser realizado antes de se calcular o ganho [6].

O problema encontrado quando se utiliza a forma alternativa, é que se requer a inversão de duas matrizes quadradas para cada ciclo de operação do filtro de Kalman. Se a ordem das matrizes for grande, isso representa um problema computacional.

De forma esquemática, o algoritmo recursivo do filtro de Kalman usando a forma alternativa, processa as medidas da seguinte forma: 
1. Cálculo das estimativas iniciais $\hat{\boldsymbol{x}}^{-}(0)=\mathrm{E}\{\boldsymbol{x}(0)\}$ e $\boldsymbol{P}^{-}(0)=\mathrm{E}\left\{e(0) e^{-T}(0)\right\}$

\section{Início}

$$
\begin{aligned}
& \text { Para } n=1,2,3, \ldots . ., \text { faça } \\
& \hat{\boldsymbol{x}}^{-}(n)=\boldsymbol{A}(n-1) \hat{\boldsymbol{x}}(n-1) \\
& \boldsymbol{P}^{-}(n)=\boldsymbol{A}(n-1) \boldsymbol{P}(n-1) \boldsymbol{A}^{\mathbf{T}}(n-1)+\boldsymbol{Q}(n) \\
& {[\boldsymbol{P}(n)]^{-1}=\left[\boldsymbol{P}^{-}(n)\right]^{-1}+\boldsymbol{H}^{T}(n)[\boldsymbol{R}(n)]^{-1} \boldsymbol{H}(n)} \\
& \boldsymbol{K}(n)=\boldsymbol{P}(n) \boldsymbol{H}^{T}(\boldsymbol{n})[\boldsymbol{R}(n)]^{-1} \\
& \hat{\boldsymbol{x}}(n)=\hat{\boldsymbol{x}}^{-}(n)+\boldsymbol{K}(n)\left[\boldsymbol{y}(n)-\boldsymbol{H}(n) \hat{\boldsymbol{x}}^{-}(n)\right]
\end{aligned}
$$

Fim

A figura 4.4 mostra o diagrama completo da operação do filtro de Kalman discreto no tempo usando a forma alternativa. 


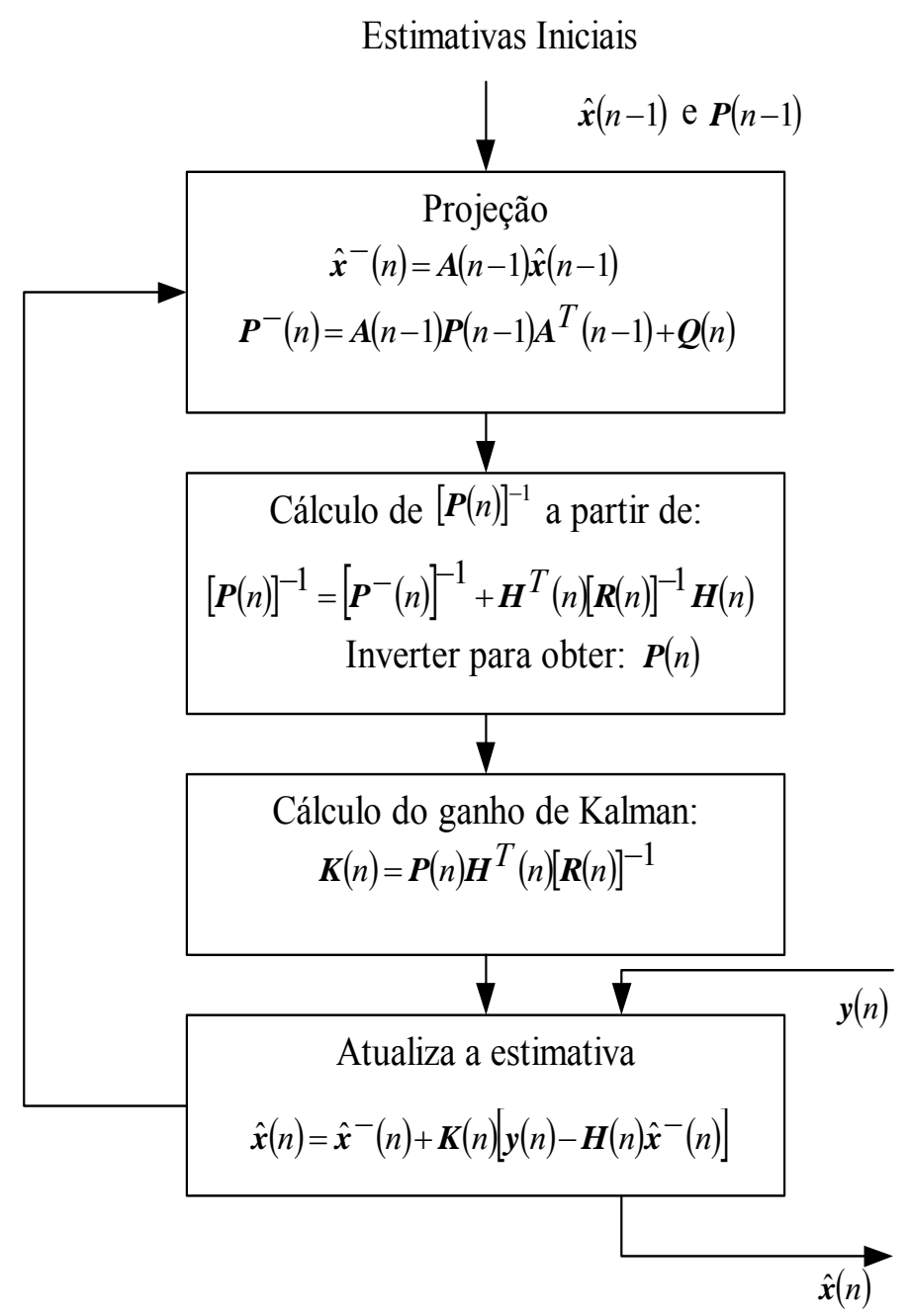

FIGURA 4. 4 - Ciclo de operação do filtro de Kalman de tempo discreto para as formas alternativas.

\subsection{Filtro de Kalman de Freqüência Discreta (FKF)}

O filtro de Kalman de freqüência discreta foi desenvolvido por Fujimoto e Ariki [1] em 2000. Para o seu desenvolvimento considere o $l$-ésimo quadro definido por uma janela de análise em que $X(k, l)$ denota o espectro complexo do sinal sem ruído $x(n, l)$ e $v(n, l)$ o ruído branco gaussiano. Admitindo $x(n, l)$ o sinal contaminado por um ruído branco temse: 


$$
y(n, l)=x(n, l)+v(n, l)
$$

Sendo $X(k, l)$ a transformada discreta de Fourier (DFT) do sinal sem ruído, pode-se desta forma, reescrever $y(n, l)$ da seguinte maneira:

$$
y(n, l)=\sum_{k=0}^{N-1} X(k, l) \exp \left(j 2 \pi \frac{k n}{N}\right)+v(n, l)
$$

logo, a equação (4.41) pode ser expandida na forma matricial tomando a seguinte forma:

$$
y(n, l)=\underbrace{\left(\begin{array}{c}
1 \\
\exp \left(j 2 \pi \frac{n}{N}\right) \\
\vdots \\
\exp \left(j 2 \pi \frac{(N-1) n}{N}\right)
\end{array}\right)}_{\boldsymbol{F}_{n}} \underbrace{T}_{\boldsymbol{X}_{l}}\left(\begin{array}{c}
X(0, l) \\
X(1, l) \\
X(N-1, l)
\end{array}\right)+v(n, l)
$$

Desta forma a equação (4.42) resulta em:

$$
\mathrm{y}(n, l)=\boldsymbol{F}_{n} \boldsymbol{X}_{l}+\mathrm{v}(n, l)
$$

em que $n$ representa o tempo dentro do $l$-ésimo quadro, $\mathrm{N}$ o número de amostras no quadro e $\boldsymbol{F}_{n}$ o vetor que contém a base da transformada discreta de Fourier inversa (IDFT).

Na equação (4.43), $\boldsymbol{X}_{l}$ é um vetor que possui um espectro complexo para cada elemento no $l$-ésimo quadro. Como o tempo $n$ dentro de $x_{l}$ não tem significado, a matriz transição de estados tem valor unitário. 
Desta forma, comparando com a seção 4.4, o filtro de Kalman de freqüência discreta pode ser representado pelas seguintes equações:

$$
\begin{aligned}
& \boldsymbol{K}_{(n, l)}=\boldsymbol{P}_{(n-1, l)} \boldsymbol{F}_{n}{ }^{T}\left[\boldsymbol{F}_{n} \boldsymbol{P}_{(n-1, l)} \boldsymbol{F}_{n}{ }^{* T}+R_{(n, l)}\right]^{-1} \\
& \hat{\boldsymbol{X}}_{(n, l)}=\hat{\boldsymbol{X}}_{(n-1, l)}+\boldsymbol{K}_{(n, l)}\left\lfloor y(n, l)-\boldsymbol{F}_{n} \hat{\boldsymbol{X}}_{(n-1, l)}\right\rfloor \\
& \boldsymbol{P}_{(n, l)}=\boldsymbol{P}_{(n-1, l)}-\boldsymbol{K}_{(n, l)} \boldsymbol{F}_{n} \boldsymbol{P}_{(n-1, l)} \\
& \hat{\boldsymbol{X}}_{(0, l)}=\hat{\boldsymbol{X}}\left(e^{j \omega_{k}}\right) \\
& \boldsymbol{P}_{(0, l)}=\left(\begin{array}{cccc}
R(0, l) & 0 & \cdots & 0 \\
0 & R(1, l) & \cdots & 0 \\
\vdots & \vdots & \ddots & \vdots \\
0 & 0 & \cdots & R(N-1, l)
\end{array}\right)
\end{aligned}
$$

O algoritmo do filtro de Kalman discreto na freqüência é representado pelas equações (4.44 a 4.46). Na equação (4.44) aparece o termo $* T$, este termo representa o complexo conjugado da matriz transposta.

O vetor complexo do filtro de Kalman de freqüência discreta é dado por:

$$
\hat{\boldsymbol{X}}_{(n, l)}=[\hat{X}(0, l), \hat{X}(1, l), \cdots, \hat{X}(N-1, l)]^{T}
$$


o qual é estimado do vetor complexo $\boldsymbol{X}(k, l)$. Este pode ser reconstruído pela aplicação da transformada discreta de Fourier inversa (IDFT). Já os valores iniciais para o filtro são dados pelas equações (4.47) e (4.48) respectivamente.

\subsection{Implementação e avaliação dos algoritmos}

Baseado no contexto de redução de ruído e na mínima distorção espectral quando o sinal é reconstruído a partir de um sinal contaminado, é apresentado neste tópico, o estudo e a implementação de técnicas baseadas nos filtros de Kalman de tempo discreto e freqüência discreta em conjunto com a técnica de subtração espectral de potência.

O algoritmo proposto foi desenvolvido por Fujimoto e Ariki [1], que usaram para reconstrução do sinal contaminado por ruído, o filtro de Kalman de freqüência discreta em conjunto com a subtração espectral adaptativa pelo fato do mesmo apresentar melhores resultados em relação à subtração espectral no que se diz respeito à distorção espectral. A figura 4.5 mostra em forma de diagrama em blocos o algoritmo original proposto por [1]. 


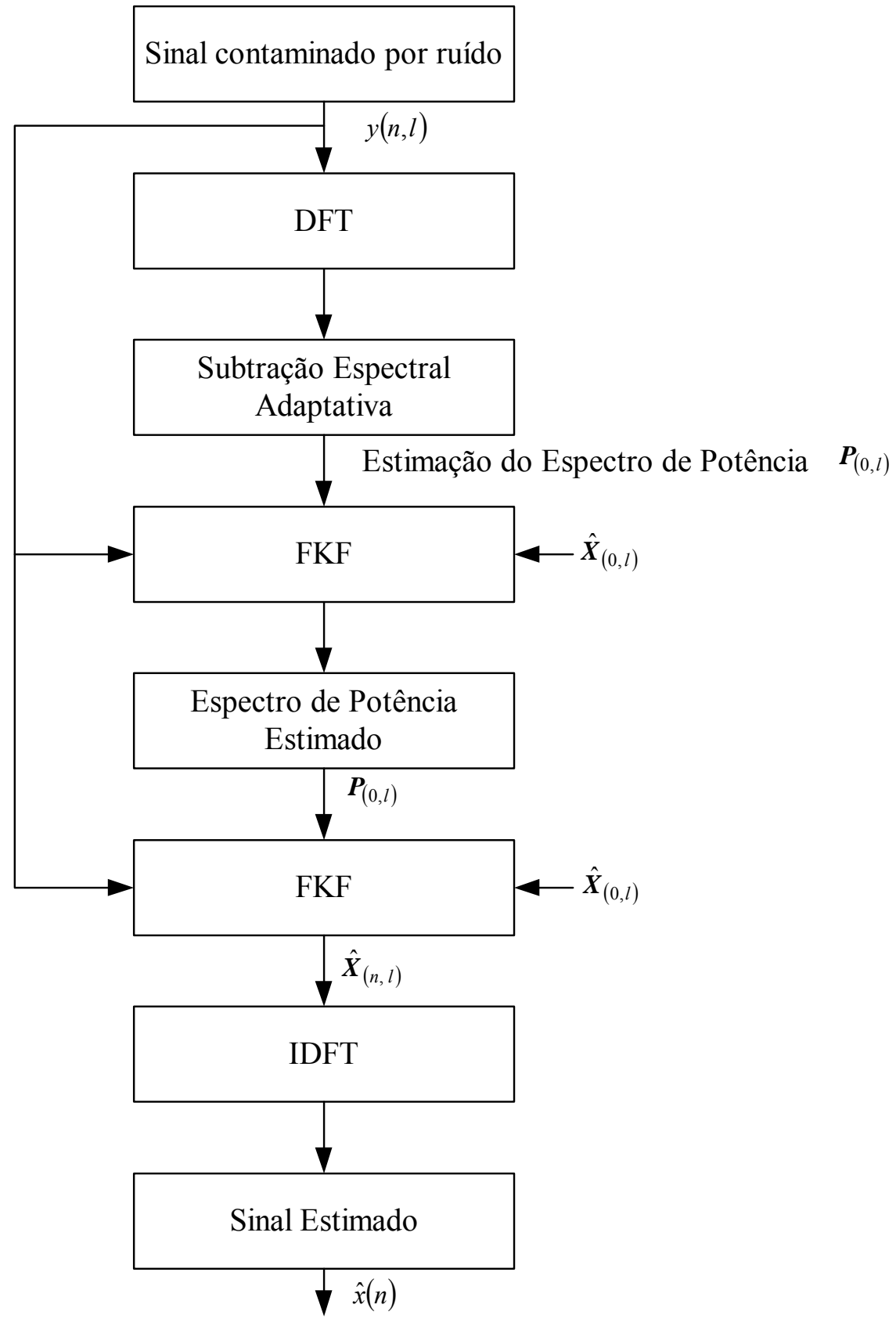

FIGURA 4. 5 - Diagrama em blocos do algoritmo original proposto por Fujimoto e Ariki.

Usando a mesma metodologia empregada em [1], foi realizado neste trabalho modificações no algoritmo original o que proporcionou resultados mais satisfatórios. As modificações realizadas foram: a substituição do filtro de Kalman de freqüência discreta 
pelo filtro de Kalman de tempo discreto e a substituição da subtração espectral adaptativa pela subtração espectral de potência.

Uma outra modificação no algoritmo original proposto por Fujimoto e Ariki [1] foi à aplicação do filtro de Kalman de freqüência discreta e tempo discreto somente uma vez ao invés de duas vezes como era proposto pelo algoritmo original.

Testes computacionais realizados demonstram que o sinal estimado após a filtragem apresenta as mesmas características em relação à aplicação do filtro somente uma vez. Sendo assim o que se conclui, é que a aplicação do filtro duas vezes resulta em um maior tempo computacional.

Uma outra mudança significativa realizada no algoritmo original foi a modificação nas condições iniciais do filtro. No algoritmo original usou-se o valor estimado após a subtração espectral adaptativa como condição inicial para a matriz erro de covariância da seguinte forma:

$$
\boldsymbol{P}_{(0, l)}=\left(\begin{array}{cccc}
|\hat{X}(0, l)|^{2} & 0 & \cdots & 0 \\
0 & |\hat{X}(1, l)|^{2} & \cdots & 0 \\
\vdots & \vdots & \ddots & \vdots \\
0 & 0 & \cdots & |\hat{X}(N-1, l)|^{2}
\end{array}\right)
$$

em que os elementos da diagonal principal de $\boldsymbol{P}_{(0, l)}$, representam o espectro de potência estimado após a subtração espectral adaptativa.

No algoritmo proposto neste trabalho, a condição inicial de $\boldsymbol{P}_{(0, l)}$ para o filtro discreto de Kalman na freqüência é dada pela equação (4.48). Já a condição inicial da 
estimativa $\hat{\boldsymbol{X}}_{(0, l)}$ no algoritmo original segundo Fujimoto e Ariki [1] é dada da seguinte forma:

$$
\hat{\boldsymbol{X}}_{(0, l)}=\left[0_{0}, 0_{1}, \ldots, 0_{N-1}\right]^{T}
$$

em que $\hat{\boldsymbol{X}}_{(0, l)}$ corresponde a um vetor de zeros.

Para o caso do algoritmo de filtragem de Kalman na Freqüência implementado neste trabalho, a condição inicial é o espectro estimado após a subtração espectral de potência, conforme a equação (4.47). No caso do algoritmo de filtragem de Kalman no tempo, a condição inicial é a estimativa de `(n) após a subtração espectral.

A figuras 4.6 mostra em forma de diagrama em blocos as operações envolvidas para redução de ruído usando o filtro de Kalman de Freqüência discreta combinado com a subtração espectral de potência. 


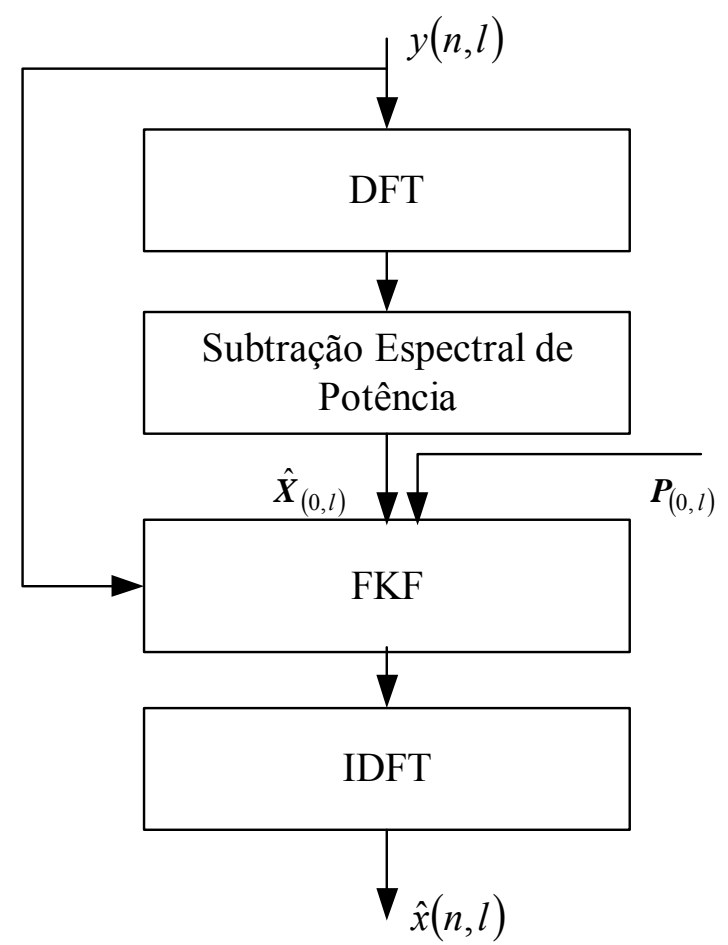

FIGURA 4. 6 - Diagrama em blocos do algoritmo do filtro de Kalman de freqüência discreta, em conjunto com a subtração espectral de potência.

Para mostrar a eficiência deste algoritmo na redução de ruído, será apresentado um exemplo de um sinal correspondente à palavra "elétrica" contaminado por ruído branco, o qual obteve uma relação sinal/ruído segmentada de entrada (SNRseg) de 3 dB. Desta forma, o sinal original, o sinal contaminado por ruído e o sinal estimado são mostrados nas figuras $4.7,4.8$ e 4.9 respectivamente.

Neste exemplo utilizou-se a subtração espectral de potência descrita no capítulo 3 e uma janela de Hamming de tamanho 512 com sobreposição espectral de 50\%. 


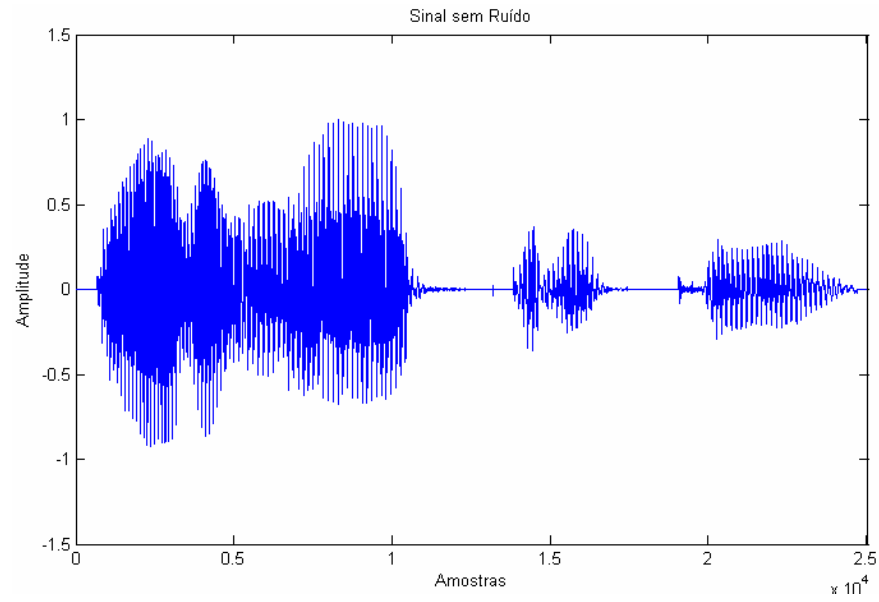

FIGURA 4. 7 - Sinal original correspondente à palavra "Elétrica".

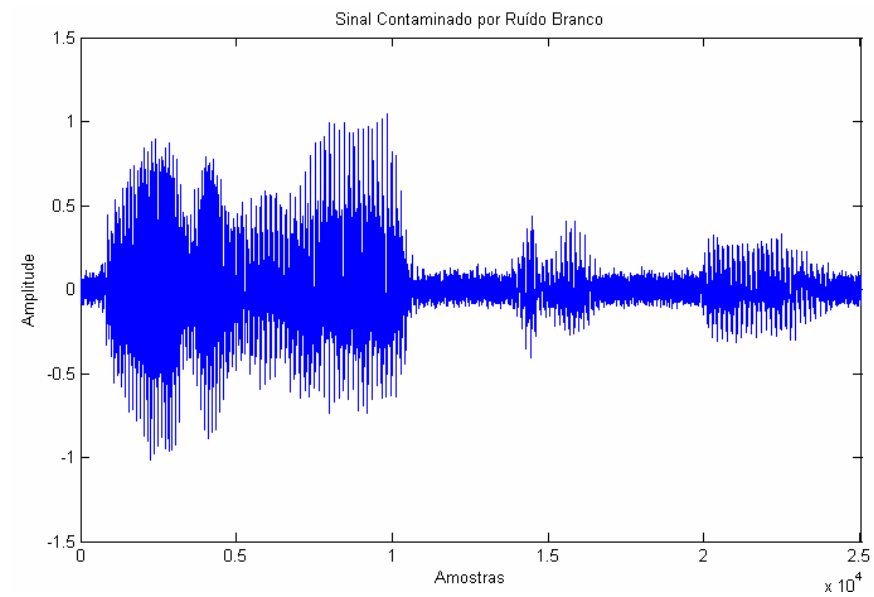

FIGURA 4. 8 - Sinal contaminado por ruído branco.

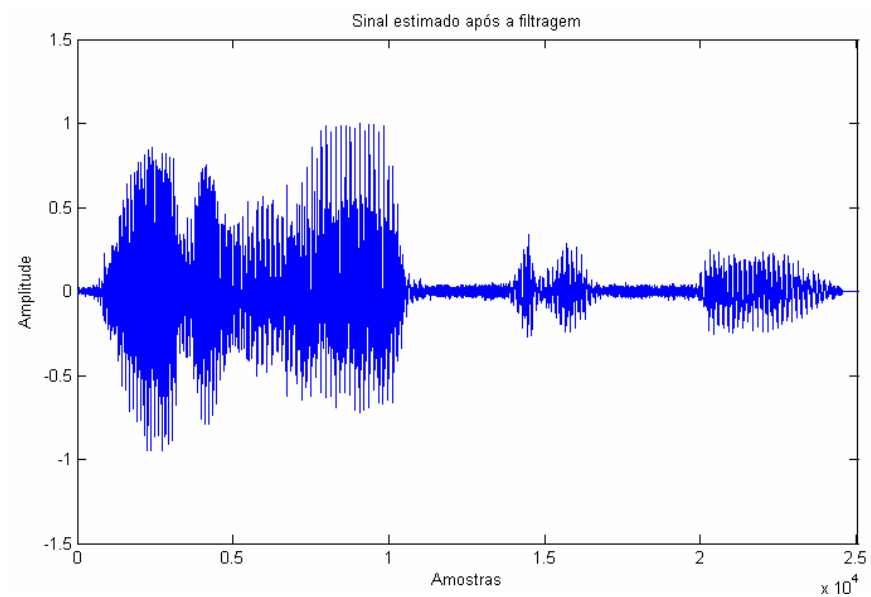

FIGURA 4. 9 - Sinal estimado após a filtragem de Kalman na freqüência, em conjunto com subtração espectral de potência. 
Observando-se as figuras 4.8 e 4.9, nota-se claramente a redução de ruído principalmente nos trechos de silêncio. Neste exemplo, houve um aumento na SNRseg de 5 $\mathrm{dB}$, o que comprova a eficiência do algoritmo em relação à redução de ruído em sinais de voz contaminados por ruído aditivo.

O uso do filtro de Kalman na freqüência em conjunto com a subtração espectral de potência, se mostra também eficiente em relação à distorção espectral, quando comparado com a técnica de subtração espectral aplicada isoladamente na reconstrução do sinal.

A medida utilizada para medir a distorção espectral comentada no parágrafo acima será apresentada no capítulo 5, onde serão apresentados mais resultados.

Uma outra modificação neste trabalho foi a implementação do filtro de Kalman de tempo discreto em conjunto com a subtração espectral de potência. Esta implementação é ilustrada na forma de diagrama em blocos pela figura 4.10 que representa as operações envolvidas.

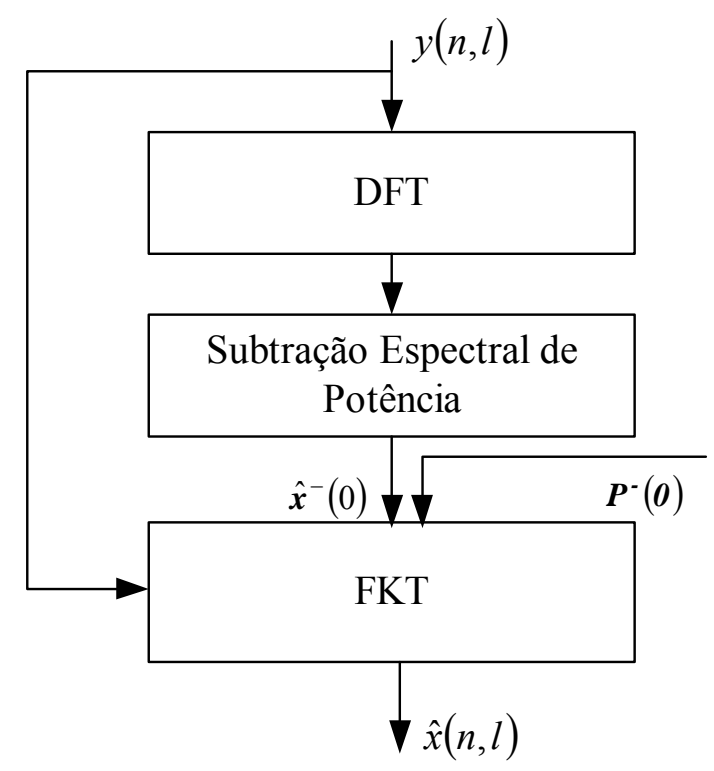

FIGURA 4. 10 - Diagrama em blocos do algoritmo do filtro de Kalman de tempo discreto, em conjunto com a subtração espectral de potência. 
Para mostrar também a eficiência deste algoritmo na redução de ruído, será apresentado um exemplo de um sinal correspondente à palavra "elétrica" também contaminado por ruído branco, o qual obteve uma relação sinal/ruído segmentada de entrada (SNRseg) de $3 \mathrm{~dB}$.

Neste exemplo também utilizou a subtração espectral de potência descrita no capítulo 3 e a janela utilizada, foi uma janela de Hamming de tamanho 512 com sobreposição espectral de 50\% como no exemplo anterior.

Os resultados são apresentados nas figuras 4.11, 4.12 e 4.13 respectivamente.

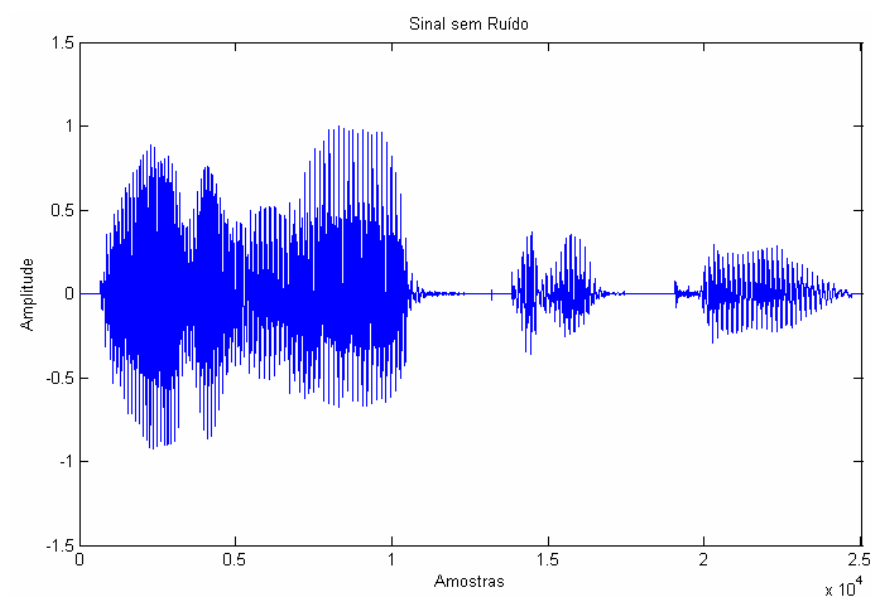

FIGURA 4. 11 - Sinal original.

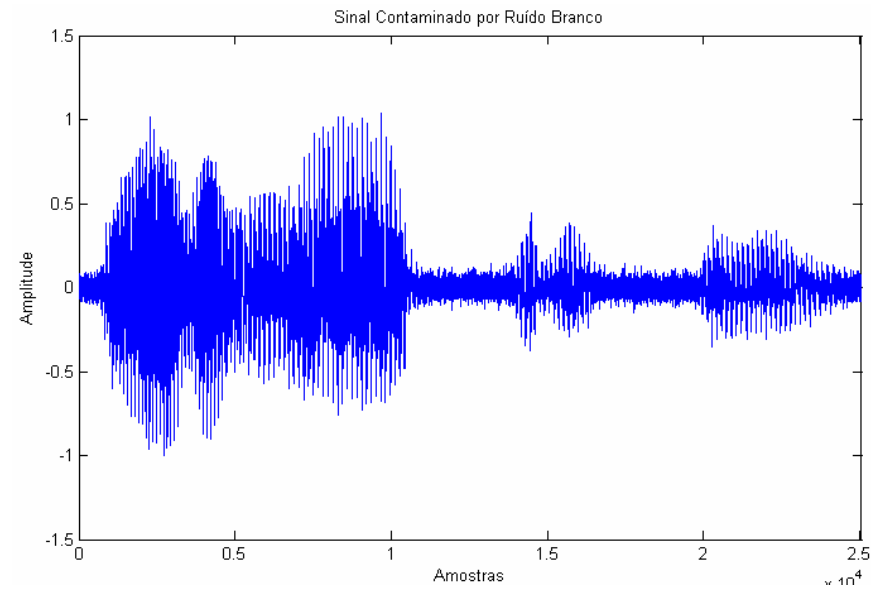

FIGURA 4. 12 - Sinal contaminado por ruído branco. 


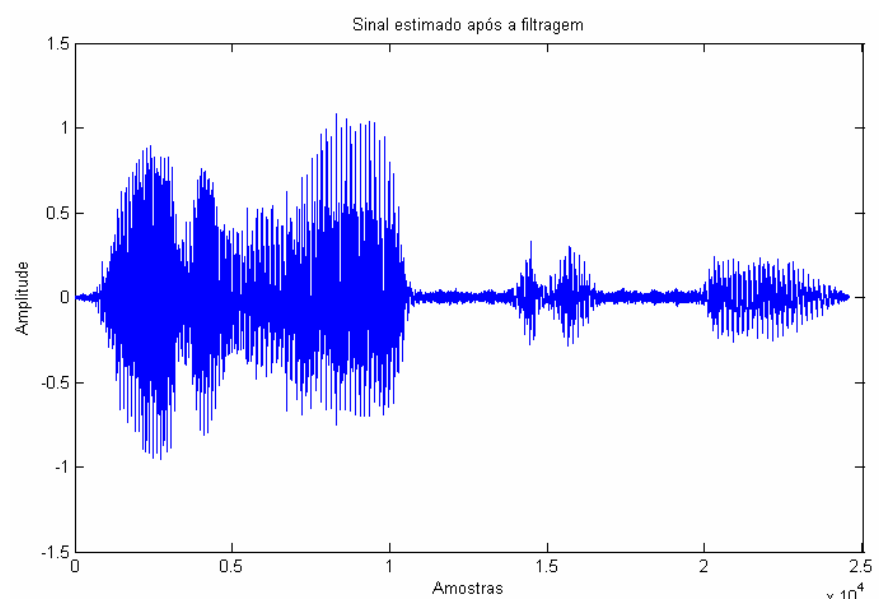

FIGURA 4. 13 - Sinal estimado após a filtragem usando o filtro de Kalman de tempo discreto, em conjunto com a subtração espectral de potência.

Neste exemplo o aumento na SNRseg foi de $5 \mathrm{~dB}$, o que também comprova a eficiência deste algoritmo na redução de ruído em sinais de voz. Já a distorção espectral envolvida apresentou resultados melhores com relação à subtração espectral e a filtragem de Kalman na freqüência.

Mais resultados envolvendo os algoritmos das figuras 4.6 e 4.10 será apresentado no capítulo 5 .

\subsection{Divergência do Filtro de Kalman}

Segundo Selmini [6], desde a publicação do filtro de Kalman em 1960, este se tornou uma técnica de filtragem poderosa e largamente utilizada em várias áreas e ao mesmo tempo se tornou um assunto de pesquisas científicas. Com a intensificação dos estudos sobre o filtro de Kalman e com várias aplicações, notou-se que em certas condições o filtro poderia divergir. 
Por divergência considera-se que os erros de estimação passam a possuir um valor médio não nulo, divergindo dessa forma do valor esperado:

$$
\mathrm{E}[\boldsymbol{x}(n)-\hat{\boldsymbol{x}}(n)]=0
$$

e conseqüentemente a estimativa do estado diverge do estado verdadeiro do sistema, levando dessa forma a resultados bem diferentes do esperado.

Segundo Selmini [6], dois tipos de divergências podem ser encontradas:

Divergência aparente: o valor do erro de estimação deixa de ter média nula e seu valor permanece constante (estacionário) no decorrer do tempo.

Divergência verdadeira: neste caso, além do erro de estimação deixar de ter média nula, o seu valor cresce no decorrer do tempo.

De acordo com Brown e Wang [16], duas são as principais causas da divergência do filtro:

Problemas numéricos: este tipo de problema é inevitável quando operações aritméticas são realizadas usando computador digital. Os resultados estão sujeitos aos erros de arredondamento ("roundoff errors") devido ao comprimento de palavra utilizada pelo computador para fazer a representação. Dessa forma, os erros de arredondamento são cumulativos e podem distorcer os resultados finais do filtro de Kalman.

Problemas de modelagem: também são responsáveis por divergências do filtro, uma vez que este é muito sensível aos erros de modelagem. 


\subsection{Considerações Finais}

Neste capítulo foi apresentada a teoria dos filtros de Kalman de tempo e freqüência discretos aplicada ao processamento de sinais de voz contaminados por ruído. O uso destes filtros por sua vez se faz presente na reconstrução de sinais de voz, uma vez que, a subtração espectral aplicada isoladamente não provê resultados satisfatórios em relação à distorção espectral. Desta forma, a subtração espectral será responsável pelo préprocessamento do sinal contaminado, que será usado como condição inicial para ambos os filtros como descrito na seção 4.7 e os filtros responsáveis pela diminuição do ruído é da distorção espectral. Sendo assim, estas duas técnicas apresentadas comprovam a eficiência na redução de ruído e sobre tudo a eficiência em relação à distorção espectral.

Além do desenvolvimento das equações que compõem ambos os filtros, o capítulo também apresenta algumas dificuldades que podem surgir quando as técnicas dos filtros de Kalman são empregadas, dentre elas, temos a divergência, ou seja, o erro de estimação passa a ter um valor médio diferente de zero. A divergência pode ser dividida basicamente em dois grupos: divergência aparente e divergência verdadeira, e pode ser provocada por problemas numéricos e de modelagem. 


\section{$5 \quad$ Resultados}

\subsection{Introdução}

Este capítulo apresenta a avaliação dos resultados obtidos na reconstrução dos sinais de voz, utilizando os filtros de Kalman de tempo e freqüência discretos em conjunto com a subtração espectral de potência.

As medidas utilizadas para avaliar o desempenho dos algoritmos foram: a relação sinal/ruído segmentada (SNRseg) e a distância de Itakura-Saito, para medir as distorções causadas na reconstrução dos sinais de voz. Estas medidas são descritas na seção seguinte.

\subsection{Relação sinal/ruído segmentada (SNRseg)}

Conhecendo-se o sinal de voz $x(n)$ mais o ruído $v(n)$, pode-se determinar a potência do sinal e a potência do ruído de modo a se encontrar a relação sinal/ruído, conforme o cálculo de SNR dado por [5]:

$$
S N R=10 \log _{10} \frac{\sum_{n} x^{2}(n)}{\sum_{n} v^{2}(n)}
$$

na qual $x(n)$ representa o sinal original e $v(n)$ o ruído branco adicionado.

Porém, tal medida é considerada uma estimativa pobre em relação à qualidade do sinal degradado por distorções de ruído, pois em trechos onde se tem sinal mais forte a relação é muito maior do que os trechos onde se tem sinal mais fraco. Por este motivo é apresentada uma medida conhecida como relação sinal/ruído segmentada, cuja finalidade é 
calcular a relação sinal/ruído em cada segmento de forma a equilibrar os trechos de sinal com maior ou menor intensidade. A SNR segmentada é definida por Deller et all [5] como:

$$
\text { SNRseg }=\frac{1}{M} \sum_{j=0}^{M-1} 10 \log _{10}\left[\sum_{n=m j-N+1}^{m j} \frac{x^{2}(n)}{[x(n)-\hat{x}(n)]^{2}}\right]
$$

na qual $m j$ representa o limites de cada um dos $M$ quadros, cada um de tamanho $N$.

Em alguns casos quando se utiliza o cálculo da SNRseg, podem aparecer, valores negativos provenientes de instantes de silêncio de fala. Para tal, é utilizado um limiar de OdB ou seja, se o cálculo da SNRseg em um determinado trecho do sinal for menor que 0dB considera-se 0dB [5].

Por outro lado, em um trecho de atividade sonora em que o cálculo da SNRseg for maior do que $35 \mathrm{~dB}$ considera-se $35 \mathrm{~dB}$ a SNRseg neste trecho. Isto se deve ao fato de que o ouvinte não consegue perceber SNRseg maior que $35 \mathrm{~dB}$ [5].

\subsection{Distância de Itakura-Saito}

A SNR não provê uma medida significante de desempenho quando dois sinais se diferem em seus espectros de amplitude. Entretanto as medidas de distância são sensíveis às variações de espectro. Neste contexto, tem-se a medida de Itakura-Saito responsável por apresentar a dessemelhança entre o sinal de fala original e o sinal estimado. Assim, pode-se calcular a distância de Itakura-Saito, através de parâmetros LPC. Sua principal característica é oferecer uma medida da semelhança entre dois vetores LPC ou, em outras palavras, uma medida da probabilidade de que um vetor LPC com coeficiente $b_{k}$ obtido de 
sinal contaminado por ruído ou processado, tenha sido computado a partir do sinal de fala original com coeficientes LPC $a_{k}$. Assim, a distância de Itakura-Saito é dada por [5]:

$$
d(a, b)=\log \left[\frac{a R a^{T}}{b R b^{T}}\right]
$$

em que (a) é o vetor dos coeficiente LPC do sinal original, (R) é a matriz de autocorrelação do sinal original e (b) é o vetor de coeficiente LPC do sinal estimado.

\subsection{Implementação e Análise dos Algoritmos}

Para processar, os algoritmos descritos em forma de diagrama em blocos, pelas figuras 4.6 e 4.10, foram utilizados diversos sinais de voz colhidos na placa sound blaster com uma taxa de amostragem de $22050 \mathrm{~Hz}$ com 16 bits. Estes sinais então, foram contaminadas por ruídos do tipo branco gaussiano e colorido e em seguida, processados pelos algoritmos.

A janela aplicada em ambos os processamentos foi uma janela de Hamming com tamanho de 512 amostras usando sobreposição de $50 \%$.

A subtração espectral utilizada como pré-processamento, foi a subtração espectral de potência descrita no capítulo 3. O parâmetro $\alpha$ utilizado para controlar o nível de ruído a ser subtraído do processo de subtração é encontrado pela equação (3.13) e o limite espectral $\beta$, fixado em 0,02. A retificação usada é dada pela equação (3.14). 


\subsubsection{Processamento utilizando Ruído Branco Gaussiano}

Nesse primeiro teste, foi considerado um ruído aditivo branco gaussiano adicionado ao sinal de voz correspondente à palavra 'Elétrica'. A figura 5.1 mostra a forma de onda do sinal original antes de ser contaminado pelo ruído branco gaussiano que está representado na figura 5.2. Depois de contaminado, a forma de onda do sinal é processada pelo filtro de Kalman de tempo discreto (FKT) em conjunto com a subtração espectral de potência em que o resultado pode ser visto na figura 5.3.

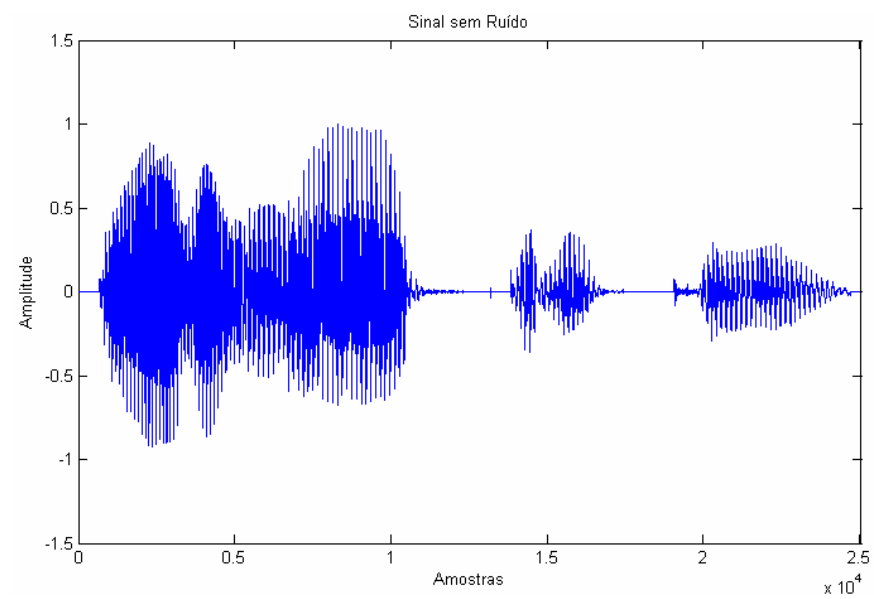

FIGURA 5. 1 - Sinal original correspondente à palavra "Elétrica".

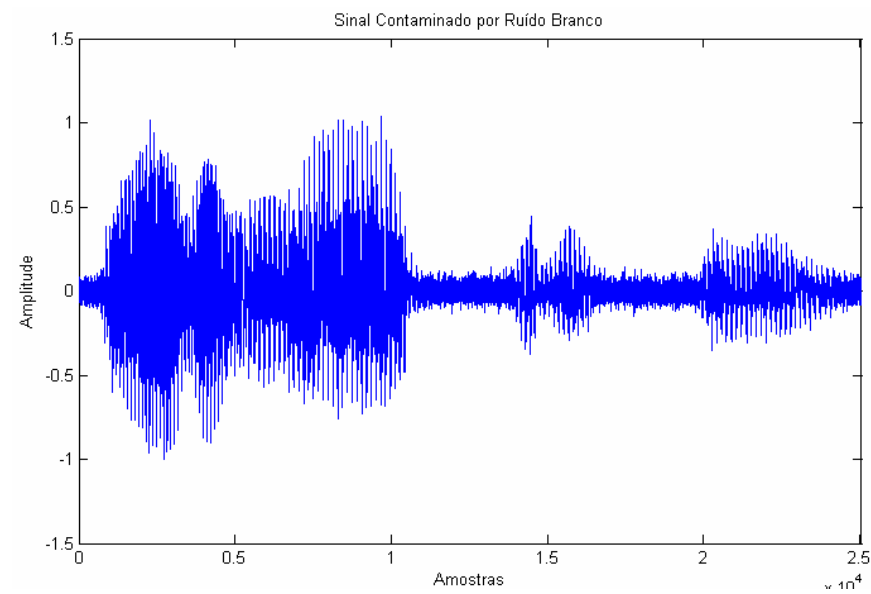

FIGURA 5. 2 - Sinal contaminado por ruído branco. 


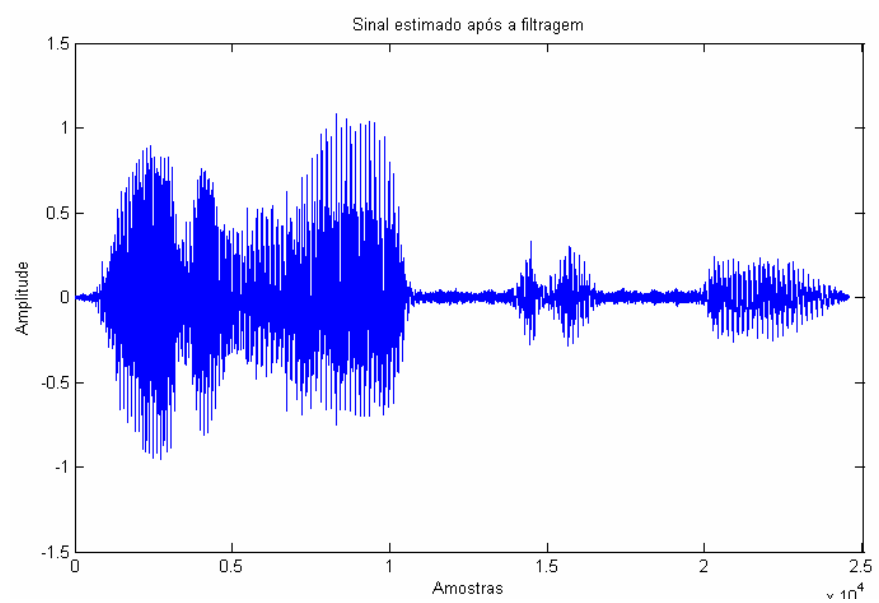

FIGURA 5. 3 - Sinal estimado após o processamento da filtragem de Kalman no tempo em conjunto com a subtração espectral.

Comparando a figura 5.2 com a figura 5.3 nota-se claramente uma redução do ruído usando o algoritmo de filtragem de Kalman no tempo em conjunto com a subtração espectral, principalmente nos trechos de silêncio do sinal.

Para avaliar o sinal processado, foi utilizada a relação sinal/ruído segmentada (SNRseg). Para esse teste utilizando ruído branco gaussiano tem-se na entrada do algoritmo uma SNRseg de $3 \mathrm{~dB}$ e na saída do algoritmo $8 \mathrm{~dB}$. Apesar do algoritmo apresentar um aumento de $5 \mathrm{~dB}$ na relação sinal/ruído segmentada, ainda existe após o processamento um fenômeno conhecido como ruído musical, o qual tenta-se eliminar ou reduzir sua intensidade de acordo com o capítulo 3.

Uma outra medida utilizada foi à distância de Itakura-Saito, que foi usada para avaliar se o sinal processado sofreu distorções quando reconstruído em relação ao sinal original. Nesse teste a distância de Itakura-Saito foi de 0,3290. Sendo assim, utilizando-se o mesmo algoritmo foram calculadas cinco distâncias de Itakura-Saito com diferentes relações sinal/ruído de entrada segmentada usando o mesmo sinal. Os resultados são apresentados na figura 5.4. 


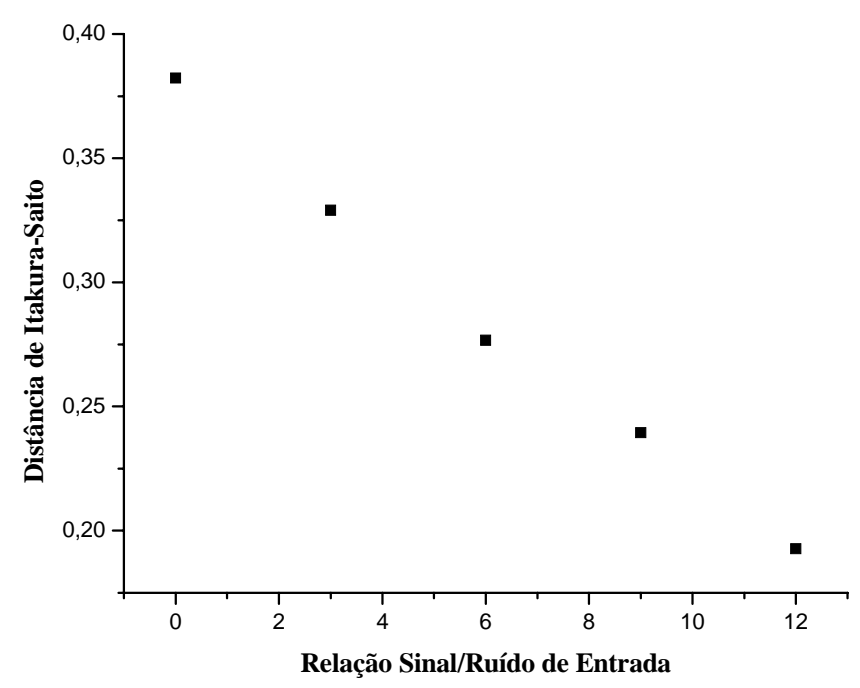

FIGURA 5. 4 - Distância de Itakura-Saito em função da SNRseg de entrada, para o algoritmo FKT com ruído branco.

Pela figura 5.4, nota-se que quanto maior a relação sinal/ruído de entrada segmentada, menor é à distância de Itakura-Saito. Isto significa que o sinal processado quase não sofreu distorções quando reconstruído.

Um outro parâmetro importante para avaliar os resultados oriundos do sinal processado é o espectrograma. O espectrograma é um gráfico bidimensional na qual a posição vertical corresponde à freqüência e a posição horizontal ao tempo. Assim, a cor padrão particular nos espectrogramas é indicativa da energia de sinal nesse padrão. O código de cores (em energia decrescente) é o seguinte: vermelho é o mais alto, seguido do amarelo e depois do azul. As figuras 5.5, 5.6 e 5.7 correspondem aos espectrogramas do sinal original, sinal contaminado e sinal estimado respectivamente. 


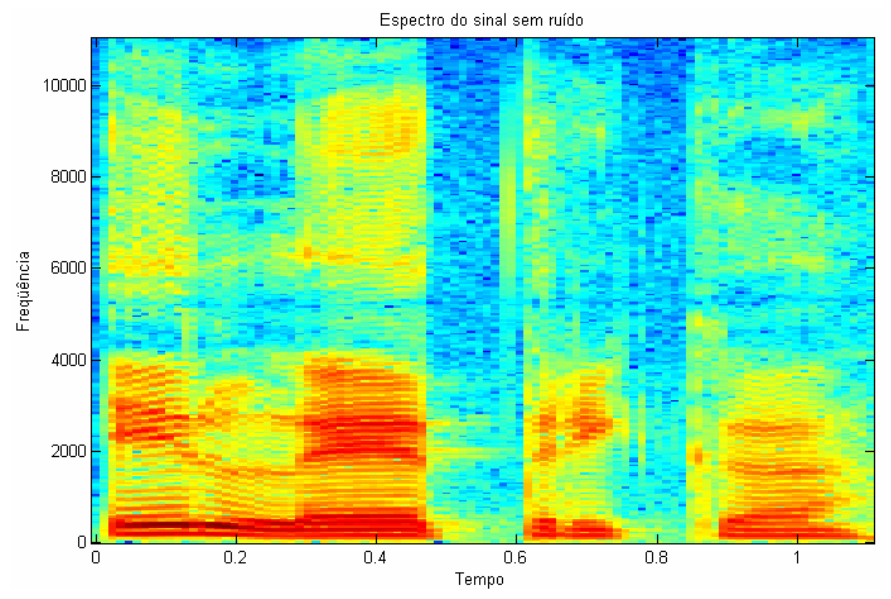

FIGURA 5. 5 - Espectrograma do sinal original.

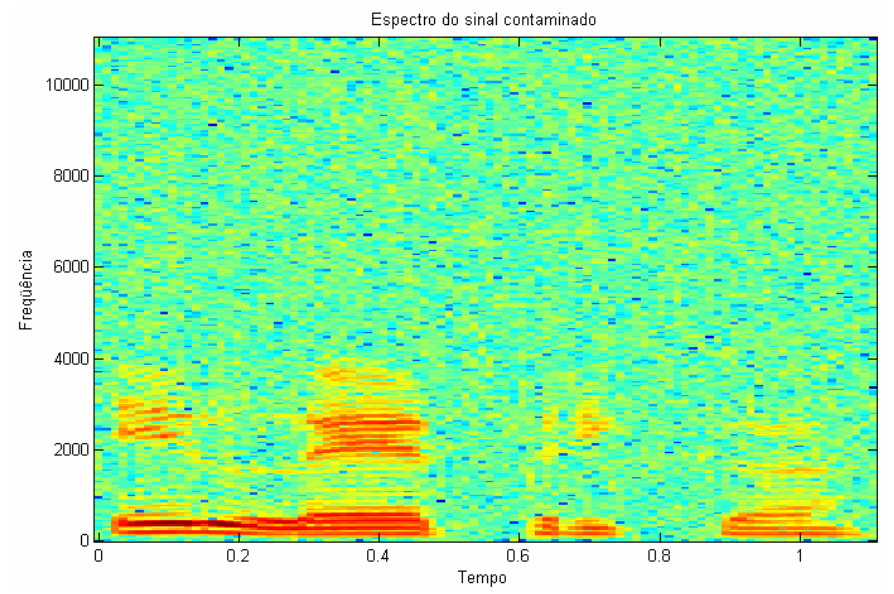

FIGURA 5. 6 - Espectrograma do sinal contaminado.

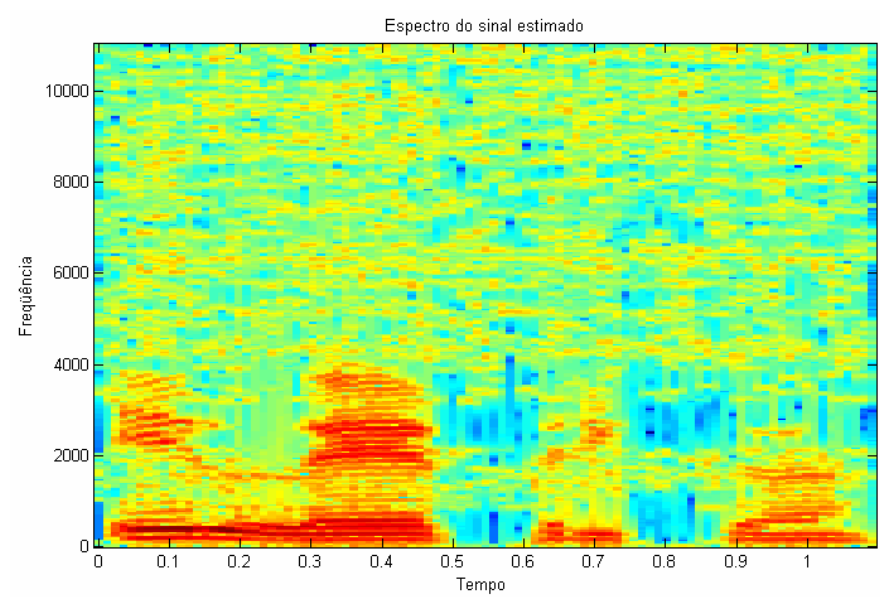

FIGURA 5. 7 - Espectrograma do sinal estimado, após o processamento da filtragem de Kalman no tempo em conjunto com a subtração espectral. 
Conforme análise dos três espectrogramas percebe-se na figura 5.7 (sinal filtrado) que nas altas freqüências entre 2000 e $3000 \mathrm{~Hz}$ a intensidade do sinal foi ressaltada pelo algoritmo de filtragem se comparado com o espectrograma da figura 5.6 (sinal corrompido por ruído). Este também mostra que o algoritmo conseguiu realçar outras freqüências superiores, mas não com a mesma energia entre 2000 e 3000Hz. Pode-se perceber também que apesar de uma redução da intensidade do ruído, um ruído residual permanece.

Para o segundo teste, foi utilizado o algoritmo de filtragem de Kalman de freqüência discreta em conjunto com a subtração espectral de potência. Neste teste foi adicionado ao sinal de voz original, ruído branco, o qual obteve uma relação sinal/ruído segmentada de entrada de $3 \mathrm{~dB}$ e uma relação sinal/ruído segmentada de saída de $8 \mathrm{~dB}$. Este processamento resultou em um aumento de $5 \mathrm{~dB}$ no sinal estimado. Sendo assim, as figuras 5.8, 5.9 e 5.10 representam o sinal original, sinal contaminado por ruído branco e sinal estimado após o processamento respectivamente.

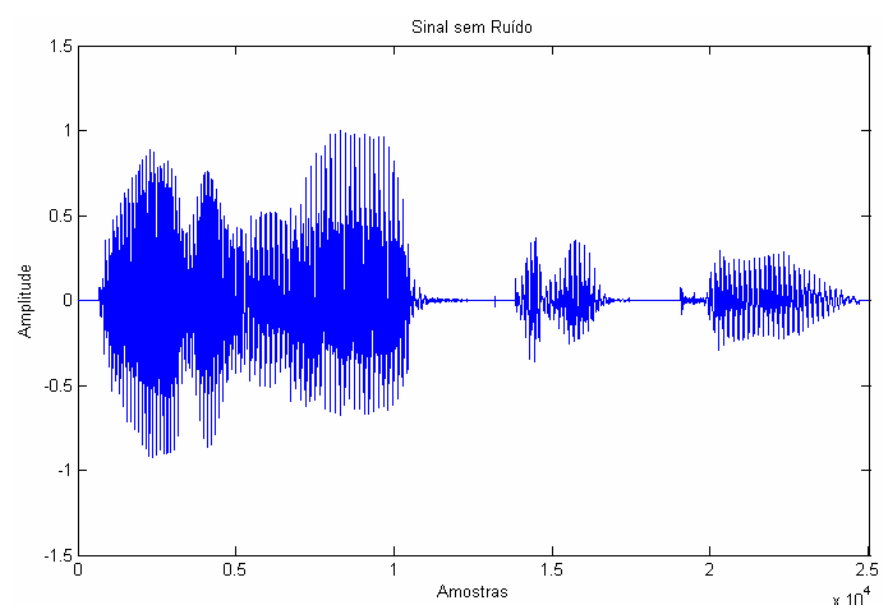

FIGURA 5. 8 - Sinal original correspondente à palavra "Elétrica". 


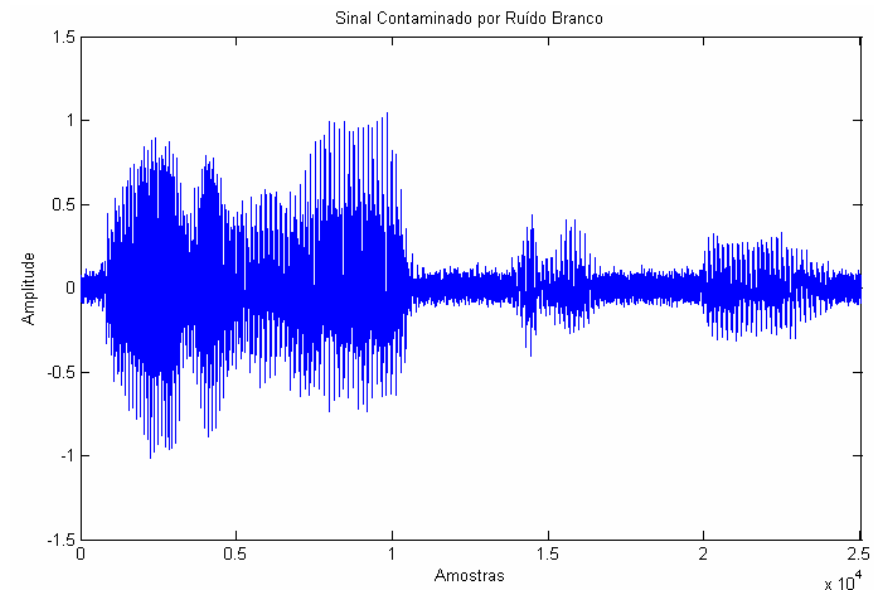

FIGURA 5. 9 - Sinal contaminado por ruído branco.

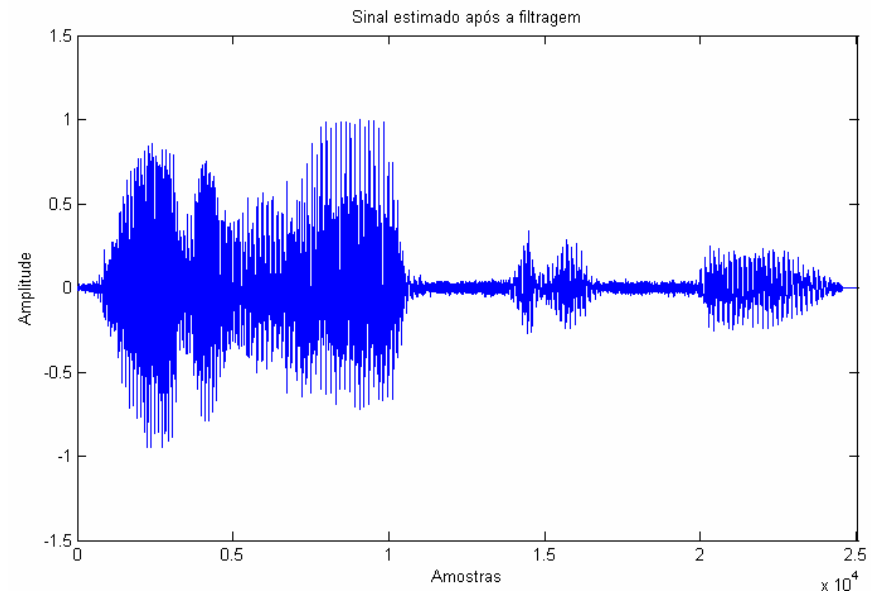

FIGURA 5. 10 - Sinal estimado após o processamento da filtragem de Kalman na freqüência em conjunto com a subtração espectral.

A distância de Itakura-Saito para este teste obteve um valor de 0,3328. Sendo assim, para o mesmo algoritmo foram calculadas cinco distâncias com diferentes relações sinal/ruído de entrada segmentada. Os resultados são apresentados na figura 5.11. 


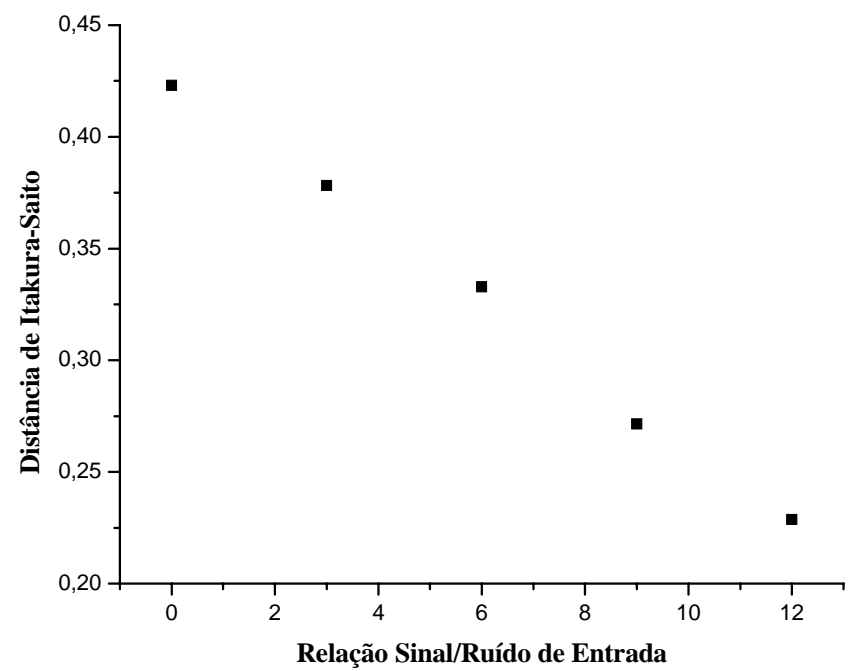

FIGURA 5. 11 - Distância de Itakura-Saito em função da SNR de entrada segmentada, para o algoritmo FKF usando ruído branco.

Pela figura 5.11, nota-se também, que quanto maior a relação sinal/ruído de entrada menor é à distância de Itakura-Saito, o que também significa, menor distorção no sinal reconstruído.

Outro parâmetro utilizado para este teste foram os espectrogramas. Os espectrogramas do sinal original, sinal contaminado por ruído branco e sinal após o processamento, são apresentados pelas figuras 5.12, 5.13 e 5.14 respectivamente.

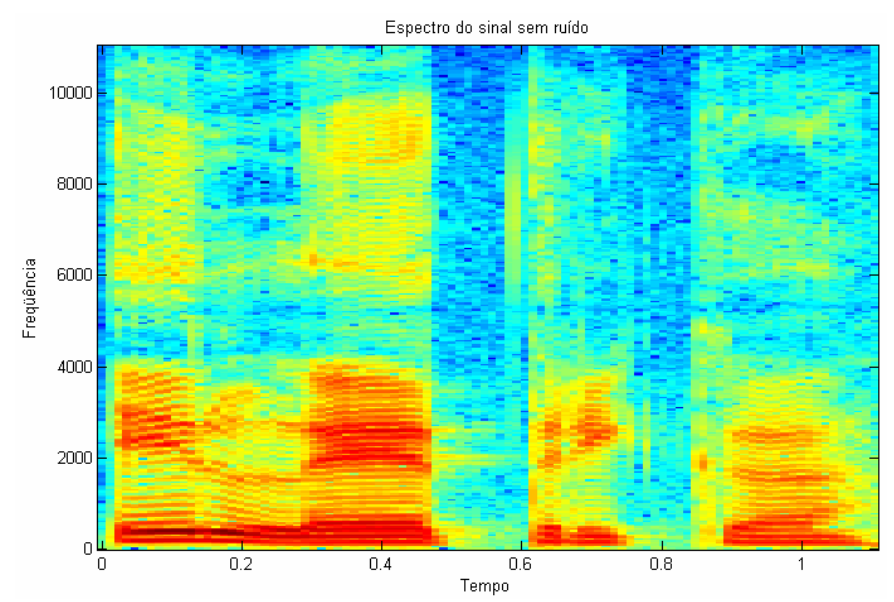

FIGURA 5. 12 - Espectrograma do sinal original. 


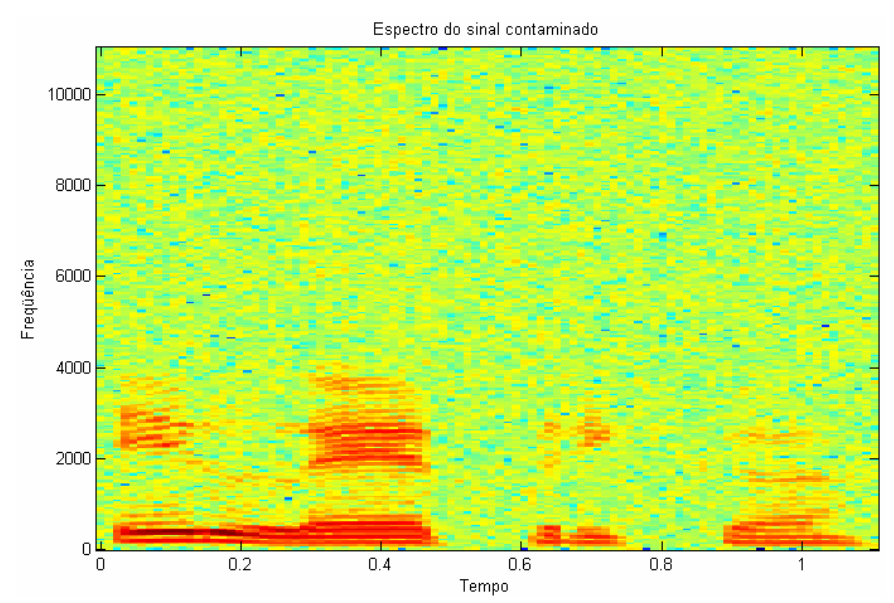

FIGURA 5. 13 - Espectrograma do sinal contaminado por ruído branco.

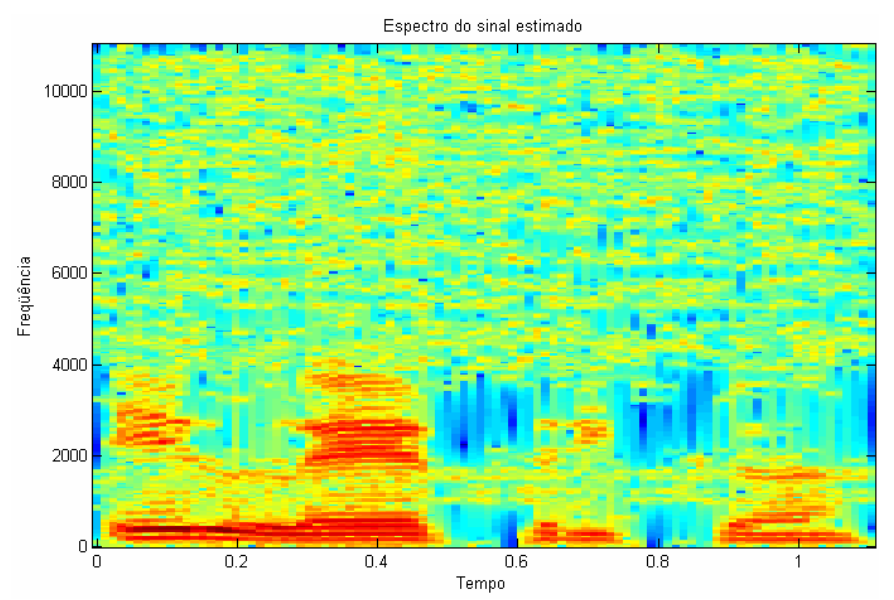

FIGURA 5. 14 - Espectrograma do sinal estimado após o processamento da filtragem de Kalman na freqüência em conjunto com a subtração espectral.

Conforme análise dos três espectrogramas percebe-se na figura 5.14 (sinal filtrado) que nas altas freqüências entre 2000 e $3000 \mathrm{~Hz}$, a intensidade do sinal foi ressaltada pelo algoritmo de filtragem se comparado com o espectrograma da figura 5.13 (sinal corrompido por ruído), mas também verifica-se que as freqüências mais altas, também foram ressaltadas, mas com menos energia. Pode-se perceber também que apesar de uma redução da intensidade do ruído, um ruído residual permanece. 
Para avaliar a eficiência do algoritmo proposto neste trabalho, a figura 5.15, apresenta uma comparação entre a técnica proposta FKT e as técnicas de subtração espectral de potência e FKF, usando como parâmetro de comparação: a distância de Itakura-Saito em função da relação sinal/ruído de entrada segmentada. A palavra aqui testada foi "Elétrica".

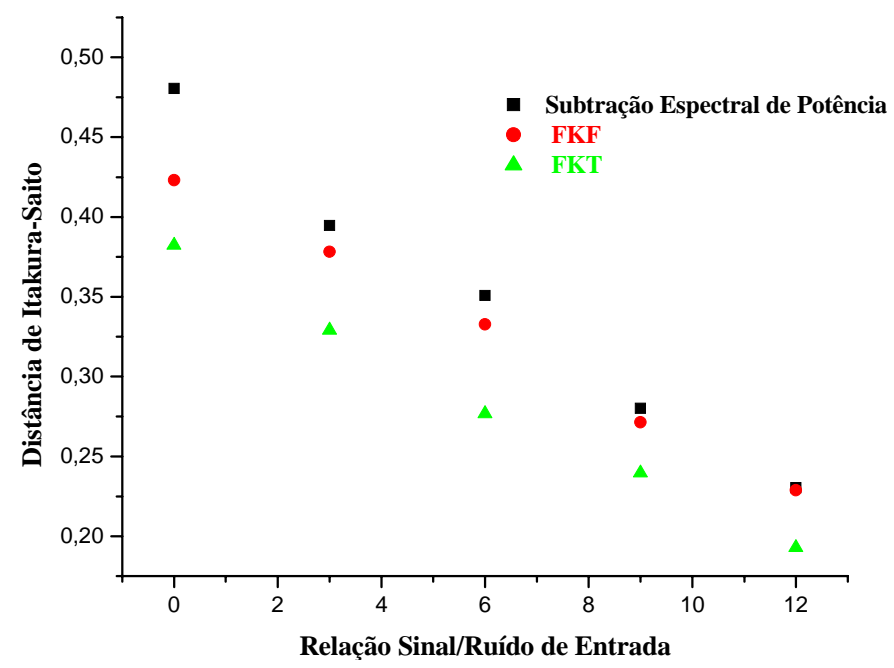

FIGURA 5. 15 - Distância de Itakura-Saito em função da SNR de entrada segmentada, como comparação para as três técnicas utilizadas neste trabalho.

A figura 5.15 revela que a técnica proposta neste trabalho (FKT) é superior com relação à distorção espectral, quando comparada com as técnicas de subtração espectral de potência e FKF.

Para comprovar de fato a eficiência da técnica proposta, objetivando mínima distorção espectral e redução de ruído na reconstrução do sinal, são apresentados nas tabelas $5.1,5.2,5.3,5.4,5.5,5.6,5.7,5.8$ e 5.9 resultados de 25 palavras processadas pelos 
algoritmos de subtração espectral de potência, FKF e FKT. As relações sinal/ruído de entrada usadas nestes testes, foram: $0 \mathrm{~dB}, 3 \mathrm{~dB}$ e $6 \mathrm{~dB}$.

TABELA 5. 1 - Resultados dos testes para as 25 palavras com SNR de entrada de $0 \mathrm{~dB}$, usando a subtração espectral de potência, para o caso do ruído ser branco.

\begin{tabular}{|l|c|c|}
\hline \multicolumn{3}{|c|}{ Relação Sinal/Ruído de Entrada de 0 dB para a técnica de Subtração Espectral de } \\
Potência
\end{tabular}


TABELA 5.2 - Resultados dos testes para as 25 palavras com SNR de entrada de $0 \mathrm{~dB}$, usando FKF, para o caso do ruído ser branco.

\begin{tabular}{|l|c|c|}
\hline \multicolumn{2}{|c|}{ Relação Sinal/Ruído de Entrada de 0 dB para a técnica FKF } \\
\hline Palavras & $\begin{array}{c}\text { Relação Sinal/Ruído de } \\
\text { Saída em dB }\end{array}$ & Distância de Itakura-Saito \\
\hline Bala & $8 \mathrm{~dB}$ & 1,0151 \\
\hline Boi & $6 \mathrm{~dB}$ & 0,9130 \\
\hline Bola & $8 \mathrm{~dB}$ & 1,2594 \\
\hline Cão & $8 \mathrm{~dB}$ & 0,8742 \\
\hline Casa & $5 \mathrm{~dB}$ & 0,2622 \\
\hline Cola & $8 \mathrm{~dB}$ & 1,3697 \\
\hline Dado & $6 \mathrm{~dB}$ & 0,6960 \\
\hline Dia & $7 \mathrm{~dB}$ & 0,4427 \\
\hline Elefante & $9 \mathrm{~dB}$ & 0,3166 \\
\hline Elétrica & $8 \mathrm{~dB}$ & 0,4231 \\
\hline Fala & $5 \mathrm{~dB}$ & 0,9618 \\
\hline Igreja & $7 \mathrm{~dB}$ & 0,4162 \\
\hline Janela & $7 \mathrm{~dB}$ & 0,6621 \\
\hline Lã & $8 \mathrm{~dB}$ & 0,9651 \\
\hline Lata & $11 \mathrm{~dB}$ & 0,4430 \\
\hline Maio & $8 \mathrm{~dB}$ & 0,8342 \\
\hline Manga & $7 \mathrm{~dB}$ & 0,7352 \\
\hline Mão & $7 \mathrm{~dB}$ & 0,9748 \\
\hline Medo & $6 \mathrm{~dB}$ & 0,5488 \\
\hline Mel & $8 \mathrm{~dB}$ & 1,0304 \\
\hline Modem & $9 \mathrm{~dB}$ & 0,5964 \\
\hline Vovó & $7 \mathrm{~dB}$ & 0,7169 \\
\hline Tabela & $6 \mathrm{~dB}$ & 0,4483 \\
\hline Tia & $7 \mathrm{~dB}$ & 0,5617 \\
\hline Tio & $8 \mathrm{~dB}$ & 0,5005 \\
\hline & $7 \mathrm{~dB}$ & \\
\hline Média & & 0,7187 \\
\hline & & \\
\hline & & \\
\hline & & \\
\hline & & \\
\hline
\end{tabular}


TABELA 5. 3 - Resultados dos testes para as 25 palavras com SNR de entrada de $0 \mathrm{~dB}$, usando FKT, para o caso do ruído ser branco.

\begin{tabular}{|l|c|c|}
\hline \multicolumn{3}{|c|}{ Relação Sinal/Ruído de Entrada de 0 dB, para a técnica FKT } \\
\hline Palavras & $\begin{array}{c}\text { Relação Sinal/Ruído de } \\
\text { Saída em dB }\end{array}$ & Distância de Itakura-Saito \\
\hline Bala & $8 \mathrm{~dB}$ & 0,8745 \\
\hline Boi & $6 \mathrm{~dB}$ & 0,8225 \\
\hline Bola & $9 \mathrm{~dB}$ & 1,2006 \\
\hline Cão & $9 \mathrm{~dB}$ & 0,7936 \\
\hline Casa & $5 \mathrm{~dB}$ & 0,2222 \\
\hline Cola & $8 \mathrm{~dB}$ & 1,2368 \\
\hline Dado & $6 \mathrm{~dB}$ & 0,6960 \\
\hline Dia & $7 \mathrm{~dB}$ & 0,4253 \\
\hline Elefante & $9 \mathrm{~dB}$ & 0,2512 \\
\hline Elétrica & $8 \mathrm{~dB}$ & 0,3823 \\
\hline Fala & $5 \mathrm{~dB}$ & 0,8549 \\
\hline Igreja & $8 \mathrm{~dB}$ & 0,3241 \\
\hline Janela & $7 \mathrm{~dB}$ & 0,5570 \\
\hline Lã & $8 \mathrm{~dB}$ & 0,8087 \\
\hline Lata & $11 \mathrm{~dB}$ & 0,3626 \\
\hline Maio & $8 \mathrm{~dB}$ & 0,7250 \\
\hline Manga & $8 \mathrm{~dB}$ & 0,6192 \\
\hline Mão & $7 \mathrm{~dB}$ & 0,7484 \\
\hline Medo & $6 \mathrm{~dB}$ & 0,4763 \\
\hline Mel & $8 \mathrm{~dB}$ & 0,9050 \\
\hline Modem & $9 \mathrm{~dB}$ & 0,5261 \\
\hline Vovó & $7 \mathrm{~dB}$ & 0,5859 \\
\hline Tabela & $7 \mathrm{~dB}$ & 0,3736 \\
\hline Tia & $7 \mathrm{~dB}$ & 0,5554 \\
\hline Tio & $8 \mathrm{~dB}$ & 0,4551 \\
\hline & & 0,6313 \\
\hline Média & $8 \mathrm{~dB}$ & \\
\hline & & \\
\hline
\end{tabular}

Observando as tabelas 5.1, 5.2 e 5.3, nota-se que a partir dos valores médios, a técnica proposta neste trabalho apresenta resultados melhores em relação à distorção espectral. Já a relação sinal/ruído é maior em $1 \mathrm{~dB}$ quando comparada com as técnicas FKF e subtração espectral de potência. 
TABELA 5. 4 - Resultados dos testes para as 25 palavras com SNR de entrada de $3 \mathrm{~dB}$, usando a subtração espectral de potência, para o caso do ruído ser branco.

\begin{tabular}{|l|c|c|}
\hline \multicolumn{3}{|c|}{ Relação Sinal/Ruído de Entrada de 3 dB, para a técnica de Subtração Espectral de } \\
Potência
\end{tabular}


TABELA 5. 5 - Resultados dos testes para as 25 palavras com SNR de entrada de $3 \mathrm{~dB}$, usando FKF, para o caso do ruído ser branco.

\begin{tabular}{|l|c|c|}
\hline \multicolumn{2}{|c|}{ Relação Sinal/Ruído de Entrada de 3 dB, para a técnica FKF } \\
\hline Palavras & $\begin{array}{c}\text { Relação Sinal/Ruído de } \\
\text { Saída em dB }\end{array}$ & Distância de Itakura-Saito \\
\hline Bala & $10 \mathrm{~dB}$ & 0,9628 \\
\hline Boi & $7 \mathrm{~dB}$ & 0,7791 \\
\hline Bola & $10 \mathrm{~dB}$ & 1,1858 \\
\hline Cão & $10 \mathrm{~dB}$ & 0,8031 \\
\hline Casa & $6 \mathrm{~dB}$ & 0,1898 \\
\hline Cola & $10 \mathrm{~dB}$ & 1,2643 \\
\hline Dado & $7 \mathrm{~dB}$ & 0,6192 \\
\hline Dia & $9 \mathrm{~dB}$ & 0,4148 \\
\hline Elefante & $9 \mathrm{~dB}$ & 0,2278 \\
\hline Elétrica & $8 \mathrm{~dB}$ & 0,3782 \\
\hline Fala & $6 \mathrm{~dB}$ & 0,8543 \\
\hline Igreja & $8 \mathrm{~dB}$ & 0,3798 \\
\hline Janela & $8 \mathrm{~dB}$ & 0,6002 \\
\hline Lã & $10 \mathrm{~dB}$ & 0,8386 \\
\hline Lata & $12 \mathrm{~dB}$ & 0,3592 \\
\hline Maio & $10 \mathrm{~dB}$ & 0,7132 \\
\hline Manga & $9 \mathrm{~dB}$ & 0,6647 \\
\hline Mão & $8 \mathrm{~dB}$ & 0,8386 \\
\hline Medo & $7 \mathrm{~dB}$ & 0,4786 \\
\hline Mel & $10 \mathrm{~dB}$ & 0,9057 \\
\hline Modem & $11 \mathrm{~dB}$ & 0,5205 \\
\hline Vovó & $8 \mathrm{~dB}$ & 0,6767 \\
\hline Tabela & $8 \mathrm{~dB}$ & 0,3948 \\
\hline Tia & $9 \mathrm{~dB}$ & 0,4869 \\
\hline Tio & $10 \mathrm{~dB}$ & 0,4369 \\
\hline & $9 \mathrm{~dB}$ & \\
\hline Média & & 0389 \\
\hline & & \\
\hline & & \\
\hline
\end{tabular}


TABELA 5. 6 - Resultados dos testes para as 25 palavras com SNR de entrada de $3 \mathrm{~dB}$, usando FKT, para o caso do ruído ser branco.

\begin{tabular}{|l|c|c|}
\hline \multicolumn{2}{|c|}{ Relação Sinal/Ruído de Entrada de 3 dB, para a técnica FKT } \\
\hline Palavras & $\begin{array}{c}\text { Relação Sinal/Ruído de } \\
\text { Saída em dB }\end{array}$ & Distância de Itakura-Saito \\
\hline Bala & $10 \mathrm{~dB}$ & 0,7908 \\
\hline Boi & $7 \mathrm{~dB}$ & 0,7142 \\
\hline Bola & $10 \mathrm{~dB}$ & 0,9932 \\
\hline Cão & $10 \mathrm{~dB}$ & 0,7313 \\
\hline Casa & $6 \mathrm{~dB}$ & 0,1602 \\
\hline Cola & $10 \mathrm{~dB}$ & 1,1375 \\
\hline Dado & $7 \mathrm{~dB}$ & 0,5054 \\
\hline Dia & $9 \mathrm{~dB}$ & 0,3547 \\
\hline Elefante & $9 \mathrm{~dB}$ & 0,1933 \\
\hline Elétrica & $8 \mathrm{~dB}$ & 0,3250 \\
\hline Fala & $6 \mathrm{~dB}$ & 0,7200 \\
\hline Igreja & $10 \mathrm{~dB}$ & 0,2453 \\
\hline Janela & $8 \mathrm{~dB}$ & 0,4332 \\
\hline Lã & $10 \mathrm{~dB}$ & 0,7617 \\
\hline Lata & $12 \mathrm{~dB}$ & 0,2738 \\
\hline Maio & $10 \mathrm{~dB}$ & 0,5690 \\
\hline Manga & $9 \mathrm{~dB}$ & 0,5449 \\
\hline Mão & $8 \mathrm{~dB}$ & 0,7345 \\
\hline Medo & $7 \mathrm{~dB}$ & 0,3964 \\
\hline Mel & $10 \mathrm{~dB}$ & 0,8150 \\
\hline Modem & $10 \mathrm{~dB}$ & 0,4360 \\
\hline Vovó & $8 \mathrm{~dB}$ & 0,5078 \\
\hline Tabela & $8 \mathrm{~dB}$ & 0,3225 \\
\hline Tia & $9 \mathrm{~dB}$ & 0,4726 \\
\hline Tio & $10 \mathrm{~dB}$ & 0,4267 \\
\hline & $9 \mathrm{~dB}$ & \\
\hline Média & & 0,5452 \\
\hline & & \\
\hline & & \\
\hline
\end{tabular}

Observando as tabelas 5.4, 5.5 e 5.6, nota-se que a partir dos valores médios, a técnica proposta neste trabalho, apresenta resultados melhores em relação à distorção espectral. Já a relação sinal/ruído é maior em 1 dB quando comparada com a subtração espectral de potência e para FKF é a mesma. 
TABELA 5.7 - Resultados dos testes para as 25 palavras com SNR de entrada de $6 \mathrm{~dB}$, usando a subtração espectral de potência, para o caso do ruído ser branco.

\begin{tabular}{|l|c|c|}
\hline \multicolumn{3}{|c|}{ Relação Sinal/Ruído de Entrada de 6 dB, para a técnica de Subtração Espectral de } \\
Potência
\end{tabular}


TABELA 5. 8 - Resultados dos testes para as 25 palavras com SNR de entrada de $6 \mathrm{~dB}$, usando FKF, para o caso do ruído ser branco.

Relação Sinal/Ruído de Entrada de $6 \mathrm{~dB}$, para a técnica FKF

\begin{tabular}{|l|c|c|}
\hline \multicolumn{1}{|c|}{ Palavras } & $\begin{array}{c}\text { Relação Sinal/Ruído de } \\
\text { Saída em dB }\end{array}$ & Distância de Itakura-Saito \\
\hline Bala & $11 \mathrm{~dB}$ & 0,8763 \\
\hline Boi & $9 \mathrm{~dB}$ & 0,7015 \\
\hline Bola & $11 \mathrm{~dB}$ & 1,1063 \\
\hline Cão & $12 \mathrm{~dB}$ & 0,7361 \\
\hline Casa & $7 \mathrm{~dB}$ & 0,1384 \\
\hline Cola & $11 \mathrm{~dB}$ & 1,1487 \\
\hline Dado & $9 \mathrm{~dB}$ & 0,5587 \\
\hline Dia & $10 \mathrm{~dB}$ & 0,3482 \\
\hline Elefante & $11 \mathrm{~dB}$ & 0,2147 \\
\hline Elétrica & $10 \mathrm{~dB}$ & 0,3328 \\
\hline Fala & $7 \mathrm{~dB}$ & 0,7304 \\
\hline Igreja & $10 \mathrm{~dB}$ & 0,3051 \\
\hline Janela & $9 \mathrm{~dB}$ & 0,5423 \\
\hline Lã & $12 \mathrm{~dB}$ & 0,7504 \\
\hline Lata & $13 \mathrm{~dB}$ & 0,3289 \\
\hline Maio & $11 \mathrm{~dB}$ & 0,6386 \\
\hline Manga & $11 \mathrm{~dB}$ & 0,5665 \\
\hline Mão & $9 \mathrm{~dB}$ & 0,7429 \\
\hline Medo & $8 \mathrm{~dB}$ & 0,4373 \\
\hline Mel & $11 \mathrm{~dB}$ & 0,8976 \\
\hline Modem & $11 \mathrm{~dB}$ & 0,4659 \\
\hline Vovó & $10 \mathrm{~dB}$ & 0,5968 \\
\hline Tabela & $10 \mathrm{~dB}$ & 0,3281 \\
\hline Tia & $10 \mathrm{~dB}$ & 0,4210 \\
\hline Tio & $12 \mathrm{~dB}$ & 0,4105 \\
\hline & $10 \mathrm{~dB}$ & 0,5730 \\
\hline Média & & \\
\hline & & \\
\hline & & \\
\hline
\end{tabular}


TABELA 5. 9 - Resultados dos testes para as 25 palavras com SNR de entrada de $6 \mathrm{~dB}$, usando FKT, para o caso do ruído ser branco.

\begin{tabular}{|l|c|c|}
\hline \multicolumn{2}{|c|}{ Relação Sinal/Ruído de Entrada de 6 dB, para a técnica FKT } \\
\hline & $\begin{array}{c}\text { Relação Sinal/Ruído de } \\
\text { Saída em dB }\end{array}$ & Distância de Itakura-Saito \\
\hline Bala & $11 \mathrm{~dB}$ & 0,7235 \\
\hline Boi & $9 \mathrm{~dB}$ & 0,6414 \\
\hline Bola & $11 \mathrm{~dB}$ & 0,9383 \\
\hline Cão & $12 \mathrm{~dB}$ & 0,6454 \\
\hline Casa & $7 \mathrm{~dB}$ & 0,1495 \\
\hline Cola & $11 \mathrm{~dB}$ & 1,0224 \\
\hline Dado & $9 \mathrm{~dB}$ & 0,4963 \\
\hline Dia & $10 \mathrm{~dB}$ & 0,2949 \\
\hline Elefante & $11 \mathrm{~dB}$ & 0,1287 \\
\hline Elétrica & $10 \mathrm{~dB}$ & 0,2392 \\
\hline Fala & $7 \mathrm{~dB}$ & 0,6025 \\
\hline Igreja & $10 \mathrm{~dB}$ & 0,2453 \\
\hline Janela & $9 \mathrm{~dB}$ & 0,4271 \\
\hline Lã & $12 \mathrm{~dB}$ & 0,6854 \\
\hline Lata & $13 \mathrm{~dB}$ & 0,2888 \\
\hline Maio & $11 \mathrm{~dB}$ & 0,5248 \\
\hline Manga & $11 \mathrm{~dB}$ & 0,4730 \\
\hline Mão & $9 \mathrm{~dB}$ & 0,6360 \\
\hline Medo & $8 \mathrm{~dB}$ & 0,3730 \\
\hline Mel & $11 \mathrm{~dB}$ & 0,7290 \\
\hline Modem & $11 \mathrm{~dB}$ & 0,4102 \\
\hline Vovó & $10 \mathrm{~dB}$ & 0,4285 \\
\hline Tabela & $10 \mathrm{~dB}$ & 0,2572 \\
\hline Tia & $10 \mathrm{~dB}$ & 0,3630 \\
\hline Tio & $12 \mathrm{~dB}$ & 0,4050 \\
\hline & $10 \mathrm{~dB}$ & 0,4851 \\
\hline Média & & \\
\hline & & \\
\hline
\end{tabular}

Analisando as tabelas 5.7, 5.8 e 5.9, nota-se que a partir dos valores médios, a técnica proposta neste trabalho, apresenta resultados melhores em relação à distorção espectral. Já a relação sinal/ruído apresenta resultados próximos. 


\subsubsection{Processamento utilizando Ruído Colorido}

Conforme apresentado na seção anterior, o sinal de voz resultante dos processamentos entre os dois algoritmos (Filtros de Kalman de Tempo e Freqüência discretos em conjunto com a subtração espectral), quando contaminado por ruído branco gaussiano, apresenta uma redução de ruído considerável e uma baixa distorção comparada com a subtração espectral de potência. Nesse terceiro teste, então, considera-se o sinal de voz contaminado por ruído colorido.

Para gerar o ruído colorido utilizou-se um filtro $A R$ de ordem 8 de acordo com Ma. Ning et all [18]:

$$
\begin{aligned}
& v(n)=-0.0851 v(n-1)+0.019126 v(n-2) \\
& +0.0458 v(n-3)+0.0229 v(n-4) \\
& +0.1057 v(n-5)+0.1553 v(n-6) \\
& -0.132 v(n-7)-0.76 v(n-8)+w(n)
\end{aligned}
$$

Desta forma, o sinal de voz sem ruído, o sinal contaminado por ruído colorido e o sinal após o processamento de filtragem usando Kalman de tempo discreto em conjunto com a subtração espectral de potência, são apresentados pelas figuras 5.16, 5.17 e 5.18, respectivamente. 


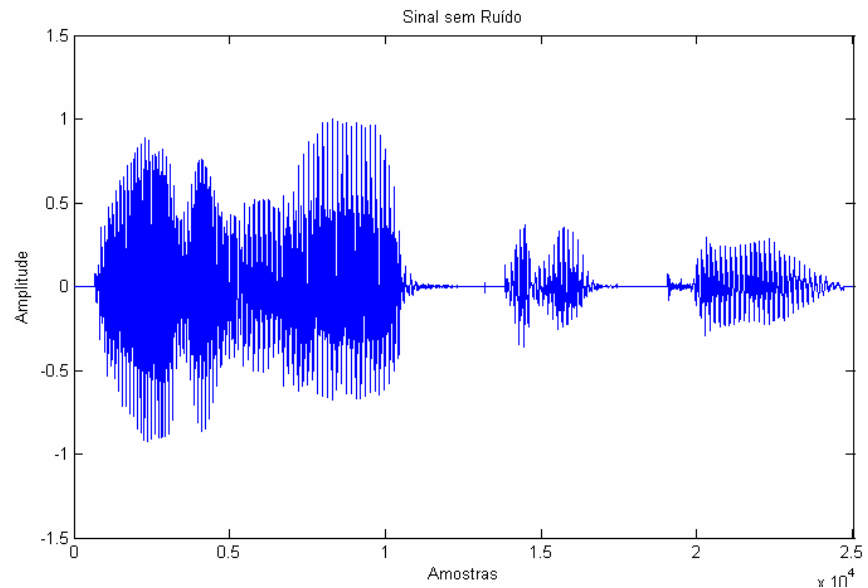

FIGURA 5. 16 - Sinal original correspondente à palavra "Elétrica".

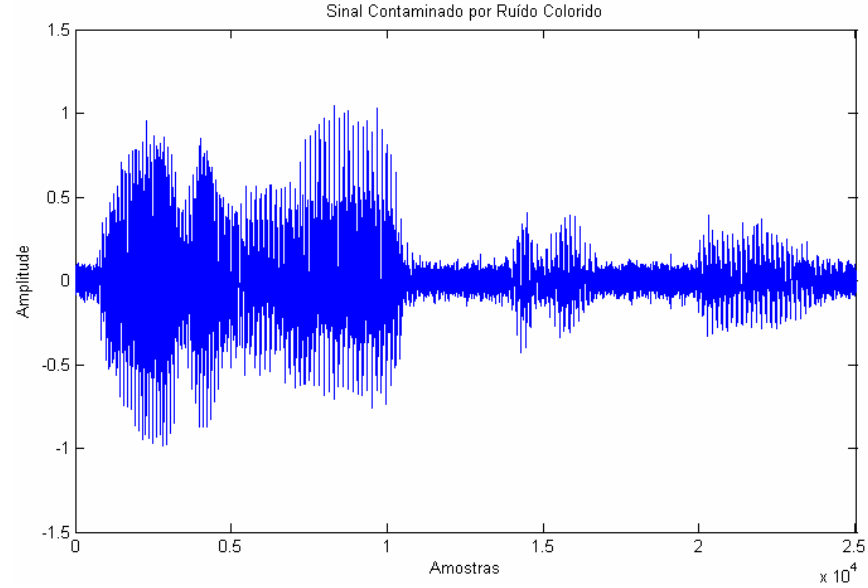

FIGURA 5. 17 - Sinal contaminado por ruído colorido.

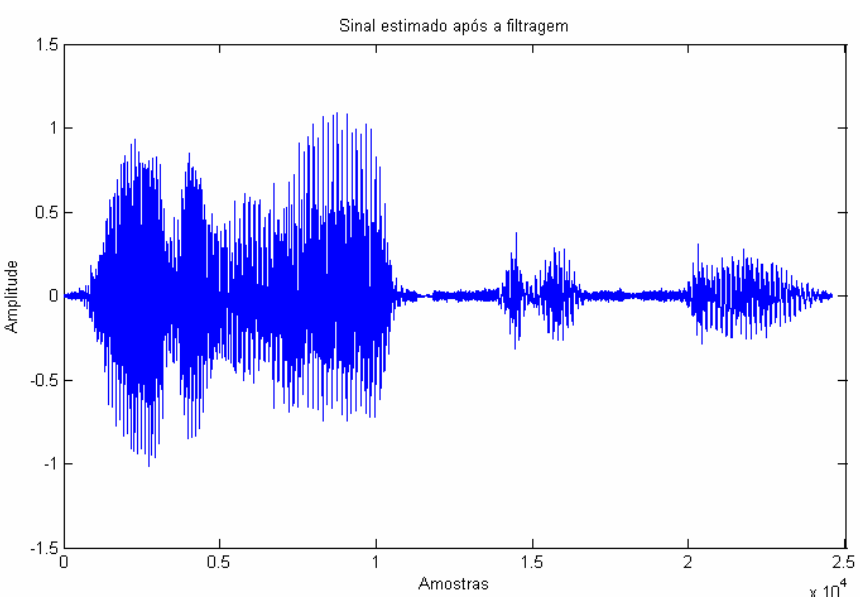

FIGURA 5. 18 - Sinal estimado após o processamento da filtragem de Kalman no tempo em conjunto com a subtração espectral, para o caso de ruído colorido. 
A relação sinal/ruído de entrada segmentada para este teste foi de $3 \mathrm{~dB}$ e a de saída foi de $8 \mathrm{~dB}$. Isto proporcionou um aumento na relação sinal/ruído de $5 \mathrm{~dB}$. Já a distância de Itakura-Saito obteve um valor de 0,2199. Comparando com a distância analisada no primeiro teste com ruído branco, verifica-se que o sinal contaminado por ruído colorido, apresenta menor distorção quando reconstruído.

Outro parâmetro importante analisado são os espectrogramas, que são apresentados pelas figuras 5.19, 5.20 e 5.21 que correspondem ao sinal sem ruído, sinal contaminado por ruído colorido e sinal estimado após o processamento respectivamente.

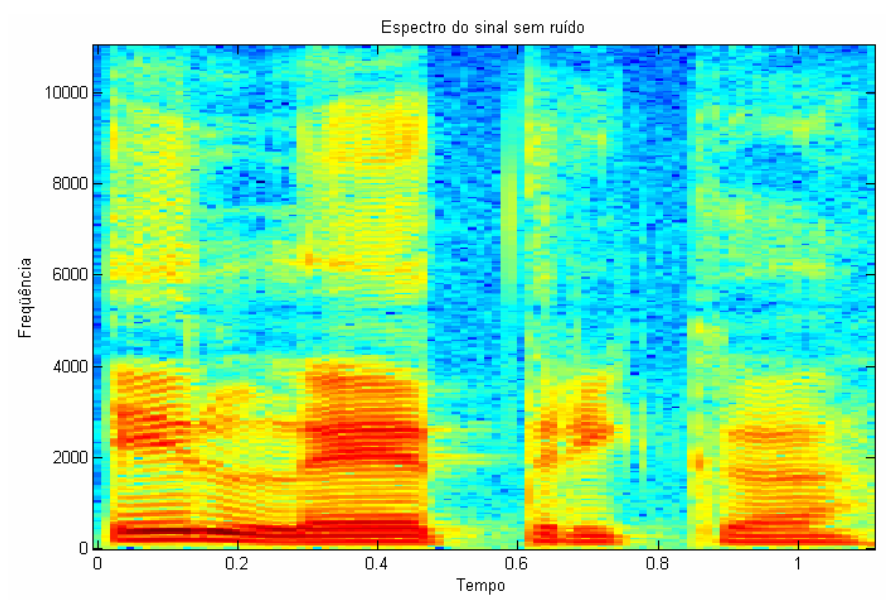

FIGURA 5. 19 - Espectrograma do sinal original.

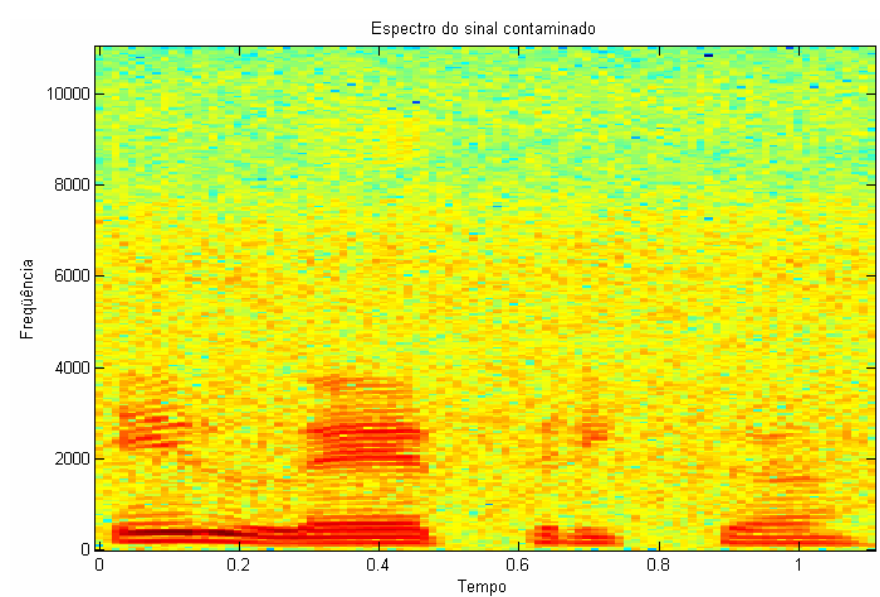

FIGURA 5. 20 - Espectrograma do sinal de voz contaminado por ruído colorido. 


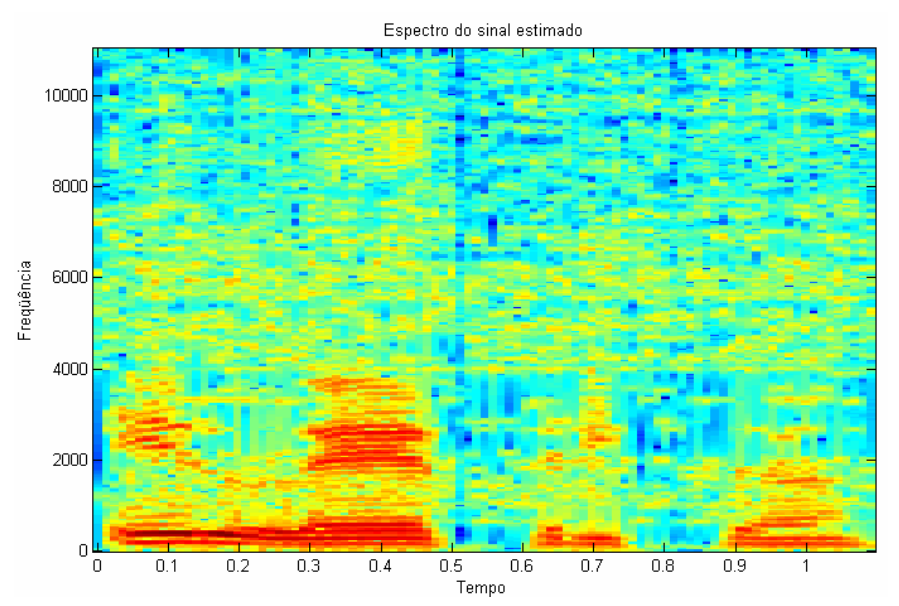

FIGURA 5. 21 - Espectrograma após a filtragem de Kalman no tempo em conjunto com a subtração espectral, para o caso do ruído colorido.

Comparando o espectrograma da figura 5.21 que corresponde ao sinal filtrado com o espectrograma da figura 5.20 que corresponde ao sinal contaminado, nota-se novamente que o espectrograma da figura 5.21 realçou com maior intensidade as freqüências que estão na faixa de 2000 e $3000 \mathrm{~Hz}$, mas também realçou freqüências acima destas, só que, com menos energia. Pode-se perceber também que apesar de uma redução da intensidade do ruído, um ruído residual permanece.

No quarto teste usou-se o algoritmo FKF em conjunto com a subtração espectral. Nesse teste foi adicionado ao sinal original, ruído colorido. Sendo assim, o sinal original, sinal contaminado por ruído colorido e sinal estimado após o processamento, é apresentado pelas figuras $5.22,5.23$ e 5.24 respectivamente. 


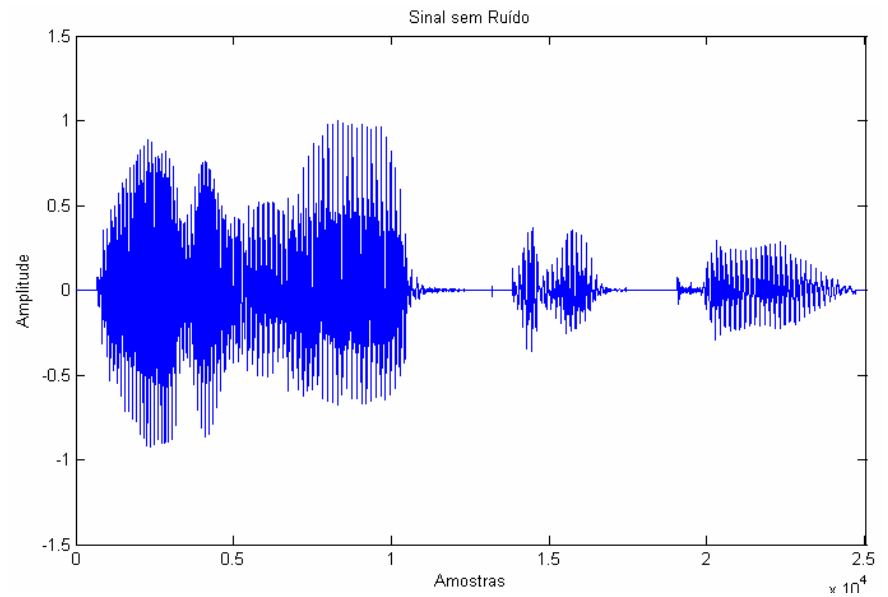

FIGURA 5. 22 - Sinal original.

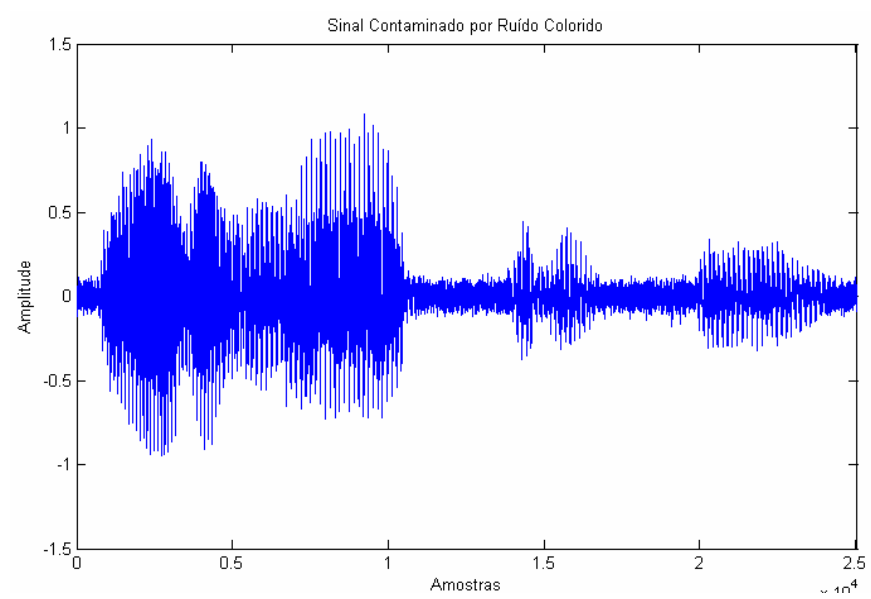

FIGURA 5. 23 - Sinal contaminado por ruído colorido.

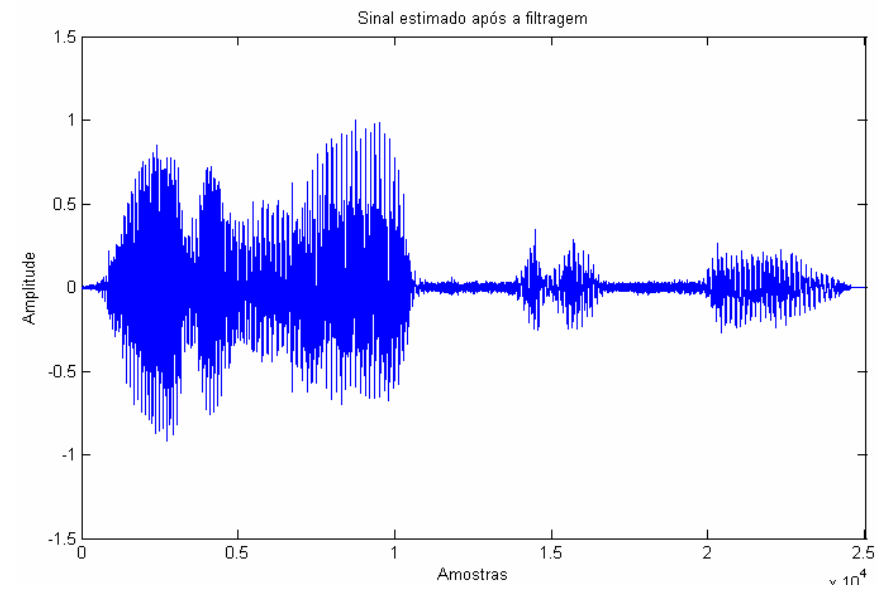

FIGURA 5. 24 - Sinal estimado após o processamento da filtragem de Kalman na freqüência em conjunto com a subtração espectral, para o caso de ruído colorido. 
A relação sinal/ruído de entrada segmentada para este teste foi de $3 \mathrm{~dB}$ e a de saída de $8 \mathrm{~dB}$. O aumento de relação sinal/ ruído foi de $5 \mathrm{~dB}$. Já a distância de Itakura-Saito foi de 0, 2829. Comparando a distância de Itakura deste teste com o segundo teste, verifica-se também que o sinal sofre menos distorções quando contaminado com ruído colorido.

Os espectrogramas do sinal original do sinal contaminado por ruído colorido e sinal após o processamento são mostrados pelas figuras 5.25, 5.26 e 5.27.

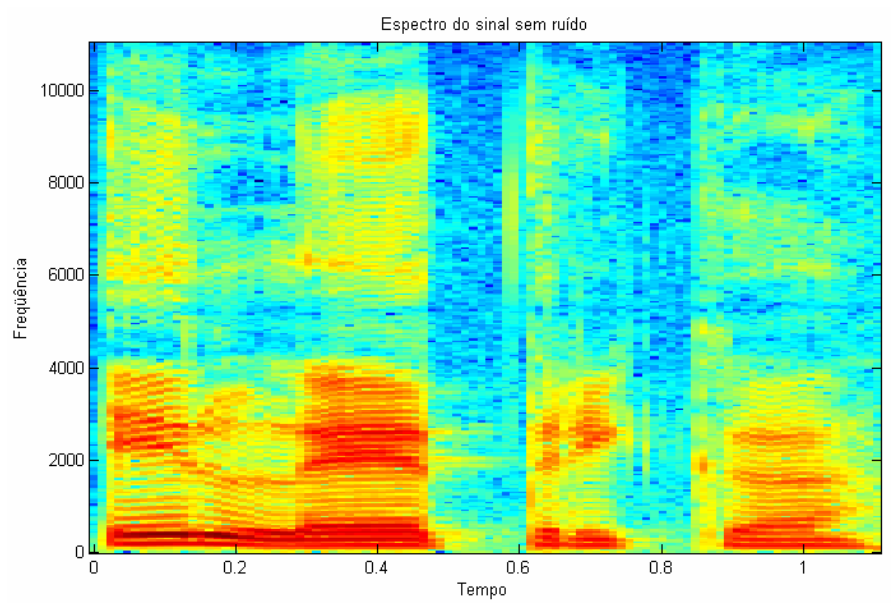

FIGURA 5. 25 - Espectrograma do sinal original.

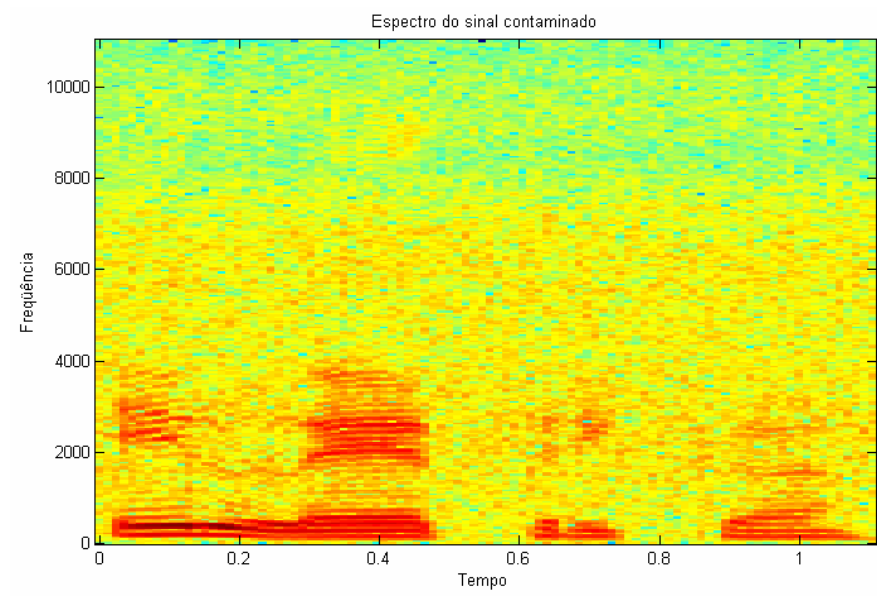

FIGURA 5. 26 - Espectrograma do sinal contaminado por ruído colorido. 


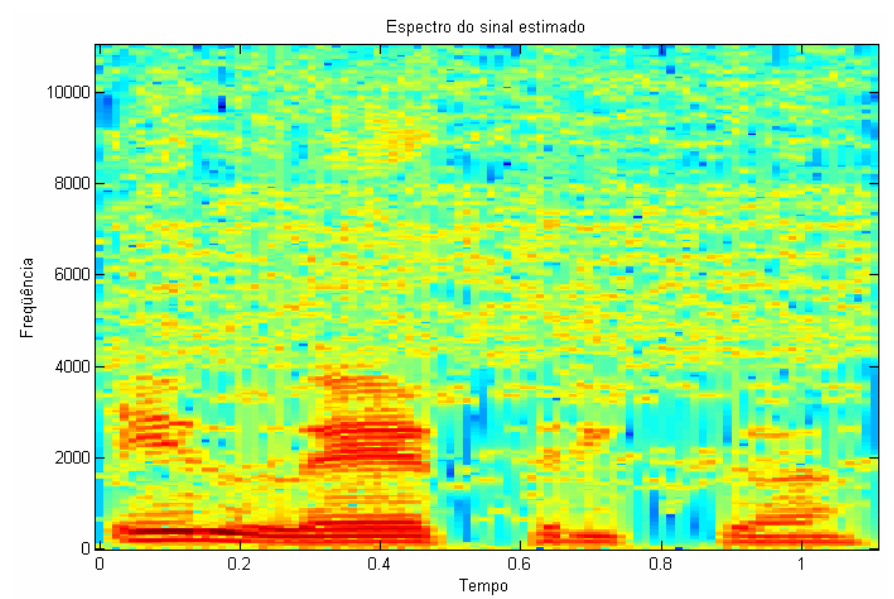

FIGURA 5. 27 - Espectrograma após a filtragem de Kalman na freqüência em conjunto com a subtração espectral, para o caso de ruído colorido.

Conforme análise dos três espectrogramas percebe-se também na figura 5.27 (sinal filtrado) que nas altas freqüências entre 2000 e $3000 \mathrm{~Hz}$, a intensidade do sinal foi ressaltada pelo algoritmo de filtragem se comparado com o espectrograma da figura 5.26 (sinal corrompido por ruído). Também verifica-se que freqüências superiores a 2000 e 3000 $\mathrm{Hz}$ foram ressaltadas, mas com menos energia. Pode-se perceber também que apesar de uma redução da intensidade do ruído, um ruído residual permanece.

Utilizando ainda a palavra "Elétrica", é apresentado na figura 5.28, uma comparação entre os três algoritmos descritos neste trabalho. O parâmetro de comparação utilizado é a distância de Itakura-Saito em função da relação sinal/ruído de entrada segmentada. 


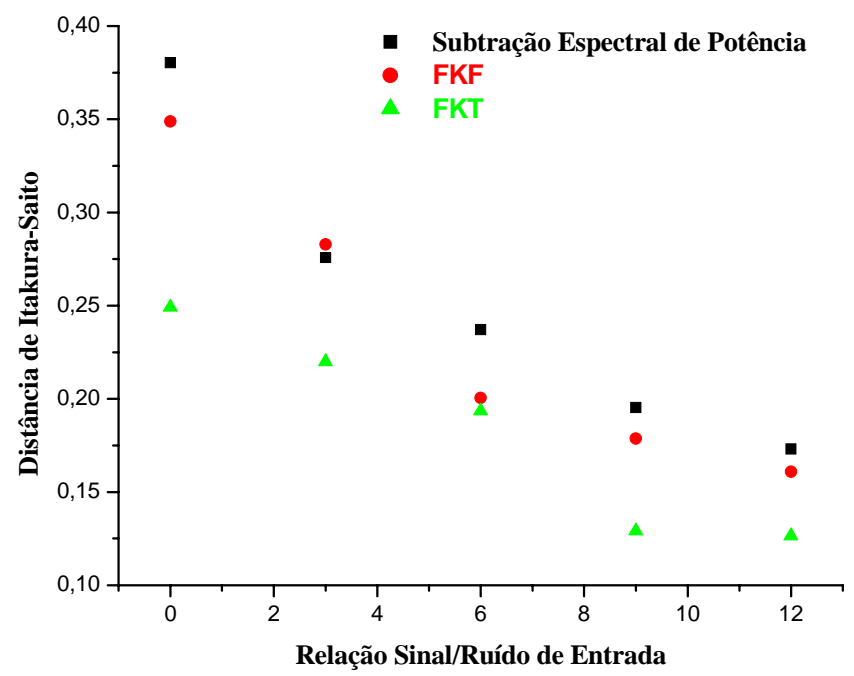

FIGURA 5. 28 - Distância de Itakura-Saito em função da SNR de entrada segmentada para o caso do ruído ser colorido.

A partir da figura 5.28, pode-se notar que a técnica proposta apresenta resultados melhores em relação à distorção espectral do que FKF e subtração espectral de potência.

Para avaliar de uma maneira geral a eficiência dos algoritmos e mostrar que a técnica proposta (FKT), é superior com relação à distorção espectral, as tabelas 5.10, $5.11 \mathrm{e}$ 5.12, apresentam testes utilizando os algoritmos de subtração, FKF e FKT. Para estes ensaios, usou-se, 25 palavras. Estas palavras foram contaminadas com ruído colorido, o que resultou, em uma relação sinal/ruído de entrada de $3 \mathrm{~dB}$. 
TABELA 5. 10 - Resultados dos testes para as 25 palavras com SNR de entrada de $3 \mathrm{~dB}$, usando a subtração espectral de potência, para o caso do ruído ser colorido.

Relação Sinal/Ruído de Entrada de 3 dB, para a técnica de Subtração Espectral de Potência

\begin{tabular}{|l|c|c|}
\hline \multicolumn{1}{|c|}{ Palavras } & $\begin{array}{c}\text { Relação Sinal/Ruído de } \\
\text { Saída em dB }\end{array}$ & Distância de Itakura-Saito \\
\hline Bala & $9 \mathrm{~dB}$ & 0,7404 \\
\hline Boi & $7 \mathrm{~dB}$ & 0,6290 \\
\hline Bola & $9 \mathrm{~dB}$ & 0,9234 \\
\hline Cão & $10 \mathrm{~dB}$ & 0,5415 \\
\hline Casa & $5 \mathrm{~dB}$ & 0,1661 \\
\hline Cola & $9 \mathrm{~dB}$ & 1,1022 \\
\hline Dado & $7 \mathrm{~dB}$ & 0,4260 \\
\hline Dia & $8 \mathrm{~dB}$ & 0,2425 \\
\hline Elefante & $9 \mathrm{~dB}$ & 0,1961 \\
\hline Elétrica & $8 \mathrm{~dB}$ & 0,2758 \\
\hline Fala & $5 \mathrm{~dB}$ & 0,6593 \\
\hline Igreja & $8 \mathrm{~dB}$ & 0,2230 \\
\hline Janela & $7 \mathrm{~dB}$ & 0,3319 \\
\hline Lã & $8 \mathrm{~dB}$ & 0,6559 \\
\hline Lata & $11 \mathrm{~dB}$ & 0,2540 \\
\hline Maio & $10 \mathrm{~dB}$ & 0,5505 \\
\hline Manga & $8 \mathrm{~dB}$ & 0,4943 \\
\hline Mão & $8 \mathrm{~dB}$ & 0,6513 \\
\hline Medo & $6 \mathrm{~dB}$ & 0,2986 \\
\hline Mel & $9 \mathrm{~dB}$ & 0,7943 \\
\hline Modem & $9 \mathrm{~dB}$ & 0,3515 \\
\hline Vovó & $8 \mathrm{~dB}$ & 0,4933 \\
\hline Tabela & $8 \mathrm{~dB}$ & 0,2138 \\
\hline Tia & $8 \mathrm{~dB}$ & 0,3394 \\
\hline Tio & $9 \mathrm{~dB}$ & 0,3280 \\
\hline & & 0,4753 \\
\hline Média & $8 \mathrm{~dB}$ & \\
\hline & & \\
\hline & & \\
\hline & & \\
\hline
\end{tabular}


TABELA 5. 11 - Resultados dos testes para as 25 palavras com SNR de entrada de $3 \mathrm{~dB}$, usando FKF, para o caso do ruído ser colorido.

\begin{tabular}{|l|c|c|}
\hline \multicolumn{2}{|c|}{ Relação Sinal/Ruído de Entrada de 3 dB, para a técnica FKF } \\
\hline Palavras & $\begin{array}{c}\text { Relação Sinal/Ruído de } \\
\text { Saída em dB }\end{array}$ & Distância de Itakura-Saito \\
\hline Bala & $9 \mathrm{~dB}$ & 0,6662 \\
\hline Boi & $7 \mathrm{~dB}$ & 0,6046 \\
\hline Bola & $9 \mathrm{~dB}$ & 0,9220 \\
\hline Cão & $10 \mathrm{~dB}$ & 0,5531 \\
\hline Casa & $5 \mathrm{~dB}$ & 0,1407 \\
\hline Cola & $9 \mathrm{~dB}$ & 1,0720 \\
\hline Dado & $7 \mathrm{~dB}$ & 0,4061 \\
\hline Dia & $9 \mathrm{~dB}$ & 0,2100 \\
\hline Elefante & $9 \mathrm{~dB}$ & 0,1800 \\
\hline Elétrica & $8 \mathrm{~dB}$ & 0,2889 \\
\hline Fala & $6 \mathrm{~dB}$ & 0,6219 \\
\hline Igreja & $8 \mathrm{~dB}$ & 0,1959 \\
\hline Janela & $8 \mathrm{~dB}$ & 0,3247 \\
\hline Lã & $9 \mathrm{~dB}$ & 0,6211 \\
\hline Lata & $11 \mathrm{~dB}$ & 0,2297 \\
\hline Maio & $10 \mathrm{~dB}$ & 0,5080 \\
\hline Manga & $9 \mathrm{~dB}$ & 0,4873 \\
\hline Mão & $9 \mathrm{~dB}$ & 0,5597 \\
\hline Medo & $7 \mathrm{~dB}$ & 0,2958 \\
\hline Mel & $9 \mathrm{~dB}$ & 0,4873 \\
\hline Modem & $10 \mathrm{~dB}$ & 0,3410 \\
\hline Vovó & $8 \mathrm{~dB}$ & 0,4837 \\
\hline Tabela & $8 \mathrm{~dB}$ & 0,2002 \\
\hline Tia & $10 \mathrm{~dB}$ & 0,3288 \\
\hline Tio & $8 \mathrm{~dB}$ & 0,3171 \\
\hline & & \\
\hline Média & & 0,4534 \\
\hline & & \\
\hline & & \\
\hline
\end{tabular}


TABELA 5. 12 - Resultados dos testes para as 25 palavras com SNR de entrada de $3 \mathrm{~dB}$, usando FKT, para o caso do ruído ser colorido.

\begin{tabular}{|l|c|c|}
\hline \multicolumn{2}{|c|}{ Relação Sinal/Ruído de Entrada de 3 dB, para a técnica FKT } \\
\hline Palavras & $\begin{array}{c}\text { Relação Sinal/Ruído de } \\
\text { Saída em dB }\end{array}$ & Distância de Itakura-Saito \\
\hline Bala & $9 \mathrm{~dB}$ & 0,5504 \\
\hline Boi & $7 \mathrm{~dB}$ & 0,4814 \\
\hline Bola & $9 \mathrm{~dB}$ & 0,7341 \\
\hline Cão & $10 \mathrm{~dB}$ & 0,4152 \\
\hline Casa & $5 \mathrm{~dB}$ & 0,1106 \\
\hline Cola & $10 \mathrm{~dB}$ & 0,7461 \\
\hline Dado & $7 \mathrm{~dB}$ & 0,3998 \\
\hline Dia & $9 \mathrm{~dB}$ & 0,1819 \\
\hline Elefante & $9 \mathrm{~dB}$ & 0,1734 \\
\hline Elétrica & $8 \mathrm{~dB}$ & 0,2199 \\
\hline Fala & $6 \mathrm{~dB}$ & 0,4936 \\
\hline Igreja & $8 \mathrm{~dB}$ & 0,1470 \\
\hline Janela & $8 \mathrm{~dB}$ & 0,2224 \\
\hline Lã & $9 \mathrm{~dB}$ & 0,4878 \\
\hline Lata & $11 \mathrm{~dB}$ & 0,2038 \\
\hline Maio & $10 \mathrm{~dB}$ & 0,3977 \\
\hline Manga & $9 \mathrm{~dB}$ & 0,3797 \\
\hline Mão & $8 \mathrm{~dB}$ & 0,4091 \\
\hline Medo & $7 \mathrm{~dB}$ & 0,1895 \\
\hline Mel & $9 \mathrm{~dB}$ & 0,6204 \\
\hline Modem & $10 \mathrm{~dB}$ & 0,3042 \\
\hline Vovó & $8 \mathrm{~dB}$ & 0,3700 \\
\hline Tabela & $8 \mathrm{~dB}$ & 0,1610 \\
\hline Tia & $8 \mathrm{~dB}$ & 0,2995 \\
\hline Tio & $10 \mathrm{~dB}$ & 0,2291 \\
\hline & & 0,3571 \\
\hline Média & & \\
\hline & & $\mathrm{dB}$ \\
\hline
\end{tabular}

Analisando as tabelas 5.10, 5.11 e 5.12, pode-se verificar que o algoritmo FKT apresenta resultados melhores com relação à subtração e FKF para a distorção espectral. Nota-se também que para o caso do ruído ser colorido, as distorções são menores quando comparadas com o ruído branco. 


\subsection{Considerações Finais}

Nesse capítulo foi realizada uma análise dos resultados dos dois algoritmos discutidos no capítulo 4 (Filtro de Kalman de tempo discreto em conjunto com a subtração espectral de potência e filtro de Kalman de freqüência discreta também em conjunto com a subtração espectral de potência).

Para a avaliação do algoritmo foram realizados vários testes com diferentes sinais de voz corrompidos por dois tipos de ruído: ruído branco gaussiano e ruído colorido. Todos os processamentos apresentaram resultados semelhantes no que se diz respeito à redução de ruído. Neste trabalho foram reportados os resultados do processamento da palavra "elétrica".

Para validação dos resultados foram utilizadas duas medidas: a relação sinal/ruído segmentada e a distância de Itakura-Saito. Nestas análises verificou-se que a técnica proposta FKT apresenta resultados melhores com relação à distorção espectral quando comparado com as técnicas de subtração e FKF. Já as relações sinal/ruído, obtiveram resultados próximos para ambas às técnicas.

Nota-se também que quando o sinal é contaminado por ruído colorido o mesmo quando processado a partir dos algoritmos, apresenta menor distorção espectral em relação ao processamento usando ruído branco. 


\section{Conclusões}

Este trabalho apresentou o estudo e a implementação de dois algoritmos: o filtro de Kalman no Tempo e o filtro de Kalman Freqüência. Estes, utilizaram como condição inicial, o sinal estimado após a técnica de subtração espectral de potência em virtude desta apresentar resultados melhores em relação a subtração espectral de magnitude.

A comprovação da eficiência destas técnicas foram comparativas, tendo como critério de avaliação, as medidas de distância de Itakura-Saito, Relação sinal/ruído segmentada e o espectrograma.

Para os testes foram utilizados diversos tipos de palavras, as quais foram colhidas na placa sound blaster amostradas a uma taxa de $22050 \mathrm{~Hz}$ com 16 bits. Em seguida a estas palvras, adicionou-se ruídos do tipo branco gaussiano e colorido.

Tanto os testes com ruído branco gaussiano quanto com ruído colorido produziram resultados satisfatórios. Assim, as modificações realizadas neste trabalho, comprovam que, a técnica proposta (Filtro de Kalman de Tempo Discreto combinado com subtração espectral de potência), apresentou resultados melhores do que os algoritmos de subtração espectral de potência aplicado isoladamente e Filtro de Kalman de Freqüência Discreta também em conjunto com subtração espectral de potência com relação à distorção espectral. Já as relações sinal/ruído para ambas as técnicas se mantiveram próximas.

Em ambos os algoritmos, nota após o processamento uma redução considerável da intensidade do ruído aditivo, mas percebe-se a presença de um ruído residual conhecido como ruído musical, quase impossível de se eliminar gerado pela subtração espectral.

Dessa forma, o projeto foi concluído após um estudo do algoritmo de filtragem de Kalman de tempo discreto e freqüência discreta juntamente com a técnica de subtração 
espectral. Estes algoritmos foram implementados e os testes realizados provaram sua eficiência.

Durante o desenvolvimento deste trabalho surgiram algumas idéias que não foram colocadas em prática neste trabalho, algumas delas fáceis de se implementar, mas que, entretanto, necessitam de um estudo mais abrangente e fogem dos objetivos iniciais deste trabalho. Algumas propostas para trabalhos futuros poderiam englobar:

- Estudo detalhado da curva empírica proposta por Berouti et all [13];

- Substituição da Subtração Espectral de Potência por técnicas de filtragem por Wavelets;

- Substituição da Subtração Espectral de Potência por técnicas de psicoacústica. 


\section{Referências Bibliográficas}

[1] M. Fujimoto e Y.Ariki, "Noisy speech recognition using noise reduction method based on Kalman filter", IEEE Proceedings of the International Conference on Acoustics Speech and Signal Processing, ICASSP'00, Vol. 3, pp. 1727-1730, 2000.

[2] L. R. Rabinner e R. W.Schafer, Digital processing of speech signals, Cliffs: Prentice- Hall, 1978.

[3] A. C. Guerra, Estimação do sinal glotal para padrões de doenças de laringe. Tese de Doutorado. Universidade de São Paulo-USP, São Carlos, 2005.

[4] C. E M. Ribeiro, "Processamento Digital de Fala". http://www.deetc.isel.ipl.pt/ comunicacoesep/disciplinas/pdf/sebenta/pdf_prg.html, último acesso em 2 de Fevereiro de 2006.

[5] J. R. Deller, J. H. L. Hansen, e J. G. Proakis, Discrete-time Processing of Speech Signals, Prentice Hall, 1987.

[6] A. M. Selmini, Aplicação de redes neurais artificiais e filtro de Kalman para redução de ruídos em sinais de voz. Dissertação de Mestrado. Universidade de São PauloUSP, São Carlos, 2001.

[7] S. Grassi., Optimized implementation of speech processing alghoritms. Tese de doutorado. Universidade de Neuchâtel, 1998.

[8] S. V. Vaseghi, Advanced Digital Signal Processing and Noise Reduction, John Wiley \& Sons, Ltd, 2000.

[9] S. Haykin, Adaptive Filter Theory, NJ: Prentice Hall, Upper Saddle River, 2002. 
[10] M. H. Hayes, Statistical Digital Signal Processing and Modeling, John Wiley \& Sons, Ltd, 1996.

[11] S. F. Boll, "Suppression of acoustic noise in speech using spectral subtraction", IEEE Trans. Acoust., Speech, Signal Process., vol.27, pp. 113-120, Apr. 1979.

[12] R. C. V. Maciel, Melhoria na qualidade de sinais de fala degradados por ruído através da utilização de sinais sintetizados. Dissertação de mestrado. Universidade de São Paulo-USP, 2003.

[13] M. Berouti, R. Schwartz e J. Makhoul, "Enhancement of speech corrupted by acoustic noise”, Proc. IEEE Int. conf. Acoust., Speech, Signal Process., pp. 208-211, Apr. 1979.

[14] R. E. Kalman, "A New Approach to linear filtering and prediction problems", Transaction of the ASME-Journal of Basic Engineering, pp. 35-45, March 1960.

[15] G. Welch e G. Bishop, An Introduction to the Kalman Filter. http://www.cs.unc.edu/ tracker/ref/s2001/kalman/. Último acesso em 4 de março de 2005.

[16] R. G. Brown e P. Y. C. Hwang, Introduction to random signals and applied Kalman filtering, John Wiley \& Sons, Inc, 1997.

[17] Y. H. Tong, Speech processing using Kalman filtering. Bacharelado em engenharia eletrônica. Universidade de Queensland, 2001.

[18] Ma Ning, M. Bouchard e R. A. Goubran, "Perceptual Kalman Filtering for Speech Enhancement in colored noise", IEEE Proceedings of the International Conference on Acoustics Speech and Signal Processing, ICASSP'04, Vol. 1, pp. 717-720.

[19] K. K. Paliwal e A. Basu, "A speech enhancement method based on Kalman filtering", in Proc. ICASSP'87, pp. 177-180. 
[20] M. Gabrea e D. O'Shaugnessy, “Speech Signal Recovery in White Noise Using an Adaptive Kalman Filter", in Proc. Eupisco'00.

[21] J. D. Gibson, B. Koo e S. D. Gray, "Filtering of Colored Noise for Speech Enhancement and Coding”, IEEE Trans. Signal Processing, vol. 39, pp. 1732-1742, Aug. 1991.

[22] M. Gabrea, E. Grivel, e M. Najim, "A Single Microphone Kalman Filter Based Noise Canceller”, IEEE Trans. Signal Processing letters, vol. 6, pp. 55-57, Mar. 1999.

[23] Md. K. Hasan, S. Salahuddin e M. R. Khan, "A Modified A Priori SNR for Speech Enhancement Using Spectral Subtraction Rules", IEEE Trans. Signal Processing letters, vol. 11, pp. 450-453, Apr. 2004.

[24] K. Wu e P. Chen, "Efficient speech enhancement using spectral subtraction for car hands-free application", International conference on consumer Electronics, vol. 2, pp. 220 221,2001

[25] T. Lotter e P. Vary, "Noise Reduction By Maximum a Posteriori Spectral Amplitude Estimation with Supergaussian Speech Modeling”, International Workshop on Acoustic Echo and Noise Control (IWAENC 2003), Sept. 2003, Kyoto, Japan.

[26] M. Gabrea, "Robust Adaptive Kalman Filter for Speech Signal Recovery in Colored Noise", International Workshop on Acoustic Echo and Noise Control (IWAENC 2005), Sept. 2005, Netherlands.

[27] A. Kaps, “Acoustic Noise Reduction Using a Multiple-Input Single-Output Kalman Filter", International Workshop on Acoustic Echo and Noise Control (IWAENC 2005), Sept. 2005, Netherlands.

[28] I. Batina, J. Jensen e R. Heusdens, "Kalman Filtering Based Noise Power Spectral Density Estimation for Speech Enhancement”, in Proc. Eupisco'05. 
[29] R. Martin, "Spectral Subtraction Based on Minimum Statistics", in Proc. Eupisco'94.

[30] V. L. Djigan, P. Sovka e R. Cmejla, "Modified Spectral Subtraction Based Speech Enhancement", International Workshop on Acoustic Echo and Noise Control (IWAENC 1999), Sept. 1999, Pennsylvania, USA. 